\title{
COURS ELEMEN'TALE
}

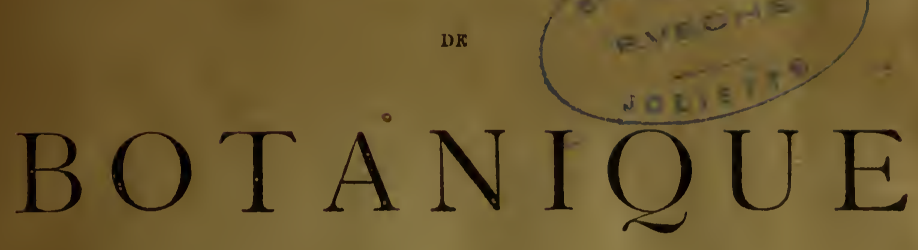

$\mathbf{E}$

\section{FLORE DU CANADA}

A L'USAGE DES MAISONS D'EDUCA'IION

PAR

L'ABBÉ J. MOYEN, S.S.

Professeur de Sciences Naturelles au Collége de Montréal.

\section{MONTRÉAL}

GEO. E. DESBARATS, MPRIMEUR-EDITEUR

1, Place-d'Armes, et 319, Rue St. Antoine.

1871 


\section{The EDITH and LORNE PIERCE COLLECTION of CANADIANA

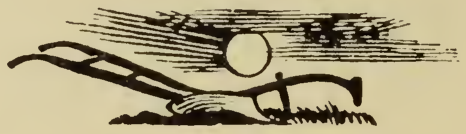

2ueen's University at Kingston 


\section{COURS ÉLÉMENTAIRE}

$\mathrm{DE}$

BOTANIQUE

RT

\section{FLORE DU CANADA}

A I'USAGE DES MAISONS D'EDUCATION

PAB

L'ABBÉ J. MOYEN, S.S.

Professeur de Sciences Naturelles au Collége de Montréal.

MONTRÉAL

GEO. E. DESBARATS, IMPRIMEUR-EDITEUR

1, Place-d'Armes, et 319, Rue St. Antoine. 
ENREerstré conformément à l'acte du Parlement du Canada, en l'année mil huit cent soixante-onze, par George E. Dessarats, au bureau du Ministre de. l'Agriculture. 


\section{HOMMAGE}

\section{$\mathbf{A}$ \\ M A R I E.}

SICUT LILIUM INTER SPINAS, SIC AMICA MEA INTER FILIAS.

(OANT. II, 2.)

Tel un Lis au milieu des épines, ainsi ma bien-aimée au milieu des ílles de Sion. 



\section{A MES ÉLÈVES.}

Vous trouverez, en substance, dans ces éléments de Botanique, les leçons qui sont enseignées au Collége de Montréal depuis un grand nombre d'années.

C'est pour vous qu'ils ont été composés, c'est à vous que je les dédie. J'ai utilisé, pour leur rédaction, les livres que j'avais entre les mains avec d'autant plus de liberté qu'il n'entrait nullement dans mes intentions de les publier. C'est sur la demande de plusieurs d'entre vous que je me suis décidé à les livier à l'impression. Les passages empruntés ne forment toutefois qu'une fraction très-peu importante du traité; j'ai eu soin d'indiquer les principaux, en référant aux auteurs qui me les ont fournis.

Mon but constant, en poursuivant ce travail, a été de vous offrir un cours de Botanique qui renfermât tous les éléments d'une instruction solide, sous une forme claire, précise et méthodique. L'ardeur avec laquelle ce cours a été suivi, les succès obtenus, ont été un ample dédommagement pour les fatigues que j'ai dû m'imposer.

Les figures qui accompagnent le texte, au nombre de 178, ont été choisies dans les ouvrages les plus estimés, et reproduites au moyen de procédés particuliers, en usage dans les ateliers de M. G. E. Desbarats; ces figures, et la légende qui en donne l'explication, forment à elles seules comme un traité dont pourraient se contenter les personnes qui ne veulent pas faire une étude approfondie de la Botanique; elles seront aussi d'un grand secours pour aider à repasser les matières à l'approche d'un examen.

La Flore du Canada, qui fait suite aux éléments de Botanique, est la partie la plus importante de cette publication. Pour peu qu'on ait d'expérience dans l'enseignement, on ne saurait douter qu'il ne soit nécessaire d'exercer l'élève à décrire les végétaux, à chercher, par voie d'analyse, le nom de ceux qu'il ne connaît point: c'est le seul moyen de bien lui faire comprendre les principes de la science, de graver dans son esprit la terminologie botanique, de le familiariser avec les formes si variées que revêtent les plantes, enfin, de lui donner une connaissance pratique du règne végétal.

Mais pour analyser les végétaux une Flore est indispensable. J'ai regretté bien des fois que celles qui ont été publiées jusqu'à ce jour soient, les unes insuffisantes, les autres d'un prix trop élevé pour le plus grand nombre 
des étudiants. Celle que je vous mets entre les mains est une Flore complète quant à l'énumération des plantes, mais abrégée dans certaines descriptions. Vous y trouverez les caractères des familles et de la plupart des genres. Quant aux espèces, je n'ai fait que signaler quelques uns de leurs caractères les plus saillants.

Les clefs analytiques ont été l'objet d'une attention toute spéciale; je me suis efforcé de les simplifier autant que possible, pour les rendre d'un usage facile aux commençants.

Les Flores de Le Maout et Decaisne, d'Asa Gray, de Torrey et Gray sont les modèles que j'ai suivis de préférence, en les abrégeant, dans la description des familles et des genres; pour les détails particuliers aux espèces qui croissent en Canada, j'ai tâché de mettre à profit les connaissances qu'ont pu me donner de nombreuses herborisations faites dans l'île de Montréal, dans les Cantons de l'Est, dans le nord des Laurentides, dans les environs du lac Simcoe, sur les rives du St. Laurent depuis Niagara jusqu'au fond du Saguenay (1), sur les rives de l'Ottawa depuis le lac des Deux-Montagnes jusqu'à Fort-Williams, sur celles de la rivière St. François dans la Beauce, etc., etc. Pour les plantes que je n'ai point trouvées moimême, je m'en suis rapporté aux renseignements donnés dans divers ouvrages qui ont été publiés en Canada durant les dix dernières années.

(1) J'ai recu aussi de nombreux échantillons des côtes du Labrador que M. Leche vallier, naturaliste, a eu l'obligeance de récolter pour moi. Parmi ces plantes je mentionnerai le Ligusticum actæifolium que quelques auteurs pensaient étranger au Canada, contrairement à l'assertion de Michaux. 


\title{
COURS ĹLÉMENTAIRE DE BOTANIQUE.
}

\author{
NOTIONS PRÉLIMLNAIRES.
}

1. Définition de la Botanique, son utilité.-La Botanique est la partie de l'histoire naturelle qui traite des plantes ou végétaux.

Les plantes sont trop connues pour qu'il soit nécessaire d'insister lon. guement sur leur définition. Linné a tracé avec clarté et précision, dans sa Philosophie botanique, la différence qui les sépare du règne minéral et du règne animal : "Les pierres, dit-il, croissent; les végétaux croissent et vivent; les animaux croissent, vivent et sentent." Les plantes sont donc dépourvues de la faculté de sentir qui caractérise les animaux; mais, comme ces derniers, elles se nourrissent, elles se reproduisent : ce sont, en un mot, des êtres vivants.

Tout le monde aime les plantes: l'élégance de leurs formes, la variété et l'éclat de leurs couleurs, la suavité de leurs parfums parlent aux sœurs les plus froids comme aux esprits les moins cultivés. Ce n'est toutefois qu'a. près une observation attentive des organes qui les composent, après une étude approfondie de leurs fonctions vitales, après avoir comparé leurs nombreuses espèces, que l'on commence à comprendre les merveilles de la végétation. L'âme se sent alors en face d'harmonies sublimes qui la jettent dans le ravissement et la forcent à s'incliner devant la puissance, la sagesse et la bonté du Dieu créateur. "J'ai aperçu le Tout-Puissant, s'écriait l'immortel Linné après une vie consacrée toute entière à l'étude des plantes, je n'ai fait que l'entrevoir et je me suis incliné sur son passage pour l'adorer."

La Botanique possède, au point de vue des intérêts matériels, une incon. testable utilité, car c'est elle qui nous apprend à connaître les plantes et nous en découvre les propriétés.

A toutes les époques on a su faire servir les végétaux à des usages variés: on leur a demandé des aliments, des habits, des meubles, des remèdes contre la maladie; mais il était réservé aux savants modernes d'élargir le cercle de ces applications. Le nombre des espèces connues, qui était à peine de 20,000, au commencement de ce siècle, a été porté depuis au-delà de 120,000 et celui des substances utiles s'est accru en proportion.

2. Division. - Ce traité élémentaire est divisé en trois parties : 1o l'organographie ou description des parties constituantes de la plante; 20 la physiologie ou étude de la vie dans les plantes; 30 la taxonomie ou classification méthodique des plantes. 


\section{- ORGANOGRAPHIE.}

\section{CHAPITRE I.}

\section{ORGANES ÉLÉMENTAIRES.}

3. Toutes les plantes ont leur structure formée d'une même matière, ls cellulose. Cette matière s'organise en cellules, en fibres et en vaisseaux, ef de l'union de ces éléments, de leurs groupements divers, résultent les organes plus complexes dont l'ensemble constitue le végétal.

4. Cellules. Tissu cellulaire.-La cellule, appelée aussi utricule, est un petit sac membraneux (fig. 1), complëtement fermé et rempli ordinairement de substances solides ou liquides que nous étudierons dans la seconde partie du traité.

Lues cellules se soudent les unes aux autres pour former une masse plus ou moins compacte (fig. 2) qu'on nomme tissu cellulaire, et dont le propre est de se laisser déchirer en tous sens avec une égale facilité. C'est dans les fruits charnus, dans les jeunes pousses et dans la moelle des tiges qu'on le trouve avec plus d'abondance.

Pour l'observer, il suffit de couper en travers l'une de ces parties, de la réduire en lame mince et transparente, et de l'examiner au microscope. Si l'on voulait isoler les cellules, il faudrait les maintenir durant quelques minutes dans de l'eau bouillante additionnée d'une faible quantité d'acide azotique.

5. Multiplication des cellules.-Le tissu cellulaire n'est à son origine qu'un liquide gommeux où se montrent des points opaques que plusieurs botanistes considèrent comme le noyau d'autant de cellules. On remarque effectivement dans celles-ci, du moins quand elles sint de formation récente, un amas granulaire qui adhère à la base de leur paroi et qui porte le nom de nucleus. Le nucleus se divise fréquemment en plusieurs autres autour desquels s'organisent des membranes distinctes. Ce travail accompli, la cellule-mère disparaît et se trouve remplacée par un groupe de cellules nouvelles. D'autres fois la multiplication a lieu par la formation dans l'intérieur des cellules, déjà parvenues à leur entier développement, d'une double cloison qui les sépare en deux utricules plus petits.

Cette multiplication des cellules, qui semblerait exiger un temps consi- dérable, s'opère, dans certains végétaux, avec une rapidité prodigieuse. Ainsi, il existe une espèce de Champignon géant, du genre Lycoperdon, qui, dans une seule nuit, acquiert la grosseur d'une gourde de grandes dimen. sions; or, un développement si prompt suppose, d'après les calculs les plus modérés, la formation de plusieurs centaines de millions de cellules par heure!

6. Modification des cellules.-Les cellules varient beaucoup par leurs figures, leurs dimensions et leur constitution intérieure. 
Elles se montrent constamment globuleuses ou ovoïdes (fig. 1), tant que nul obstacle ne gêne leur développement; mais, par suite de leur croissance, elles subissent des pressions qui les rendent polyédriques (fig. 2), ou peuvent même, si elles ne s'exercent pas de tout côté avec une égale force, leur faire prendre une forme très-irrégulière (fig. 3 ).

Il existe ordinairement, entre les cellules, des vides qui portent le nom de méats intercellulaires lorsqu'ils sont microscopiques (fig. 3), et celui de lacunes quand ils sont plus considérables (fig. 2).

La plupart des cellules ont un diamètre qui varie entre $\underset{2 \neq 0}{1}$ et $\underset{1200}{1} \mathrm{de}$ pouce, quantité beaucoup trop petite pour être appréciable à l'œil nu. Leurs dimensions changent, du reste, non-seulement d'un végétal à l'autre, mais aussi dans les differents organes de la même plante.

L'enveloppe cellulaire subit, avec le temps, des modifications importantes : d'abord mince, transparente et unie, elle acquiert de la consistance, devient opaque et présente à sa surface des ponctuations, des lignes ou des bandelettes tantôt éparses, tantôt distribuées symétriquement (tig. 4, 5, 6).

Ces changements sont dus à des membranes qui se forment sur la paroi interne de la cellule. Si les nouvelles membranes tapissaient la cavité entière de la cellule, celle-ci conserverait une surface unie; mais, assez ordinairement, le dépôt organique n'a lieu que sur quelques points ou dans certaines directions (fig. 7,8 ), et les régions qui ont conservé leur ténuité, transmettant mieux la lumière que les autres, apparaissent comme des pores ou des fentes.

D'autres changements encore plus notables se produisent dans l'enveloppe cellulaire par voie d'incrustation : ses pores sont obstrués, à la longue, par des matières solides qui s'y fixent et lui font acquérir, dans quelques cas, une dureté supérieure à celle du bois. Le noyau de la Cerise et les substances pierreuses que renferment quelques fruits, ne sont que du tissu cellulaire ainsi modifié.

7. Fibres. Tissu fibreux.-Les fibres sont des filaments creux dont les extrémités se terminent en pointe. Elles présentent toutes les modifications des cellules, dont elles ne diffèrent que par un plus grand allongement, des parois plus épaisses et un diamètre intérieur très-réduit.

Les fibres constituent, par leur réunion, le tissu fibreux (fig. 9) auquel les plantes doivent principalement leur solidité. On trouve ce tissu dans le bois, dans la partie interne de l'écorce et dans les nervures des feuilles. Dans nos arbres, les fibres sont groupées parallèlement entre elles, et c'est ce qui rend le bois plus facile à fendre en long qu'en travers : dans le sens longitudinal, on ne fait que désunir les fibres, tandis que transversalement on est obligé de les rompre.

8. Vaisseaux. Tissu vasculaire.-Les vaisseaux (fig. 10-14) sont de longs tubes destinés, conjointement avec les fibres, au transport de la sève dans les différentes parties du végétal. On donne le nom de vasculaire (du latin vasculum, vase) au tissu dont ils font partie.

Il existe trois sortes de vaisseaux: les vaisseaux ordinaires, les trachees et les vaisseaux laticiferes.

Vus au microscope, les vaisseaux de la première espèce offrent, de distance en distance, des étranglements plus ou moins prononcés qui les divisent en articles superposés. Cette structure et d'autres considérations 
les font regarder comme formés de cellules mises bout à bout et percées au point de contact.

On remarque toujours, à la surface des vaisseaux ordinaires, les points et les lignes que nous avons signalés dans les cellules. Ces apparences ont servi à les diviser en vaisseaux ponctués (fig. 10), en vaisseaux rayés (fig. 11), en vaisseaux scalariformes ou en forme d'échelle (fig. 12), et en vaisseaux spiraux. Ces derniers ressemblent aux trachées, mais ne sont pas déroulables comme elles.

Les trachées (fig. 13) possèdent une structure des plus singulières: ces vaisseaux sont formés de tibres extrêmement longues et déliées, et roulées en spirale comme les fils de laiton dans les élastiques de bretelles. Les spires sont maintenues en place par une membrane si délicate, qu'on éprouve de la difficulté à l'apercevoir, même à l'aide d'un fort grossissement.

Les trachées s'observent autour de la moelle des tiges et dans les nervures des feuilles. On parvient à les dérouler et à les voir à l'œil nu, en rompant une jeune pousse et en éloignant avec précaution les deux bords de la rupture.

Les vaisseaux laticifères, qu'on nomme aussi vaisseaux propres, diffèrent des précédents tant par leur structure que par leur contenu. Ils se montrent dans l'écorce sous forme de cylindres à surface unie, communiquant entre eux par des branches transver'sales, de manière à dessiner une espèce de réseau (fig. 14). Le liquide qu'ils renferment porte le nom de latex ou celui de suc propre, parce que sa nature diffère dans chaque espèce végétale. $\mathrm{Ce}$ liquide est souvent coloré, comme dans la Sanguinaire du Canada, et possède un mouvement particulier. Jusqu'ici les vaisseaux laticifères n'ont été observés que sur un petit nombre de plantes.

Nous voyons, en résumé, que les vaisseaux, ceux du moins qui forment les deux premières divisions, peuvent être considérés comme une réunion de fibres ou de cellules disposées en série linéaire, soudées par leurs extrémités et percées au point de contact. Les fibres ne sont, à leur tour, que des cellules minces et allongées. Il n'y a donc en réalité qu'un seul organe élémentaire, la cellule, qui est la base de toute l'organisation végétale. Cependant, pour nous conformer au langage reçu, nous donnerons toujours aux fibres et aux vaisseaux le nom d'organes élémentaires.

9. Plantes cellulaires et vasculaires.-Les plantes sont dites cellulaires ou vasculaires, selon qu'elles se composent exclusivement de cellules, ou qu'elles renferment en outre des fibres et des vaisseaux. Cette distinction n'a toutefois rien d'absolu, car toutes les plantes possèdent, au moment de leur apparition, une structure entièrement cellulaire. Ce n'est que plus tard qu'on voit, chez le plus grand nombre, certains utricules s'allonger en fibres, et plus tard encore que s'organisent les vaisseaux.

\section{CHAPITRE II.}

\section{APERÇU GÉNÉRAL SUR LES ORGANES COMPOSÉS.}

10. Avant d'étudier en détail les organes composés, il importe d'en avoir une vue d'ensemble, et la manière la plus simple de l'acquérir est de suivre 
une plante depuis le commencement de sa germination jusqu'au jour où, parvenue à l'état parfait, elle produit des semences propres à perpétuer son espèce.

Le Haricot, par sa croissance rapide et le rang élevé qu'il occupe parmi les végétaux, se prête très-bien à ce genre d'observations.

Lorsqu'on place une graine de Haricot à une faible profondeur dans une terre humide et maintenue à la température de $15^{\circ}$ ou $20^{\prime}$, elle ne tarde pas à se gonfler sous la triple influence de l'air, de la chaleur et de l'humidité, et à se déchirer pour livrer passage au germe qu'elle contient (fig. $15,16)$.

Ce germe ou plante embryonnaire présente déjà deux parties bien distinctes: l'une, de couleur jaunâtre, s'enfonce dans le sol, c'est la racine; 1 autre, colorée en vert, se dirige vers le ciel, c'est la tige.

Entre la racine et la partie supérieure de la tige se montrent (fig. 17) deux feuilles très-épaisses, convexes à l'extérieur et concaves à l'intérieur, qui ont reçu, à raison de leur forme, le nom de cotylédons, et qui sont destinées à nourrir le jeune Haricot jusqu'à ce qu'il soit en état de puiser ses aliments dans la terre. Cette fonction remplie, les cotylédons se dessèchent et meurent. En même temps on voit, à l'extrémité de la tige, se dévelop. per un bourgeon d'où sortent les feuilles proprement dites, de couleur verte et de forme lamellaire.

Cependant, la plante continue à croître: tandis que la racine multiplie dans la terre ses divisions, la tige se couvre de rameaux et ceux-ci de nouvelles feuilles. Ces phénomènes ne prennent fin qu'au moment où la force vitale commence à s'épuiser. Les sucs nourriciers s'accumulent alors de préférencen sur quelques points particulier's de la tige, pour donner naissance à un ensemble d'organes qui ont reçu le nom de fleur. La durée de la fleur est éphémère, mais elle ne se flétrit qu'après avoir produit un ou plusieurs fruits qui, semés en lieu convenable, perpétueront l'espèce végétale à laquelle ils appartiennent.

Après cette série d'actes vitaux, le Haricot meurt et se décompose. In n'en est pas ainsi de toutes les plantes. Le Pommier, par exemple, fleurit et fructifie un grand nombre de fois avant de mourir; mais, à cette différence près, ce sont les mêmes phénomènes qui se succèdent, les mêmes organes qui se produisent.

11. Organes de nutrition et de reproduction.-La racine, la tige et les feuilles ont reçu le nom d'organes de nutrition parce que de leur action dépend entièrement la vie du végétal. La fleur et le fruit, n'ayant d'autre fonction que de perpétuer l'espèce, sont appelés organes de reproduction.

12, Division du règne végétal. - Nous venons de voir que le Haricot possède deux cotylédons; nos arbres et plusieurs autres plantes en ont aussi deux ou plusieurs, mais on n'en trouve qu'un seul dans les Palmiers, le Lis, le Blé et en général dans les Graminées; quant aux végétaux inférieurs, comme les Champignons, les Mousses et les Fougères, ils ne fleurissent jamais, ne produisent point de graines, et leur semence, qui se réduit à une poussière ténue, ne renferme ni embryon, ni cotylédons par conséquent.

On a pris de là occasion de diviser les végétaux en trois grandes classes: les dicotyledones ou à deux cotylédons, les monocotylédones ou à un seul coty. lédon, et les acotylédones ou sans cotylédons.

Souvent on réunit, sous la dénomination de plantes phanérogames, les 
dicotylédones et les monocotylédones, qui toutes portent des fleurs et dont les organes de reproduction sont très-visibles. Pour la raison contraire, les acotylédones sont appelées cryptogumes.

\section{CHAPITRE III.}

\section{LA RACINE.}

13. La racine occupe la partie inférieure du végétal et croît en sens con. traire de la tige. Elle pénètre dans la terre où elle remplit une double fonction en servant à fixer le végétal et à le nourrir. Quelquefois, cependant, la racine flotte librement dans l'eau (Lentille d'eau), ou bien s'implante dans les fissures des rochers, dans les murs ou l'écorce des arbres. Plusieurs plantes, cryptogames pour la plupart, sont privées dé cet organe.

14. Parties de la racine.-On distingue trois parties dans la racine: lo le collet ou nocud vital: c'est la base de la racine, c'est-à-dire le plan par lequel elle s'unit à la tige; 20 le corps ou partie moyenne; 3o le chevelu ou l'ensemble des radicelles qui terminent la racine principale et ses ramifications (fig. 18).

Les extrémités des radicelles, formées d'un tissu délicat et sans cesse renouvelé, portent le nom de spongioles, parce qu'on les a comparées à de petites éponges par lesquelles la plante absorbe les sucs nourriciers. Cette comparaison est peu exacte, car les spongioles ont une texture serrée qui ne ressemble nullement à celle des éponges ordinaires.

15. Forme des racines.-Les racines se rapportent par leurs formes à deux types principaux: la racine pivotante, qui ne possède qu'un seul axe principal (fig. 18, 19), et la racine fasciculée, du collet de laquelle partent plusieurs axes à peu près de même importance (fig. 20). La première est surtout propre aux dicotylédones et la seconde aux monocotylédones.

La racine est encore appelée tracante, lorsque ses ramifications s'étendent près de la surface du sol (Cerisier); fibreuse, lorsque ses axes sont déliés.s (Blé); et tubéreuse, lorsqu'ils présentent des renflements charnus (Orchis, Dahlia).

16. Racines adventives.-Un a donné le nom d'adventives aux racines qui se produisent en dehors des circonstances ordinaires et sur des points du végétal qui n'étaient pas destinés à. leur donner naissance. Telles sont les racines qui croissent sur une branche de Saule qu'on a entourée de terre humide.

Quelquefois c'est sur la partie aérienne de la tige et à une distance considérable du sol que se montrent les racines adventives. Le Figuier des pagodes (Ficus religiosa) nous offíe un exemple remarquable de ce phénomène: des branches de cet arbre merveilleux descendent des racines qui flottent d'abord librement dans l'air, mais qui finissent par atteindre la terre, s'y fixent et prennent un développement assez considérable pour former des colonnes entre lesquelles les Hindous aiment à élever leurs pagodes. 
Les plantes acotylédones ne possèdent que des racines adventives ; c'est sussi parmi elles et chez les monocotylédones que se présentent le plus souvent les racines aériennes.

17. Durée des racines.-Relativement à leur durée, les racines seront annuelles, bisannuelles, vivaces et ligneuses.

Les racines annuelles sont celles qui appartiennent aux plantes qui naissent, fructifient et meurent dans l'espace d'une année (Blé). Les racines bisan. nuelles appartiennent aux plantes qui demandent deux ans pour leur développement complet: elles poussent des feuilles la première année; la seconde, elles meurent après avoir fleuri et fructifié (Carotte). Par racines vivaces on entend celles qui, durant un nombre indéterminé d'années, poussent des tiges qui se développent et meurent tous les ans (Asperge). Entin, les racines ligneuses diffèrent des précédentes par une persistance de la tige qu'elles supportent (Arbres).

18. Structure et accroissement des racines. - La racine oftire, par son mode d'accroissement et par sa structure intérieure, la plus grande analogie avec la tige.

Le collet était considéré autrefois comme le point de départ de deux systèmes vasculaires différents et croissant en sens opposé; c'est pourquoi il reçut le nom de nœud vital.

Le noud vital n'a aujourd'hui pour le botaniste aucune importance particulière, car il est démontré que les fibres et vaisseaux de la racine, au lieu d'être distincts de ceux de la tige, n'en sont que le prolongement. Ces éléments n'ont cependant pas la même disposition dans les deux organes dont nous parlons. Chez les dicotylédones, la tige, comme nous le verrons plus loin, est formée extérieurement d'une écorce mince et facile à enlever, et son axe est occupé par la moelle, qu'entoure une couche de trachées appelée étui médullaire; dans la racine des mêmes végétaux, l'écorce acquiert une forte épaisseur et se confond plus ou moins avec les tissus sousjacents ; quant à l'étui médullaire et à la moelle, ils disparaissent pour faire place à une colonne de fibres et de vaisseaux ordinaires. Ce n'est que dans le Noyer et quelques autres arbres qu'on voit la moelle franchir le collet et se distribuer dans les branches radicales.

$\mathrm{I}$ n'existe point de proportion entre la longueur de la racine et la grandeur de la plante. La Luzerne, qui est une herbe peu élevée, pénètre à douze ou quinze pieds dans la terre, au lieu que le Pin et le Sapin, dont la tige est très-haute, n'ont que de petites racines.

\section{CHAPITRE IV.}

\section{LA TIGE.}

19. La tige est la partie de la plante qui se dirige dans l'atmosphère et qui est intermédiaire entre la racine et les feuilles. Tous les végétaux vasculaires possèdent une tige, mais chez quelques-uns elle est si courte que 
les feuilles semblent naître directement de la racine. On désigne improprement ces végétaux sous le nom d'acaules, qui veut dire sans tige.

La tige est rarement simple; ordinairement elle devient rameuse, en donnant naissance à des tiges secondaires, qui peuvent elles-mêmes se ramitier en tiges de troisième ordre, de quatrième ordre, etc. Dans le langage ordinaire, on se sert des mots branche, rameau, ramuscule, ramille, pour désigner ces divisions et sous-divisions de la tige.

20. Formes de la tige.-Les tiges présentent un grand nombre de formes souvent très-élégantes et qui ont fourni à l'architecture ses plus beaux modèles. Quelques-unes de ces formes ont reçu des noms particuliers: on dit le tronc d'un Chêne, le sarment de la Vigne, le chaume du Blé, le stipe du Palmier. Cette dernière espèce de tige a la forme d'une colonne cylindrique couronnée par un bouquet de feuilles.

21. Direction des tiges.-La plupart des tiges sont dressées, mais plusieurs ne peuvent s'élever qu'au moyen d'un support. Parmi ces dernières, les unes s'attachent au support par des filaments, des crampons ou des racines adventives, et sont nommées grimpantes (Vigne); d'autres s'enroulent autour de lui et portent le nom de volubiles. Il est remarquable que chaque tige volubile s'enroule constamment dans le même sens. Ainsi, les spires du Haricot et du Liseron des haies vont de gauche à droite, tandis que celles du Chèvre-feuille et du Houblon vont de droite à gauche. (1)

Quelques tiges, impuissantes à s'élever par elles-mêmes ou à l'aide d'un appui, restent couchées sur terre. On les dit ascendantes lorsqu'elles se relèvent par leur extrémité (Catherinettes); rampantes lorsqu'elles se fixent au sol au moyen de racines adventives (Raisins d'Ours); et tracantes ou stoloniferes lorsqu'elles émettent latéralement des jets, appelés coulants, stolons, qui s'enracinent de distance en distance (Fraisier, fig. 21).

22. Rhizomes ou tiges souterraines.-Jusqu'ici nous avons supposé la tige entièrement plongée dans l'atmosphère; quelquefois, cependant, son axe principal se trouve caché sous terre et ne laisse apercevoir que ses rameaux ou axes secondaires (fig. 22).

Ces tiges souterraines, appelées rhizomes, végètent par leur extrémité antérieure pendant qu'il s'opère à l'extrémité opposée un travail de décomposition. Elles se déplacent donc chaque année d'une manière sensible, et ce curieux phénomène leur fit donner le nom de racines progressives, à une époque où l'on se méprenait sur leur nature. On ne doute plus aujourd'hui que les rhizomes ne soient de véritables tiges, car ils sont munis de bourgeons qui, par leur développement, produisent des feuilles et des fleurs, et c'est là un caractère qui ne saurait appartenir à une racine proprement dite.

La Sanguinaire du Canada, le Sceau de Salomon, les Iris et, en général, les plantes vivaces possèdent des rhizomes.

Le rhizome peut offrir deux modifications importantes. Quelquefois il est tuberculeux: c'est lorsqu'il se forme des amas de fécule sur quelques-uns de

(1) Les plantes grimpantes et volubiles sont désignées, dans les colonies françaises de l'Amérique et de l'Inde, sous le nom général de lianes, qui dérive du mot lien. 
ses points (Pomme-de-terre); d'autres fois il demeure très-court et se ramasse en une espèce de cône charnu et prend le nom de rhizome bulbeux.

Les bulbes sont formées d'un plateau entouré d'écailles tantôt soudées entre elles comme dans le Glaïeul commun (Bulbe solide, fig. 23), tantôt emboîtées les unes dans les autres comme dans l'Oignon (Bulbe tuniquée, tig. 24), tantôt enfin disposées comme les tuiles d'un toit (Bulbe écailleuse, fig. 25). Cette dernière disposition se voit dans le Lis.

23. Consistance des tiges.-Les tiges, eu égard à leur consistance, se divisent en tiges ligneuses, tiges herbacees et tiges frutescentes.

Les premières se distinguent par une dureté considérable et une persistance indéfinie ; les secondes, qui sont aqueuses, molles et fragiles, ne vivent qu'une année; enfin, les dernières ont une base ligneuse persistante et des rameaux qui se renouvellent chaque année:

Les végétaux à tige herbacée se nomment des herbes; ceux dont la tige est frutescente se nomment sous-arbrisseaux; ceux dont la tige est ligneuse se nomment arbrisseaux ou arbres, selon qu'ils se ramifient près de terre ou seulement à une hauteur considérable.

24. Structure de la tige chəz les dicotylédones.-La tige possède une structure très-différente suivant qu'elle appartient à une plante dicotylédone, monocotylédone ou acotylédone.

Lorsqu' on examine une tige de dicotylédone, celle d'un Erable, par exemple (fig. 26), on voit qu'elle se compose de deux parties: le bois ou système ligneux, et l'ecorce ou systeme cortical.

Dans le système ligneux (fig. 27), on distingue la moelle, 1'étui médullaire, la couche ligneuse et les rayons médullaires.

Le système cortical comprend à son tour quatre couches distinctes: le liber, l'enveloppe herbacée, l'enveloppe subéreuse et l'épiderme (fig. 27).

Système ligneux.-La moelle est une colonne de tissu cellulaire allant d'une extrémité à l'autre de la tige dont elle occupe le centre. Peu développée dans les plantes ligneuses, elle prédomine dans les herbes sur les autres parties. Souvent elle se dessèche de bonne heure ou se détruit même complètement. La tige devient fistuleuse par suite de la disparition de la moelle.

On a donné le nom d'étui médullaire à une mince couche de trachées qui constitue les parois de la cavité dans laquelle est logée la moelle.

La couche ligneuse est une réunion de fibres et de vaisseaux qui entourent l'étui médullaire et dont la direction est sensiblement parallèle avec celle de la tige.

Des lames de tissu cellulaire, allant de la moelle jusque dans l'écorce, séparent les éléments de la couche précédente en groupes plus ou moins nomhreux. Ces lames sont appelées rayons médullaires, parce que, vues sur une coupe transversale de la tige, elles paraissent comme des bandes étroites ou de simples lignes tirées du centre à la circonférence (fig. 26).

On aperçoit au commencement du printemps, entre le bois et l'écorce des tiges persistantes, une matière gélatineuse, appelée cambium, qui s'or- 
ganise plus tard en deux couches distinctes, l'une de nature ligneuse, l'autre fibreuse. La première s'ajoute au système ligneux et la seconde au système cortical.

Puisque le bois s'augmente ainsi tous les ans d'une couche nouvelle, le tronc et les branches des arbres doivent présenter autant de zones concentriques qu'ils comptent d'années, et il devient par là facile de déterminer leur âge. Ces zones n'ont ni la même consistance ni la même couleur. Celles du centre, plus anciennes, sont devenues compactes et ont pris une teinte foncée: elles constituent le duramen ou cœur du bois. Celles de la circonférence, appelées aubier, sont relativement tendres et de couleur blanche. On les rejette habituellement dans les ouvrages en bois, nonseulement à cause de leur peu de solidité, mais encore parce que les parties molles qui entrent dans leur composition pourraient attirer les insectes. La différence entre l'aubier et le coeur du bois est, du reste, d'autant moins prononcée que la croissance de la tige est plus rapide. C'est à peine si elle est sensible dans le Tilleul et, en général, dans les arbres connus sous le nom de bois blancs.

Système cortical.-Nous venons de voir que le bois s'accroît par sa circonférence et qu'il se compose d'une ou plusieurs zones fibro-vasculaires placées autour d'une colonne de tissu cellulaire généralement peu considé. rable; ce sont les dispositions exactement inverses que nous offire l'écorce :

L'intérieur est formé de fibres longues, Hexibles et tenaces, susceptibles, dans plusieurs cas, d'ètre utilisées par l'industrie (Lin, Chanvre). Comme il se forme tous les ans, dans les tiges ligneuses, une ou plusieurs couches de ces fibres, celles-ci se trouvent superposées à la manière des feuillets d'un livre, et c'est à cette disposition qu'elles doivent le nom de liber.

Autour du liber se montrent des rangées de cellules vertes, lâchement unies. Leur ensemble constitue l'enveloppe herbacke, siège de la respiration et d'autres fonctions importantes. C'est là seulement que se montrent les vaisseaux laticifères.

L'enveloppe subereuse, vulgairement appelée liege, est cellulaire comme la précédente, mais elle en diffère par une texture plus compacte, par sa cou. leur ordinairement brunâtre et par la régularité de ses cellules, qui oftirent l'apparence des pierres d'un édifice. Cette partie de l'écorce est très. développée dans quelques arbres, notamment dans le Chêne-liège (Quercus suber), qui fournit tout le liège du commerce.

La dernière enveloppe corticale se nomme épiderme, à cause de son analogie avec l'épiderme des animaux. C'est elle que l'on détache de la sur. face des jeunes pousses sous la forme d'une membrane incolore et transparente. Lorsqu'on examine cette membrane au microscope, on découvre à sa surface des ouvertures en forme de petites bouches: ce sont les stomates (fig. 30). Ces organes servent à mettre l'enveloppe herbacée en communication avec l'atmosphère. On les voit se dilater quand le temps est humide et se contracter durant la sécheresse; ils ne se rencontrent que sur les parties aériennes des végétaux.

L'épiderme est souvent muni d'appendices connus sous les noms de poils, d'aiguillons et de glandes. 
Les poils sont des expansions longues et menues, qui paraissent destinées à protéger la plante contre les insectes et la sécheresse. On appelle glabre tout organe dépourvu de poils.

Les aiguillons sont aussi des organes protecteurs. Ils résultent de poils agglomérés, dureis et intinement soudés entre eux.

Les glandes sont des cavités cellulaires qui sécrètent des matières particulières. Elle.s sont logées dans l'épaisseur de l'épiderme ou bien font saillie à sa surface. Parfois elles prennent la forme de poils ordinaires, comme dans l'Urtie brûlante.

Longtemps on a considéré l'épiderme comme une membrane simple, mais on sait maintenant qu' une macération prolongée la dédouble en deux pellicules, l'une intérieure formée de cellules juxta-posées : c'est l'épidernee proprement dit auquel se rapportent tous les détails précédents; liautre extérieure, unie, sans organisation apparente, et qui porte le nom de cuticule. La cuticule recouvre tout l'épiderme proprement dit ainsi que ses appendices; on la trouve aussi sur la racine et sur les organes submergés des plantes aquatiques où l'épiclerme proprement dit fait défaut.

25. Structure de la tige chez les monocotylédones.-On ne remarque dans la tige des plantes monocotylédones ni étui médullaire, ni rayons médullaires, ni zones concentriques, ni système cortical distinct.

Une coupe transversale de cette tige (fig. 28) offre l'apparence d'un cylindre de tissu cellulaire au milieu duquel sont épars des faisceaux fibrovasculaires. La distribution de ces faisceaux n'est pas uniforme: trèsserrés vers la circonférence, ils deviennent plus rares au centre ou en disparaissent même complètement. C"est ce que l'on remarque dans plusieurs Graminées, dans le Blé, en particulier, dont la tige devient ordinairement fistuleuse par suite de la destruction des cellules centrales.

Lorsqu'on suit un faisceau, depuis son entrée dans une feuille jusqu'à l'extrémité inférieure du végétal, on voit que sa direction est loin d'être rectiligne et sa composition constante. Après avoir pénétré dans la tige, il s'infléchit vers le centre, décrit un arc et revient bientôt près de l'écorce le long de laquelle il descend ensuite. Sa nature varie en même temps que sa direction. Supérieurement, il est volumineux et renferme, associés avec des fibres ligneuses, tous les vaisseaux décrits au chapitre premier; plus bas et dans le voisinage de l'écorce, il est réduit à quelques fibr'es minces et flexibles comme celles du liber chez les plantes dicotylédones.

En tenant compte de ces faits, on s'explique sans peine pourquoi la tige des arbres monocotylédones, le stipe des Palmiers, par exemple, est si difïcile à fendre; pourquoi son diamètre est le même à toutes les hauteurs et r'augmente presque point, quoique tous les ans il se forme de nombreux faisceaux entre le bois et l'écorce ; pourquoi on ne trouve de vaisseaux que dans la partie centrale; pourquoi enfin le bois de ces tiges est plus fin, plus compacte et plus fort vers la circonférence qu'à l'intérieur.

L'écorce des monocotylédones ne forme pas un système complexe comme chez les dicotylédones. Ce sont les cellules extérieures, durcies et recouvertes, au moins dans les premiers temps, par un épiderme extrêmement vivace, qui la constituent en entier. C'ependant elle s'augr- 
mente encore, chez les plantes ligneuses, de la base persistante des feuilles.

26. Structure de la tige chez les acotylédones.-Parmi les plantes acotylédones, un grand nombre sont privées de tige, plusieurs en ont une purement cellulaire et quelques-unes seulement, telles que les Lycopodes et les Fougères, possédent une tige vasculaire.

La figure 29 est la coupe transversale d'un stipe de Fougère arborescente. On voit que les faisceaux ligneux n'y sont point distribues par zones concentriques ou disséminés sans ordre comme dans les classes précédentes: ils forment un cercle étroit, interrompu de distance en distance pour laisser la moelle communiquer avec le tissu cellulaire extérieur, et beaucoup plus rapproché de la circonférence que du centre. Ces faisceaux se composent à peu près exclusivement de fibres et de vaisseaux annulaires ou scalariformes. Les trachées y font défaut.

L'écorce présente ici les mêmes particularités que chez les monocotylé. dones.

27. Plantes exogènes, endogènes et acrogènes.-Les dicotylédones s'accroissant par des couches qui se déposent annuellement entre le bois et l'écorce ou, ce qui est la même chose, par la partie extérieure du corps ligneux, ont été nommées exogenes (du grec exô, en dehors, et gennâo, engendrer).

Les monocotylédones ont été, au contraire, appelées endogènes (du grec endon, en dedans, et gennâ̂, engendrer), parce que les nouveaux faisceaux qui se forment chaque année paraissent provenir du milieu de la tige. Nous avons dit (no. 25) comment ces faisceaux, après s'être inclinés vers le centre, reviennent peu après vers la circonférence. Les monocotylédones ne sont donc pas purement endogènes, et ce n'est qu'improprement qu'on les désigne sous ce titre.

Chez les acotylédones, la tige acquiert dès la première année toute la grosseur qu'elle doit avoir. Plus tard, elle ne s'accroît qu'en hauteur et cela par l'élongation des éléments ligneux qui s'étaient formés dans la pre. mière période de sa végétation. Ces plantes ont reçu, à raison de ce fait, le nom d'acrogènes (du grec acron, extrémité, et gennâ̂, engendrer), c'est-à-dire qui ne croissent que par leur sommet.

28. Bourgeons.-Les bourgeons sont des petites masses ovoïdes qui renferment, à l'état rudimentaire, un rameau avec ses expansions latérales, c'est-à-dire ses feuilles ou ses fleurs. Certains bourgeons contiennent à la fois des feuilles et des fleurs.

C'est à l'aisselle des feuilles et à l'extrémité des anciens rameaux que naissent régulièrement les bourgeons. Mais il peut aussi s'en former d'adventifs sur tout point du végétal où la sève surabonde. C'est ainsi que de la racine des arbres s'élèvent parfois des tiges surnuméraires, connues en culture sous le nom de drageons.

Dans presque tous les arbres de nos climats, les bourgeons apparaissent au printemps, s'arrêtent bientôt dans leur développement, et ne s'allongent 
qu'au printemps suivant. Ils sont admirablement protégés contre les froids de l'hiver par des écailles dures et épaisses (fig. 31), qui sont elles-mêmes souvent garnies à l'intérieur d'un épais duvet ou bien enduites de matières résineuses propres à conserver la chaleur. Ces écailles tombent à l'époque où le bourgeon se développe.

Chez les plantes herbacées, en général, et chez un grand nombre d'arbres des contrées tropicales dont la végétation n'éprouve pour ainsi dire aucun repos, les bourgeons sont nus, c'est-à-dire dépourvus d'écailles protectrices.

Les jeunes pousses provenant du développement d'un bourgeon se nomment scions quand elles naissent sur une tige aérienne, et turions quand elles sortent de terre comme celles des Asperges.

Quelques végétaux portent des bourgeons charnus qui forment comme la transition entre le bourgeon proprement dit et l'embryon, car ils peuvent avoir une végétation à part, se détacher de la mère-plante et produire, après avoir été semés, un individu semblable à celui dont ils proviennent. Tels sont les bulbiles qui naissent à l'aisselle des feuilles du Lis bulbifère et les caïeux que produisent les rhizomes bulbeux (fig. 32, 23).

\section{CHAPITRE V.}

\section{LES FEUILLES.}

29. Structure générale des feuilies.-On appelle feuilles des expansions latérales de la tige ordinairement de couleur verte et de forme lamellaire.

Leur structure varie selon qu'elles vivent dans l'air ou dans l'eau.

Les feuilles aériennes sont formées de fibres et de vaisseaux distribués dans l'épaisseur d'une couche cellulaire qui est elle-même enveloppée par l'épiderme.

Les faisceaux fibro-vasculaires sont de même nature que ceux de la tige qui leur donne naissance. Ceux des plantes dicotylédones présentent à leur partie supérieure des trachées, sous les trachées des vaisseaux ordinaires, et sous ces derniers des fibres déliées, puis des vaisseaux laticifères (fig. 34). C'est exactement l'ordre dans lequel se succèdent les éléments de la tige de dedans en dehors. Ce fait s'explíque facilement si l'on considère que les faisceaux ne peuvent passer de la tige dans la feuille qu'en s'infléchissant de manière que leur partie centrale soit en-dessus et leur partie extérieure en-dessous.

La couche cellulaire qui entoure les faisceaux, et dont la fig. 35 représente une section transversale très-amplifiée, est analogue à la couche herbacée de l'écorce. Elle est beaucoup plus compacte et plus ferme sur la face supérieure de la feuille que sur la face inférieure, où elle forme un tissu spongieux, criblé de lacunes. Les cellules sont remplies de granules auxquels la feuille doit sa couleur. C'est ordinairement une matière verte, la chlorophylle, qu'elles contiennent.

L'épiderme des feuilles est remarquable par le grand nombre de ses sto 
mates (fig. 30). ("est sur la face inférieure qu'ils sont répandus avec le plus de profusion, et l'on attribue deur présence la couleur terne de cette tace : ils s'y élèvent au nombre de plus de 200,000 dans la feuille du Lilas.

Les feuilles submergées manquent à la fois d'épiderme et de faisceaux fibro-vasculaires. Leur structure purement cellulaire fait qu'elles se des. sèchent très-vite et se crispent quand on les expose à l'air. On voit souvent dans leur masse des lacunes remplies de gaz et destinées, selon toute apparence, à les maintenir élevées en diminuant leur poids spécitique.

30. Parties de la feuille.-La fouille peut avoir trois parties: une gaîne ou des stipules, un pétiole et un limbe (tig. 36 ).

La gaine se voit dans les plantes monocotylédones, en général, et dans plusieurs dicotyléclones herbacées. Elle est formée par une dilatation de firisceaux fibro-vasculaires qui enveloppent la tige au-dessus de leur point d'insertion; cette gaine est tantôt entière comme chez les Cypéracées, tan tût fendue en long comme chez les Graminées. Les feuilles qui en sont munies se nonment engainantes.

Au lieu d'une gaine on aura des stipules si les faisceaux, au sortir de l'axe, se séparent en trois groupes dont l'un produit la f'euille proprement dite et les deux autres forment latéralement deux appendices foliacés, épineux, filiformes ou écailleux qui tantôt restent indépendants, tantôt se soudent soit entre eux, soit avec la tige, soit enfin avec le pétiole de la feuille (fig. 37, 38).

La feuille cst dite stipulée quand elle est accompagnée de stipules, et extipulée quand ces organes font défaut.

Les stipules ne se rencontrent proprement que sur les végétaux dicoty. lédones; cependant lés Graminées, qui sont monocotylédones, portent à l'extrémité de leur gaine un prolongement appelé ligule, que plusieurs bota. nistes considèrent conme analogue aux stipules (fig. 39).

Le pétiole est le pied ou ce que l'on nomme vulgairement la queue de la feuille. Il se rattache le plus ordinairement à la tige par une articulation en forme de bourrelet (fig. 34): c'est le résultat d'une déviation et d'un raccourcissement des éléments ligneux de la feuille au point où ils se séparent de l'axe.

Le pétiole est tantôt canaliculé, c'est-à-dire creusé en gouttière, et tantôt cylindrique. Dans quelques arbres, le Tremble, par exemple, il est aplati dims le sens vertical, ce qui donne beaucoup de prise au vent et tient les feuilles dans une agitation continuelle.

Les fixisceaux du pétiole se dilatent parfois de manière à simuler un petit limbe en avant du limbe véritable (Oranger); cette expansion du pétiole, qui a reçu le nom de phyllode, constitue à elle seule la feuille de certains végétaux (fig. 45).

Les feuilles chez lesquelles le pétiole fait défaut (fig. 69) se nomment sessiles.

Le limbe présente habituellement la forme d'une lame mince; c'est à lui seul qu'est réservé le nom de feuille, dans le langage ordinaire, et c'est à lui aussi que se rapportent les détails qui vont suivie. 
Nous avons vu déjà que le limbe se compose exclusivement de cellules dans les feuilles submergées, et que dans les feuilles aériennes il comprend en outre des fibres et des vaisseaux. Les faisceaux fibro-vasculaires forment des lignes saillantes auxquelles on donne le nom de nervures; le tissu plus lâche qui remplit les intervalles des nervures est appelé par'enchyme, nom qui s'applique aussi à tout tissu cellulaire peu compacte. "'est de la distribution des nervures et du parenchyme que dépend la forme de la feuille.

31. Nerration.-Les nervures se distribuent selon trois modes principaux : tantôt le limbe est parcouru en son milieu par une nervure plus saillante que les autres et appelée côte, nervure principale, de laquelle naissent, à différentes hauteurs, dies nervures secondaires comme les barbes d'une plume de son tuyau (fig. 40), et la nervation est pennee, la feuille penni-nerve: c'est la nervation la plus commune; tantôt le pétiole se divise à l'entrée du limbe en plusieurs nervures, à peu près de même grosseur, qui divergent comme les doigts des oiseaux palmipèdles et la nervation est palmée, la feuille palmi-nerve (iig. 41) ; d'autres fois, enfin, les nervures après s'être séparées à l'entrée du limbe, comme dans le cas précédent, prennent des directions parallèles (fig. 42,39 ) : on a dans ce cas cles feuilles recti-nerves. Le 'tilleul a des feuilles penni-nerves, l'Erable des feuilles palmi-nerves, le Blé des feuilles recti-nerves.

La seule inspection des feuilles suffit presque toujours pour distinguer une plante dicotylédone de celle qui est monocotylédone. Chez les preinières, les feuilles sont généralement penni-nerves ou palmi-nerves, et les nervures, après s'être ramifiées un grand nombre de fois, s'unissent par leurs extrémités de manière à dessiner un réseau ou une sorte de dentelle (fig. 48); chez les secondes, au contraire, les feuilles sont recti-nerves et leurs ramifications, qui sont toujours peu nombreuses, restent parallèles les unes aux autres (fig. 39). On ne rencontre dians nos climats qu'un petit nombre de monocotylédones, de la famille des Aroidées et des Smilacées, dont les feuilles soient réticulées.

32. Distribution du parenchyme.-Le parenchyme se distribue très-diversement entre les nervures. Lorsqu'il les réunit toutes dans une même membrane, la feuille est simple (fig. 41) ; lorsqu'il entoure les divisions primaires du pétiole de manière à former autour de chacune d'elles un limbe distinct, la feuille est composée (fig. 38) ; si, enfin, les différents limbes n'apparaissent que sur des nervures de troisième ou quatrième ordre, la feuille est dite décomposée et sur-décomposée (fig. 62,63). Les feuilles de l'Erable sont simples; celles du Frêne, composées; celles de l'Ancolie, de l'Actée, décomposées.

33. Dśconpures des feuilles simples.-Lorsque le parenchyme occupe exactement l'espace compris entre les nervures (fig. 50), la feuille présente des bords unis et on la nomme entière. Ex. : le Lilas.

Avec des bords découpés, la feuille est dite :

Denté (fig. 46), lorsque les découpures forment des saillies courtes et aiguës. Ex. : l'Orme.

Crénelée (fig. 55), lorsque les découpures sont courtes et arrondies. Ex. : la Pensée. 
Lobee (fig. 43), lorsque les découpures sont profondes. Ex. : le Chêne.

Le mot lobe s'applique plus spécialement aux divisions arrondies ou séparées par des sinus arrondis; celles qui sont aiguës et séparées par des sinus aigus se nomment fissures, quand elles pénètrent jusqu'au tiers du demi-limbe ; partitions, quand elles s'avancent jusqu'au milieu; et segments, quand elles se rapprochent davantage de la nervure médiane.

On dira d'une feuille qu'elle est bi-tri . . . multi-fide, bi-tri ... multi-partite, bi-tri... multi-séquée, lorsque ses fissures, ses partitions ou ses segments sont au nombre de deux, de trois, etc. Souvent aussi ces mots s'emploient conjointement avec d'autres expressions désignant le mode de nervation. Ainsi, une feuille pinnati-fide, pinnati-partite, pinnati-séquée, est celle qui joint des fissures, des partitions ou des segments à une nervation pennée. On dira de même, si la nervation est palmée: feuille palmati-fide, palmatipartite, palmati-séquée.

Les découpures sont parfois si multipliées que le limbe parait déchiré, réduit en lanières ou mềne en filaments. On exprime ces divers états dé la feuille en disant qu'elle est disséquée, laciniée, déchiquetée, capillaire, otc. (fig. 44).

34. Forme des feuilles simples. - Si l'on considère l'ensemble de la feuille tel qu'il résulte de l'arrangement des nervures et du parenchyme, on lui trouvera, le plus souvent, de la ressemblance avec des objets qui nous sont familiers et auxquels on pourra la comparer pour mieux en faire saisir la description. Voici, du reste, la définition des formes que l'on rencontre le plus fréquemment. La feuille est dite:

Aciculaire, quand elle a la forme d'une aiguille. Ex. : le Pin.

Linéaire, quand elle est étroite et de même largeur sur toute son étendue. Ex. : le Blé.

Lancéolée (fig. 40), quand elle est en forme de lance. Ex. : le Laurier-Rose.

Ovale ou Ovée (fig. 46), quand elle représente la coupe longitudinale d'un œuf, sa plus grande largeur étant à la base. Ex. : le Cerisier-à-grappes.

Ob-ovale (fig. 47), quand elle présente la forme précédente renversée, c'est-à-dire ayant sa plus grande largeur au sommet. Ex. : l'Aubépine rouge ou Senellier.

Remarque: le mot ob s'emploie toujours, comme ci-dessus, pour indiquer une forme renversée.

Elliptique (fig. 48), quand elle forme une ellipse. Ex. : l'Erythrone.

Oblongue (fig. 49), quand elle forme une ellipse très-allongée et dont les bords tendent à devenir parallèles. Ex. : la Smilacine à grappe.

Cordée ou Cordiforme (fig. 50), quand sa base est échancrée en deux lobes arrondis et que son sommet est aigu. Ex. : le Lilas.

Réniforme (fig. 51), quand sa base est échancrée en deux lobes arrondis et que son sommet est très-obtus. Ex. : l'Azaret du Canada.

Sagittée (fig. 52), quand sa base est échancrée en deux lobes aigus et que le sommet est aussi aigu. Ex. : la Sagittaire.

Hastée (fig. 53), quand sa base porte deux lobes aigus coupés perpendi culairement au pétiole, et que son sommet est aigu. Ex. : l'Arroche-Fraise.

Lyree, quand elle est pinnati-fide et que la division du sommet est beau. coup plus grande que les autres. Ex. : la Benoîte.

Roncinée, quand elle est pinnati-fide et que les saillies se dirigent vers le base. Ex. : le Pissenlit. 
Amplexicaule quand elle est sessile et que sa base entoure la tige. Ex. : la Chicorée sauvage.

Connée (fig. 56), lorsqu'elle se soude par sa base avec une autre feuille qui lui est opposée. Ex. : le Chèvre-Feuille à petites fleurs.

Perfoliee (fig. 57), lorsqu'elle entoure la tige de telle manière que celleci parait la traverser. Ex. : l'Uvulaire perfoliée.

Peltée (fig. 55), quand le pétiole s'attache au milieu du limbe de manière à figurer un bouclier. Ex. : la Capucine des jardins.

35. Feuilles composées.-Chaque limbe des feuilles composées présente l'aspect d'une feuille simple et porte en conséquence le nom de foliole.

Les folioles naissent tantôt à l'extrémité du pétiole, tantôt sur ses côtés : dans le premier cas, la feuille est digitée (fig. 58), et dans le second, pennée (fig. 61). Les feuilles du Trèfle, du Lupin, du Marronier, sont digitées; celles du Noyer, du Vinaigrier, du Rosier, sont pennées.

La feuille pennée est dite pari-pennée ou abruti-pennée 'lorsque toutes ses folioles sont latérales (fig. 61); on la nomme impari-pennée ou pennée avec impaire, lorsque la foliole du sommet termine le pétiole (fig. 60).

Quand les feuilles deviennent décomposées ou sur-décomposées (no. 32), on a coutume d'indiquer le degré de composition au moyen de nombres placés devant le nom de la feuille. Ainsi, une feuille digitée, formée de trois folioles, comme celle du Trèfle, se nomme ternée; elle prendra le nom de bi-ternée si- elle est décomposée, et celui de tri-quadri...ternée si elle est sur-décomposée (fig. 63). On dira de même feuille pennée, bipennée, tri-quadri ... pennée (fig. 62).

Les feuilles décomposées atteignent parfois un développement tel que les commençants sont exposés à les prendre pour des rameaux ou même pour de grandes branches. Pour éviter cette erreur, il suffira, le plus souvent, de considérer l'insertion sur la tige du prétendu rameau : s'il porte à sa base une gaîne, des stipules ou une forte articulation, il devra être considére comme une feuille unique.

36. Feuilles anomales.-On nomme anomales les feuilles dont le limbe n'est pas lamellaire. Elles se produisent lorsque les nervures, au lieu de suivre sensiblement le même plan, se distribuent dans des plans très-différents. Le limbe peut alor's circonscrire une cavité comme dans l'Oignon et la Sarracénie (fig. 64), ou bien, si le parenchyme remplit tout l'espace compris entre les nervures, acquérir une forte épaisseur comme dans la plupart des plantes grasses.

37. Disposition des feuilles sur leur axe.-La disposition des feuilles étant constante dans chaque espèce végétale, elle fournit d'excellents caractères pour la classitication. On divise les feuilles, à ce point de vue, en radicales et caulinaires : les premières sont celles qui naissent près du collet de la racine (fig. 65), et les secondes, celles qui naissent sur des points plus élevés.

Les feuilles caulinaires se nomment alternes, lorsqu'elles sont espacées, une à une, sur la tige à des hauteurs différentes (fig. 66); opposées, lorsqu'elles sont situées deux à deux sur un même plan, vis-à-vis l'une de l'autre (fig. 68); verticillées, lorsqu'elles sont groupées circulairement autour de la tige, sur un même plan, comme une couronne (fig. 69). L'Orme a des 
feuilles alternes, l'Erable des feuilles opposées et le Laurier-Rose dess feuilles verticillées. Des feuilles qui naissent d'un même point de la tige sont dites gérninées quand elles sont au nombre de deux, et fasciculées quand elles sont plus nombreuses.

L'arrangement des feuilles est soumis à des lois d'une rigueur presque mathématique. "Les feuilles alternes, dit Milne-Edwards, ne sont jamais éparses sans ordre; elles sont disposées en spirale sur leur axe, de gauche à droite ou de droite à gauche. Il est facile de vérifier cette loi, en faisant passer un fil par tous les points successif's des insertions des feuilles. Si nous appliquons ce procédé à l'examen des feuilles du Tilleul, de la Fève, de l'Aristoloche, nous verrons qu'après le premier tour complet de spire, la troisième feuille est venue se placer au-dessus de la première; qu après le second tour, la cinquième feuille est située au-dessus de la troisième; par conséquent, la quatrième est située au-dessus de la seconde, la sixième auclessus de la quatrième, et ainsi de suite, de telle sorte que toutes les feuilles de l'arbre sont clisposées de chaque côté de leur axe en deux séries rectilignes, dont la première est formóe par les feuilles de rang impair, et la seconde par les feuilles de rang pair, disposition qui leur a valu le nom de distiques (fig. 67). Chez le Cactus élégant, ce n'est pas la troisième feuille qui vient se placer au-dessus de la première après un tour de spire, c est la quatrième ; les feuilles sont donc arrangées en trois séries rectilignes sur l'axe, elles sont tristiques. Chez d'autres végétaux, c'est la sixième feuille qui se trouve au-dessus de la première; mais tantôt il suffit d'un seul tour de spire, et tantôt il faut en parcourir deux pour trouver cette sixième feuille placée ainsi au-dessus de la première. La Pomme de terre, le Cerisier, la Pêcher nous offirent des exemples de cette dernière disposition qu'on appelle quinconce.

On a donné le nom de cycle à chaque système de feuilles qu'il faut par. courir pour arriver, après un ou plusieurs tours de spire, à la feuille placée au-dessus de celle d'où l'on est parti. Il est donc clair que pour donner l'expression exacte d'un cycle, il faut indiquer deux choses: le nombre de tours de spire, et le nombre de feuilles qui le composent. Ces deux nombres ont été pris cornme les deux termes d'une fraction dont le premier est le numérateur et le second le clénominateur. Ainsi, l'expression du cycle des feuilles distiques est $\frac{1}{2}$, parce qu'il se compose de deux feuilles sur un tour de spire........ eses cycles les plus habituels, rapprochés les uns des autres, ont donné la série $\frac{1}{2}, \frac{1}{3}, \frac{2}{5}, \frac{3}{8}$, etc., qu'il est facile de continuer par le calcul, comme on l'a fait par l'observation, si l'on remarque qu'à l'exception des deux premières, toutes les fractions de la série forment leur numérateur par l'addition des numérateurs des deux fractions précédentes, et leur dénominateur par l'addition des dénominateur's des deux mêmes fractions.

Souvent les feuilles, dans leurs séries, ne peuvent pas être rigoureusement ramenóes l'une au dessus de l'autre sur une ligne droite, et clécrivent ainsi autour de l'axe une courbe indéfinie; on les désigne sous le nom de curvisériées.

.... Quand les feuilles sont opposées, et que les deux feuilles supérieures se placent dans le milieu de l'intervalle des deux feuilles inférieures de manière à les croiser à angle droit, il y a décussation, ces feuilles sont decussées."

38. Durée des feuilles.-La durée des feuilles est variable d'un végétal ì l'autre. Dans nos contrées, la plupart des arbres se clépouillent de lenrs 
feuilles à l'autonne; quelques-uns les gardent cependant plus longtemps: les arbres verts, comme le Pin, ne conservent leur verdure pendant toute l'année que grâce à la persistance de leurs feuilles, qui restent encore en place au moinent où il s'en forme de nouvelles. En général, ce sont les feuilles articulées qui tombent le plus facilement etle plus vite; celles qui s'attachent à la tige sans articulation, celles surtout qui sont engaînartes, persistent après même qu'elles se sont desséchées.

39. Transformations des feuilles.-Dans un grand nombre de plantes, les feuilles subissent des transformations qui peuvent les rendre difficiles à reconniitre. Les tiges souterraines, particulièrement les rhizomes bulbeux, nous offirent des exemples frappants de ces transformations. Ainsi, la Jacinthe (tig. 24) se compose d'un plateau central autour duquel se superposent des feuilles charnues, de couleur blanche, qui se changent, vers la surface, en membranes écailleuses. Dans la Pomme-de-terre les feuilles se réduisent à des écailles à peine perceptibles, situées près des bourgeons ou yeux.

Des feuilles non moins profondément transformées se remarquent sur quelques tiges aériennes: celles de l'Asperge (fig. 71) consistent en de simples écailles qui naissent à la base des rameaux; celles de plusieurs espèces de Cactus sont à peine indiquées par un petit coussinet qu'on remarque sous les bourgeons. Les personnes étrangères à la botanique prennent souvent les rameaux aplatis ou anguleux de ces végétaux pour des feuilles. La même erreur peut avoir lieu relativement à l'Amarante crête-de-coq, qu'on voit dans les jardins: la tige de cette plante s'aplatit en une lame plus ou moins large, d'aspect foliacé; c'est sur cette lame que naissent les véritables feuilles qui ne sont ici encore que de petites écailles.

Les filaments herbacés appelés vrilles (fig. 70), au moyen desquels les tiges grimpantes se fixent sur leur support, n'ont la plupart du temps d'autre origine qu'une feuille ou une partie de feuille transformée. Il en est de même des épines, qu'il ne faut point confondre avec les aiguillons dont nous avons parlé précédemment (no. 24): ceux-ci appartiennent à l'épiderme et s'enlèvent avec lui; celles-là, au contraire, naissent du cœur même de la tige.

Les feuilles placées dans le voisinage des fleurs et connues sous les noms le feuilles florales et de bractées subissent aussi des transformations sur lesquelles il importe d'attirer l'attention. Ces feuilles sont généralement revêtues de couleurs d'autant plus vives qu'elles se rapprochent davantage de la fleur'; en même temps, elles prennent des dimensions de plus en plus réduites, jusqu'à devenir des écailles ou des filaments.

Quelquefois la plus élevée de ces bractées prend, au contraire, un grand développement et forme autour des fleurs une enveloppe protectrice appelée spathe. L'Arum vulgare ou Pied-de-veau posséde une spathe blanche très-grande et d'une beauté remarquable (fig. 124).

D'autres fois un certain nombre de bractées sont disposées aurdessous d'un ensemble de fleur's en une sorte de colerette qu' on nomme involucre. Les feuilles de l'involucre sont tantôt larges, indépendantes et distantes des fleurs comme dans l'Anémone, tantôt plus petites et imbriquées, comme dans le Pissenlit, tantôt soudées les unes aux autres : la cupule qui entoure les glands du Chêne n'a point d'autre origine; elle se compose de bractées écailleuses, libres dans les premiers temps, mais qui se sont soudées plus tard (fig. 147). 
Dans les Graminées, la fleur est enveloppée de bractées scarieuses auxquelles on donne le nom de glumes (fig. 171 ): ce sont elles qui forment la balle du Blé.

Enfin nous verrons plus loin que toutes les parties de la fleur et du fruit doivent être considérées comme des feuilles transformées.

Il n'y a donc en réalité, dans les plantes, qu'une racine, une tige et des feuilles: ces organes fondamentaux se montrent déjà dans l'embryon et se développent seuls dans la suite; mais par une disposition providentielle qu'on ne saurait assez admirer, ils se modifient de manière à s'adapter aux diverses fonctions vitales de la plante.

\section{CHAPITRE VI.}

\section{LA FLEUR.}

40. La fleur est un ensemble d'organes disposés en verticilles rapprochés et destinés à produire le fruit.

Les verticilles dont elle peut se composer sont, en allant de la circonférence au centre: le calice, la corolle, les étamines et le pistil (fig. 72 ).

Le calice et la corolle, que l'on désigne collectivement par les noms de perianthe et d'enveloppes florales, n'ont qu'un rôle accessoire dans la fructification, celui de protéger les étamines et le pistil. Ces derniers verticilles, nommés organes de la fécondation, forment la partie essentielle de la fleur.

\section{CALICE.}

41. Formes du calice.-Le calice est formé de petites feuilles appelées sépales, de couleur ordinairement verte et de forme variable. Les sépales demeurent quelque tois complètement libres (fig. 73), et d'autres fois se soudent ensemble par leurs bords (fig. 74): dans le premier cas, le calice est dit polysépale, et dans le second monosépale ou monophylle, comme s'il n'était formé que d'une seule feuille. La Giroflée possède un calice polysépale et l'Eillet un calice monosépale.

Il est rare que les sépales se soudent dans toute leur étendue. Le plus souventils demeurent libres par leur extrémité supérieure, laissant entre eux des vides qui rappellent les découpures des feuilles et se désignent par les mêmes mots.

La partie du calice monosépale où les sépales sont soudés s'appelle le tube, celle où ils sont libres s'appelle le limbe, et la ligne de séparation entre le tube et le limbe est la gorge du calice (fig. 74).

Le calice est dit régulier (fig. 73,74 ) lorsque toute section qui passe par son axe le divise en deux parties égales; dans le cas contraire, il est irrégulier (fig. 75). L'irrégularité a pour cause une différence dans la forme et la grandeur des sépales, ou bien un défaut de symétrie dans leur disposition.

42. Durée du calice.-Lo calice, relativement à sa durée, se nomme fugace, caduc ou persistant: fugace, quand il tombe avant l'épanouissement de la fleur (Sanguinaire); caduc, quand il disparaît après la fécondation (Tilleul); 
persistant, quand il demeure en place durant la maturation du fruit (Violette). Il peut arriver que le calice persistant se flétrisse, comme dans le Groseiller, ou que, continuant à croître, il devienne partie intégrante du fruit. Dans le premier cas il est dit marcescent et dans le second accrescent.

\section{COROLLE.}

43. La corolle occupe une position intermédiaire entre le calice et les étamines. C'est la partie la plus apparente de la fleur, ordinairement colorée, brillante et souvent odorante. Les petites feuilles qui la composent se nomment des pétales; elles sont généralement élargies à la partie supérieure et atténuées inférieurement en une sorte de pétiole qu'on nomme onglet (fig. 76).

Toutes les définitions données plus haut pour le calice s'appliquent à la corolle, en ayant soin de substituer le mot pétale à celui de sépale.

44. Formes de la corolle polypétale.-Certaines formes de corolles polypétales régulières sont caractéristiques pour toutes les plantes d'une ou de plusieurs familles, et ont reçu des noms particuliers. On appelle:

Cruciforme (fig. 77 ), la corolle formée de quatre pétales en croix. Ex. : la Giroflée.

Caryophyllée (fig. 78), celle qui est formée de cinq pétales munis de longs. onglets. Ex. : l'Eillet.

Rosacée (fig. 79), celle qui est formée de cinq pétales, au moins, à onglets courts et à limbe étalé en rosace. Ex. : le Rosier.

La plupart des Légumineuses, telles que le Pois et le Haricot, possèdent une corolle polypétale irrégulière dont l'ensemble dessine grossièrement un papillon aux ailes étendues : cette corolle se nomme papilionacée. Elle se compose de cinq pétales dont l'un s'élève au-dessus des autres qu'il enveloppe, et se nomme l'étendard; deux sont placés sur les côtés et portent le nom d'ailes; les deux autres, placés à la partie inférieure, forment la carène, ainsi nommée parce qu'elle représente l'avant d'une nacelle (fig. 80, 81).

45. Formes de la corolle monopétale.-La corolle monopétale régulière peut affecter l'une des six formes suivantes:

Campanulée (fig. 82) : tube dilaté dès sa base et s'évasant en forme de cloche. Ex. : la Campanule.

Infundibuliforme (fig. 83): tube conique, évasé supérieurement en entonnoir. Ex. : le Tabac.

Rotacée (fig. 84) : tube court, limbe plan etétalé. Ex. : la Pomme-de-terre.

Hypocrateriforme (fig. 85) : tube court et droit, limbe évasé en forme de soucoupe. Ex.: le Litâs.

Tubulee (fig. 86) : tube cylindrique et allongé. Ex.: la Grande Consoude. Urcéolée (fig. 87): tube dilaté en son milieu et contracté aux extrémités. Ex. : la Gaulthéria ou thé des bois.

Parmi les corolles monopétales irré gulières, on distingue la corolle ligulée (fig. 89), dont le tube est fendu et le limbe rejeté de côté en forme de languette. Ex.: le Pissenlit.

La corolle labiée (fig. 88), dont la gorge est ouverte et le limbe partagé en deux divisions inégales qu'on appelle lèvres. Ex.: la Menthe.

La corolle personnée (fig. 90), dont le limbe se partage en deux lèvres rap- 
prochées qui lui donnent quelque ressemblance avec un masque ou un mufle de veau. Ex.: la Linaire.

\section{ETAMINES.}

46. Les étamines forment le troisième verticille de la fleur. Chacune d'elles comprend généralement trois parties : le filet, l'anthère et le connectif (fig. 91, 92).

47. Filet.-Le filet est un support mince qui remplit dans l"ètamine le même rôle que le pétiole dans la feuille. On le nomme :

Capillaire, quand il est fin comme un fil.

Subule, quand il se termine en pointe effilée.

Pétaloïde, quand il s'élargit en forme de pétale.

Géniculé, quand il est plié de manière à faire un angle.

Bifurqué, ıłuand il se divise supérieurement en deux branches.

L'étamine qui manque de tilet se nomme sessile.

48. Anthère.-L'anthère est un petit sac plus ou moins allongé et rempli d'une poussière ordinairement jaune, connue sous le nom de pollen. Elle se compose presque toujours de deux loges ou cavités distinctes, faciles à reconnaitre par la proéminence qu'elles forment à droite et à gauche d'un sillon qui les sépare. Ces loges, à une époque déterminée, doivent donner issue au pollen. Leur déhiscence s'opère quelquefois au moyen de valvules (fig. 93), plus souvent par des pores situés au sommet (fig. 94), et ordinairement par des fentes longitudinales ou transversales (fig. 95). Une strie indique sur chaque loge l'endroit où la déhiscence doit avoir lieu. Si cette strie est tournée vers le centre de la fleur, l'anthère est introrse; lorsqu'elle r'egarde la circonférence, l'anthère est extrorse.

Le pollen apparait, au microscope, comme un amas de grains dont la forme varie selon les espèces végétales. Ces grains placés dans l'eau ne tardent pas à se gonfler, se déchirent et laissent échapper une matière Huide, la fovilla, qui joue un rôle essentiel dans la fécondation des graines (fig. 96).

Chez quelques plantes, les Orchidées, par exemple, le pollen est agglutiné vers le haut du filet et constitue une masse (fig. 97) à laquelle on a donné le nom de pollinie.

Les étamines qui ne renferment point de pollen sont dites steriles (fig. 92, ls).

49. Connectif--Les loges de l'anthère sont quelquefois accolées l'une à l'autre sans corps intermédiaire. Le plus souvent elles sont réunies au moyen d'une substance qui a reçu, à raison de sa fonction, le nom de connectif. Cette substance peut n'occuper qu'un point entre les loges, s'étendre sur toute leur longueur ou même la dépasser et former au-dessus d'elles des appendices variés. Dans les deux derniers cas (fig. 91), on dit de l'anthère qu'elle est adnée au connectif. L'anthère est encore basifixe (fig. 94), oscillante (fig. 95), ou pendante selon que le filet s'attache au connectif vers la base des loges, vers leur milieu ou à leur sommet.

50. Etamines considérées dans leur ensemble.-Le nombre des étamines varie depuis un jusqu'à plus de cent. Tant que ce nombre ne dépasse pas 
dix, les étamines sont dites définies; s’il va au-delà, on les nomme indéfinies.

Il pout arriver que dans lì même fleur certaines étamines soient plus longues que d'autres. A ce point de vue, elles s'appellent didynames, lorsqu'elles sont au nombre de quatre dont deux longues et deux petites (tig. 98 ) ; et tétrailynames, lorsqu'elles sont au nombre de six dont quatre grande. alternant par paires avec deux autres plus petites (fig. 99).

Les étamines peuvent, conmme les sépales et les pétales, se souder ensemble. Lor'squ'elles adhèrent par les anthères, comme dans le Pissenlit, on les nomme synantherées (fig. 89); lorsque la soudure a lieu par les filets seulement, elles sont adelphes: on les nommera monailelphes, diadelphes.... polyadelphes, selon que les filets forment un faisceau unique conme dans la Mauve (fig. 100), ou deux phalanges comme dans le Haricot (fig. 101), ou enfin se divisent en plusieurs groupes comme dans le Tilleul et le Millepertuis.

Dans quelques cas assez rares, dont les Lobelies nous fournissent un exemple, les étamines adhèrent tout à la fois par les filets et par les anthères.

51. Nature des étamines.-Les botanistes considèrent les étamines comme des feuilles dont le limbe s'est replié sur lui-même de manière à circonscrire la cavité qui loge le pollen. Parmi les faits nombreux qui viennent à l'appui de cette opinion, nous mentionnerons celui des fleurs doubles. On nomme ainsi les fleurs dont les étamines se sont changées en pétales sous l'influence de la culture. Un grand nombre de plantes, telles que le Rosier et le Camellia, nous présentent ce curieux phénomène. Cesse-t-on de les cultiver, elles reviennent à leur état normal: les pétales surnuméraires disparaissent et un nombre égal d'étamines les remplace. Ces faciles transformations sont une preuve qu'il y a communauté d'origine entre les organes dont nous parlons; elles montrent que les étamines ne sont que des feuilles encore plus profondément modifiées que les, pétales, et auxquelles la nature a donné une forme en rapport avec les fonctions particulières qu'elles ont à remplir dans la fleur.

\section{PISTIL.}

52. Le pistil est le verticille qui occupe le centre de la fleur. Chacune des feuilles qui le composent porte le nom de carpelle. Dans ces feuilles, qui sont généralement sessiles (fig. 102), le limbe s'est contourné sur lui-même de manière à clore une cavité arrondie, l'ovaire; en même temps, les bords repliés vers l'intérieur de la cavité se sont soudés ensemble, présentant par' là une disposition analogue à celle des coutures clans nos vêtements. Audessus de l'ovaire, le limbe carpellaire, devenu très-étroit, se prolonge en un tube effilé terminé lui-même par un épanouissement arrondi ou de forme allongée. Ce tube a reçu le nom de style et l'épanouissement qui le surmonte, celui de stigmate (fig. 103).

Ce n'est que dans le Cerisier sauvage et un petit nombre d'autres végétaux que l'on voit nettement dessinées les dispositions décrites ci-dessus. En général, les feuilles carpellaires sont tellement modifiées que la seule vue est insuffisante pour nous renseigner sur leur véritable nature. Mais la facilité avec laquelle elles se transforment en pétales par la culture, leur structure intérieure, leur retour, après maturation des graines, à la forme d'une petite feuille, ne laissent aucun doute sur leur origine.

Le style, avons-nous dit, surmonte l'ovaire; dans certain cas, cependant, 
il semble naître sur les côtés ou même à la base de ce dernier (tig. 104) : cette disposition est due à une déviation de l'ovaire, dont le sommet s'est intléchi vers la partie inférieure de la fleur.

Assez souvent le style fait défaut, et le stigmate, devenu sessile, repose immédiatement sur l'ovaire (lig. 112, 113).

53. Ovaire simnle et ovaire comnosé.-Dans quelques familles végétales, les Renonculacées, par exemple, les carpelles du pistil restent isolés ; le plus souvent ils se soudent les uns aux autres soit par les ovaires seulcment, soit par les ovaires et les styles à la fois, ou même par les stiggmates.

On appelle simple l'ovaire du carpelle libre (fig. 105), et composé celui qui résulte de plusieurs carpelles unis ensemble (fig. 109).

Dans l'ovaire composé, les deux bords de chaque carpelle se soudent à ceux des carpelles voisins; il en résulte des cloisons doubles qui s'aplatissent par l'effet de la compression et s'avancent ordinairement jusqu'au centre de la cavité ovarienne, qu'elles partagent en compartiments : l'ovaire devient ainsi multiloculaire ou à plusieurs loges (fig. 108).

Quelquefois les cloisons, au lieu de s'avancer jusqu'au centre de l'ovaire. s'arrêtent en-deçà, se dédoublent en partie et donnent naissance à deux petites lames qui s'infléchissent, en sens contraire, vers la circonférence (fig. 107); dans ce cas, il ne se forme que des loges incomplètes.

54. Ovules.-L'ovaire tire son nom de petits corps arrondis que renferme sa cavité (fig. 106), et que l'on nomme des ovules.

Les ovules sont formés d'un mamelon central, le nucelle. qui est généralement recouvert de deux membranes. A la partie supérieure, ces membranes laissent une ouverture, nommée micropyle, par laquelle pénètre la fovilla au moment de la fécondation. Un autre point remarquable dans l'ovule est l'ombilic, plus communément appelé le hile. C'est par là qu'il communique avec l'ovaire et en tire sa nourriture. Très-souvent la communication a lieu au moyen d'un petit cordon qu'on nomme funicule (fig. 106, (3)).

Les ovules présentent trois formes principales: on les nomme orthotropes (fig. 1(06, (1)) lorsqu'ils sont droits comme un œuf: anatropes (fig. 106, (2)) quand leur pointe est inclinée de côté ; campylotropes (fig. 106, (3)) lorsqu'ils sont courhés à la manière d'un rein. Cette dernière forme, qui est la plus commune, se voit dans le Haricot.

55. Placentation.-Lorsqu'on fend longitudinalement une gousse de Haricot, on aperçoit sur les bords soudés du carpelle une ligne saillante à laquelle sont attachés les ovules et qui a reçu le nom de placenta.

Tous les ovaires simples ont leurs placentas situés contre la paroi, et leur placentation est dite parietale (fig. 102).

Dans l'ovaire composé à loges complètes, les bords des carpelles se trouvent portés au centre, et les ovules naissent de l'aisselle des loges: cet ovaire est dit à placentation axile (fig. 108).

Il peut arriver que les cloisons disparaissent et que tous les placentas restent isolés au centre sous forme d'une colonne à laquelle sont suspendus les ovules : on a alors une placentation centrale (fig. 109).

Dans tous les autres cas où l'ovaire composé devient uni-loculaire, c'està-dire à une seule loge. par la destruction des cloisons. ou bien ne présente que des loges incomplètes, les placentas se trouvent éloignés du centre et 
la placentation est dite pariétale comme dans le cas de l'ovaire simple (fig. 107).

\section{VERTICULES FLORAUX CONSIDÉRÉS DANS LEURS RAPPORTS.}

56. Types floraux.-Le mot type, quand on l'applique aux fleurs, sert à indiquer l'état plus ou moins complexe de leurs verticilles. Lorsque ceux-ci comprennent chacun deux parties, la fleur est à type binaire; elle serait à type ternaire, quaternaire ou quinaire si les verticilles renfermaient trois, quatre ou cinq parties.

Le type ternaire est le seul qu'on remarque chez les monocotylédones; les dicotylédones, au contraire, n'offrent presque jamais le type ternaire et sont le plus souvent à type quinaire.

Ce qui précède supposerait que tous les verticilles d'une fleur sont composés d'un même nombre de folioles; il n'en est cependant pas toujours ainsi. Quelquefois des avortements partiels ont lieu; d'autres fois, et ce cas est assez fréquent, un verticille devient double on multiple des autres. Ainsi, le Lis avec un ovaire à trois loges, formé par conséquent de trois carpelles, possède six étamines et un périanthe de six folioles. Lorsqu'il y a multiplication d'un ou de plusieurs organes floraux, le type emprunte son nom au verticille le plus simple. D'après cette règle, on dira que le Lis est à type ternaire.

57. Insertion des verticilles floraux.-L'axe floral porte à son extrémité (fig. 103) une surface élargie connue sous le nom de réceptacle ou de torus : c'est là que prennent naissance les divers organes de la fleur, dans l'ordre indiqué précédemment.

Lorsque le réceptacle s'allonge notablement, les verticilles se trouvent portés à des hauteurs différentes, et les folioles dont ils se composent, devenant sensiblement alternes, décrivent une spirale régulière comme les feuilles ordinaires. La spire se continue d'un verticille à l'autre; c'est ainsi qu'on voit les sépales alterner avec les pétales, ceux-ci avec les étamines, etc.

Lorsque le réceptacle est plan ou peu convexe, la disposition en spirale disparaît ou du moins est beaucoup plus difficile à saisir; même dans ce cas, les folioles d'un verticille alternent avec celles du verticille voisin, à moins que des avortements ou le dédoublement de certaines parties ne viennent masquer cet ordre.

La proximité qui existe entre les verticilles floraux occasionne assez fréquemment des soudures. On considère comme origine d'un verticille le point où il devient libre de toute adhérence avec les autres verticilles. D'après cette convention, les étamines seront censées naître du pistil, de la corolle ou du calice, suivant qu'elles seront soudées avec l'un ou l'autre de ces organes. On les nomme

Épigynes (fig. 110) lorsqu'elles naissent du pistil, comme dans l'Aralia nudicaulis, vulg. Salsepareille.

Cerisier.
Hypogynes (fig. 112) lorsqu'elles naissent du réceptacle, comme dans la

Perigynes (fig. 111) lorsqu'elles naissent du calice, comme dans le Renoncule et le Pavot.

Il n'existe aucun terme spécial pour indiquer l'insertion des étamines 
sur la corolle. On les dira épigynes, périgynes ou hypogynes, suivant qeu la corolle naitra elle-même du pistil, du calice ou du réceptacle.

Le calice monosépale et l'ovaire se soudent fréquemment ensemble. Le premier est alors censé naître du second, qui occupe, en conséquence, une position inférieure. De là les noms d'ovaire supere et d'ovaire infère: l'ovaire est supère quand il est libre d'adhérence avec le calice; il est infère dans le cas contraire (fig. 73,111 ).

Assez souvent l'adhérence entre deux verticilles s'opère par l'intermé diaire d'un tissu glanduleux; ce tissu prend le nom de disque lorsqu'il fait saillie entre les verticilles qu'il unit, comme dans la Spirée corymbifère et dans le Narcisse (fig. 113, 112).

58. Préfloraison.-La préfloraison est l'état de la fleur avant son épanouissement. La disposition que présentent à ce moment les folioles du calice et celles de la corolle est caractéristique pour les espèces végétales.

La préfloraison est dite imbriquée (fig. 115) lorsque chaque foliole a l'un de ses bords couverts par la foliole précédente et qu'elle couvre elle-même, par son bord libre, la foliole suivante; valvaire (fig. 116), lorsque les folioles voisines sont juxta-posées sans se couvrir; tordue (fig. 117), lorsque les folioles sont contournées sur leur axe.

Le Géranium a un calice imbriqué et une corolle tordue. Dans le Tilleul, le calice est valvaire.

59. Fleurs incomplètes.-La fleur n'est complète qu'autant qu'elle possède un calice, une corolle, des étamines et un pistil. L'absence de l'une quelconque de ces parties la rend incomplète. On nomme

apérianthée ou achlamydée, la fleur qui n'a aucune des deux enve. loppes tlorales;

monoperianthée, celle qui n'a que le calice ou la corolle;

apétale, celle qui manque de corolle.

Conme il serait parfois difficile de décider si c'est le calice ou la corolle qui fait défaut dans les fleurs à une seule enveloppe Horale, on est convenu, en pratique, d'appeler toutes ces Heur's apétales.

Sous le rapport des organes de la fécondation, une fleur est dite pistil ;

hermaphrodite ou parfaite, quand elle possède des étanines et un

unisexuée, quand elle n'a que des étamines ou un pistil;

neutre, quand elle est privée de ces deux organes à la fois.

Les fleurs de la Queue de lézard sont apérianthées ; celles de l'Anémone et de la Caltha des marais sont monopérianthées ou apétales; celles du Pom. mier sont parfaites; celles du Coudrier, du Chanvre sont unisexuées; celles des Boules-de-neige sont neutres.

La fleur unisexuće est encore appelée fleur mâle ou staminée ou sterile; fleur femelle ou pistillee ou fertile, suivant quelle renferme des étamines ou un pistil.

On ne trouve pas toujours les mêmes fleurs sur toutes les plantes de la mêne espèce, et il a fallu créer des termes pour indiquer cette particularité. On dit d'une plante qu'elle est polygame quand elle porte des fleurs parfaites et des fleurs unisexuées : monoïque, lorsqu'elle n'a que des fleurs unisexuées dont les unes sont staminées et les autres pistillées; 
diö̆que, lorsqu'elle n'a que des fleur's unisexuées, toutes staminées ou toutes pistillées.

Le Chanvre, le Saule, le Peuplier, etc., ont leurs fleurs pistillées sur un pied et leur's fleur's staminées sur un pied différent: ce sont donc des plantes dioïques. Le Bouleau porte sur le même pied, mais sur des points différents, des fleurs staminées et des fleurs pistillées : il est donc monoïque. L'Erable à sucre est un exemple de plante polygame.

\section{INFLORESCENCE.}

60. Définition.-Dans son acception la plus générale, le mot inflorescence désigne l'arrangement des fleurs sur leur axe qu'on appelle axe floral et pédoncule, ou bien encore hampe, s'il s'élève directement de terre comme dans la Tulipe et la Primevère.

Dans un sens plus restreint, on donne le nom d'inflorescence à l'ensemble des fleurs qui ne sont séparées que par des bractées (No. 39); les fleurs entre lesquelles se voient des feuilles ordinaires devront être considérées cơmme appartenant à des inflorescences différentes, quand bien même elles seraient portées sur le même rameau de la plante.

61. Inflorescences inc'éfinies et définies.-L'inflorescence est dite indéfinie, quand l'axe floral produit latéralement des fleurs, à mesure qu'il croît. Comme cette croissance de l'axe varie avec les conditions climatériques, le nombre des tleurs qu il doit porter est nécessairement indéterminé : de là le nom d'inflorescence indéfinie.

Dans l'inflorescence indéfinie, les fleurs les plus éloignées de l'extrémité de l'axe étant les plus anciennes, sont aussi les plus développées (fig. 125). Cette circonstance leur a valu le nom de centrifuges.

L'inflorescence est, au contraire, définie quand l'axe, après avoir pris șoll entier accroissement, se termine par une fleur. Cette fleur terminale reste quelquefois solitaire, comme dans la Sanguinaire, mais plus ordinairement il se montre au-dessous d'elle un ou plusieurs axes secondaires qui continuent l'inflorescence jusqu'à épuisement de la force vitale.

Ce qui caractérise essentiellement l'inflorescence définie (fig. 130), c'est que les fleur's y sont d'autant plus développées qu'elles naissent plus près de l'extrémité de l'axe floral principal. Aussi les nomme-t-on centripetes.

Dans quelques plantes l'inflorescence est indéínie sur l'axe primaire et définie sur les axes secondaires : il en résulte une inflorescence mixte.

62. Forme des inflorescences indéfinies.-Les inflorescences indéfinies se présentent sous un grand nombre de formes, parmi lesquelles nous mentionnerons l'épi, le chaton, le cône ou strobile, le spadice, la grappe, la panicule, le thyr'se, le corymbe, l'ombelle et le capitule.

L'épi (fig. 118) se compose de fleurs sessiles ou presque sessiles ordinairement très-rapprochées. Ex. : le Blé, le Plantain.

Le chaton (tig. 119) se compose de fleurs unisexuées, naissant à l'aisselle de bractées plus ou moins écailleuses. Ex. : le Saule, le Bouleau, le Noyer.

Le cône ou strobile (fig. 123) ne diffère du chaton que par ses bractées qui sont plus épaisses et plus dures. Ex. : le Pin, le Merisier.

Le spadice (fig. 124) est formé par un axe charnu portant des fleurs staminées à sa partie supérieure et des fleurs pistillées à sa partie inférieure. 
Dans les premiers temps, il est enveloppé dans une spathe (no. 39), et c'est à cette circonstance qu'il doit son nom. Ex. : le Pied-de-veau, l'Oignon sauvage.

La grappe (fig. 125) est une inflorescence dans laquelle le pédoncule porte des axes secondaires, appelés pédicelles, terminés par une fleur et tous à peu près de même longueur. Quand les axes secondaires se ramitient en axess tertiaires, la grappe est dite composée. Ex. : le Gadelier.

La panicule (fig. 126) est une grappe composée dont la largeur diminue de la base au sommet. Ex. : l'Avoine.

Le thyrse est une grappe composée dont la largeur diminue du milieu aux extrémités. Ex. : le Lilas.

Le corymbe (fig. 127) est une grappe simple ou composée dans laquelle les axes inférieurs atteignent le niveau des axes supérieurs et dont toutes les fleurs se trouvent en conséquence portées à la même hauteur. Ex. : le Millefeuille ou Herbe à dinde, la Tanaisie, le Cornouillier.

L'ombelle (fig. 128) ne diffère du corymbe que par la position de ses axes secondaires qui, au lieu de naître à différentes hauteurs, forment un verticille. Ces axes secondaires, appelés rayons de l'ombelle, portent quelquefois une ombelle plus petite ou ombellule à leur extrémité, et l'ombelle devient alors composée. Fx. : la Carotte, le Panais.

Le capitule est une inflorescence dont les fleurs sont réunies en tête : c'est un épi raccourci. Ex. : le Trèfle, la Reine Marguerite, le Soleil, le Pissenlit (fig. 129).

On voit par les définitions précédentes que toutes les inflorescences indéfinies ne sont en réalité que des moditications de l'épi et de la grappe.

63. Forme des inflorescences définies.-Les inflorescences définies portent le nom général de cymes. La cyme peut affecter la plupart des formes que nous venous d'étudier. On aura donc des cymes en grappe (Vigne), des cymes en panicule (Sureau), etc. Elle possède aussi des formes qui lui sont propres. Elle se nomme :

dicothome (fig. 130) lorsque l'axe primaire se termine par une fleur placée entre deux feuilles ou deux bractées opposées, à l'aisselle desquelles s'élèvent deux axes secondaires qui se comportent comme l'axe primaire, et donnent naissance à des axes tertiaires etc., comme dans le Millepertuis ;

scorpiö̈de (fig. 131) lorsqu'elle forme une grappe roulée en crosse, rappelant la queue du scorpion; elle se compose alors d'une suite d'axes d'ordre différent qui naissent les uns des autres toujours du même côté (fig. 132) donnant ainsi naissance à une ligne brisée qui tend à revenir sur elle-même, comme dans la Cynoglosse et l'Héliotrope;

contracté (fig. 133) lorsque ses axes sont inégalement raccourcis, se rapprochent et deviennent quelquefois nuls. On donne aussi à cette forme, dont la Menthe nous offie un exemple, le nom de glomérule.

\section{CHAPITRE VII.}

\section{LE FRUIT..}

64.-Le fruit est un ovaire fécondé et parvenu à son entier développement. Les parois de l'ovaire prennent, dans le fruit, le nom de péricarpe et les ovules féconáés celui de graines. 
65. Nature et forme du péricarpe.-Les feuilles carpellaires, qui constituent les parois de l'ovaire dans la fleur, sont formées, comme les feuilles ordinaires, d'un tissu parenchymateux (no. 30), recouvert sur les deux faces par une membrane épidermique; nous devons donc nous attendre à trouver dans le péricarpe trois parties distinctes : on appelle épicarpe celle qui correspond à l'épiderme extérieur des carpelles; mésocarpe, celle qui correspond au parenchyme ; et endocarpe, celle que forme l'épiderme intérieur. La couleur, l'épaisseur et la consistance de ces trois parties sont extrêmement variables, comme on pourra s'en convaincre par les exemples suivants.

Dans la Cerise, la Prune et la Pêche, la peau qu'on enlève avec plus ou moins de facilité est l'épicarpe ; la pulpe qu'on mange est le mésocarpe, et le noyau l'endocarpe.

Dans la Pomme, l'endocarpe est ce tissu écailleux qui entoure les graines.

Dans la Noix, l'épicarpe uni au mésocarpe forme cette enveloppe coriace qu'on nomme le brou, et l'endocarpe est le noyau qui renferme l'amande. Dans l'Orange, l'épicarpe et le mésocarpe constituent la peau épaisse qu'on rejette, et l'endocarpe est une membrane délicate qui entoure la partie comestible. Dans le Melon, l'épicarpe est à peine distinct; le mésocarpe est cette couche charnue dont on:mange la partie intérieure, et l'endocarpe est réduit, comme dans l'orange, en une peau mince qui entoure les graines. Enfin, dans certains fruits le péricarpe tout entier est si mince et tellement adhérent à la graine, qu'il faut une observation attentive pour découvrir sa présence; c'est ce qu'on observe dans le Blé.

66. Induvies du fruit.-Nous avons supposé que le péricarpe est formé uniquement par les carpelles du pistil ; c'est là, en effet, le cas le plus ordinaire : la fécondation des ovules opérée, les étamines se flétrissent et tombent, la corolle ne tarde pas à subir le même sort, et si le calice persiste plus longtemps, généralement il se dessèche et ne devient point partie intégrante du fruit.

Il y a, cependant, des exceptions à cette loi générale. Un ou même plusieur's verticilles floraux peuvent se souder à l'ovaire fécondé, s'ils ne l'étaient déjà, et prendre avec lui de l'accroissement: ce sont ces parties accessoires du fruit auxquelles on a donné le nom d'induvies. La Pomme est un fruit induvié : le tube clu calice est ici confondu avec l'épicarpe, et son limbe desséché forme au sommet du fruit ce que l'on nomme vulgairement la mouche de la pomme.

Ce que nous mangeons dans la Fraise n'est autre chose que le réceptacle de la fleur devenu succulent. A la surface de ce réceptacle se montrent des petits grains arrondis et secs : ces grains sont autant de fruits complets; il y en a un nombre égal à celui des carpelles que renfermait la fleur du Fraisier.

67. Modifications dans l'intérieur du péricarpe.-Les ovaires composés ne conservent pas toujours en mûrissant le nombre de loges qu'ils renfermaient d'abord. Quelquefois des ovules, n'ayant pas été fécondés, se dessèchent, et la loge qui les contenait s'affaisse et disparaît. D'autres fois des cloisons se détruisent, diminuant par là même le nombre des loges. Mais dans quelques cas, c'est l'inverse qui a lieu : de fausses cloisons 
se forment par des replis du péricarpe, et l'ovaire se trouve divisé en cavités plus nombreuses qu'auparavant. Il résulte de ces faits qu'on ne peut pas juger par l'inspection du fruit du nombre d'ovules et de loges que possédait l'ovaire avant la fécondation.

Dans quelques fruits on aperçoit entre le péricarpe et la graine une matièr'e pulpeuse provenant tantôt des placentas, tantôt de l'endocarpe, tantôt de la graine elle-même. C'est l'endocarpe qui donne naissance dans l'Orange aux cellules allongées et succulentes qui constituent la partie comestible de ce fruit.

-68. La graine.-Un fruit qui ne contient qu'une seule graine est appeli monosperme; celui qui en contient un petit nombre est appelé oligosperme; enfin, on donne le nom de polysperme à celui qui en referme plusieurs.

La graine est généralement formée de trois parties: l'épisperme ou l'en. veloppe, l'endosperme, plus connu sous le nom d'albumen, et l'embryon (fig. 134).

L'albumen et l'embryon réunis constituent l'anande, qui est la partie comestible du Blé, du Haricot, de la Noix et d'un grand nombre d'autres fruits.

L'épisperme est généralement formé de deux membranes dont l'extérieure, qui est épaisse et colorée, porte le nom de testa. Ces membranes sont le.s mêmes qui couvraient le nucelle des ovules, mais elles se sont modifiées durant la maturation.

L'albumen est une matière amylacée, destinće à nourrir la jeune plante jusqu'à ce qu'elle soit en état do puiser dans la terre les sucs nourricier's qui lui sont nécessaires. Sa consistance varie suivant les espèces végétales : tantôt il est farineux et tantôt dur comme de la cor'ne.

L'albumen est très-développé dans le Blé ; c'est lui qui, sous l'action de la meule, donne la farine; l'épisperme, confondu ici avec le péricarpe, forme le son, et l'embryon n'occupe qu'un espace restreint vers lia base de la graine (fig. 143).

L'embryon se nomme extraire ou intraire, selon qu'il entoure l'albumen (fig. 136), ou qu'il en est entouré (fig. 134). Dans plusieurs espèces de graines, dans celles du Pommier, par exemple, l'albumen fait défaut et il est alors remplacé clans ses fonctions par les cotylédons dont nous parlerons un peu plus loin.

L'embryon est une plante en miniature dans laquelle on distingue une radicule ou petite racine, une tigclle ou petite tige, et une yemmule ou bourgeon terminal d'où s'échapperont les premières feuilles.

La plupart du temps, il est difficile de reconnaitre ces diverses parties avantqu'elles ne se soient un peu allongées par la germination.

Entre la radicule et la tigelle (fig. 17), on aperçoit une ou plusieur's feuilles modifiées, souvent épaisses, charnues, bombées à l'extérieur et légèrement creuses à l'intérieur: ce sont les cotylédons. C'est surtout dans les graines où l'albumen fait défaut que les cotylédons prennent un large accroissement, car alors ce sont eux qui doivent nourrir la jeune plante. L'orsqu'ils n'ont pas cette fonction à remplir, ils sont simplement membraneux. Leur position dans la graine, la manière dont ils sont pliés, etc., fornissent d'excellents caractères pour la détermination des espèces; mais ces caractères, pour être bien saisis, exigent un oeil sûr et bien exercé. 
69. Déhiscence du fruit.-Lorsque la graine est devenue apte à produire une nouvelle plante, elle doit trouver issue à traver's le péricarpe qui l'avait protégée jusqu'à ce moment.

("est la décomposition du péricarpe qui met les graines en liberté dans les fruits à noyau et dans la plupart des fruits charnus : ces fruits, après maturation, se détachent de la plante, tombent sur le sol et ne tardent pas à se décomposer sous l'influence des agents chimiques.

Les fruits secs, au contraire, s'ouvrent presque tous spontanément, et c'est à ce phénomène que s'applique le nom de déhiscence.

La déhiscence s'opère par des moyens variés qu il serait trop long de décrire en détail. Nous ne pouvons donner ici que quelques indications générales.

Dans les fruits simples ou formés d'un seul carpelle, la déhiscence a lieu tantôt par la suture ventrale seule (fig. 105); tantôt par la suture ventrale et la suture dorsale à la fois (fig. 138): dans le premier cas, le péricarpe ne forme qu une seule valve, et dans le second il devient bi-valve.

Ce que nous appelons ici suture ventrale est la ligne suivant laquelle sont soudés les bords du carpelle; la suture dorsale longe le dos du carpelle et correspond à sa nervure médiane; elle est généralement indiquée par une strie ou par une ligne saillante.

Dans les fruits multiloculaires ou à plusieurs loges, provenant d'un ovaire composé, la déhiscence se fait selon trois modes principaux : on la nomme septifrage, lorsque les cloisons des loges se détachent du milieu des valves pour rester fixées au placenta (fig. 141); septicide, lorsque les cloisons se lécollent en deux lames de manière à mettre en liberté les carpelles qui étaient soudés (fig. 140); loculicide, lorsque la rupture a lieu suivant la suture dorsale des carpelles (fig. 139).

Très-souvent la déhiscence est à la fois septicide et loculicide; le fruit ouvert présente alors un nombre de valves double de celui des carpelles (fig. 138).

Enfin, la déhiscence est dite transversale ou horizontale, lorsque le péricarpe s'ouvre transversalement en deux moitiés comme une boîte à savonnette (fig. 142).

La déhiscence de quelques fruits présente un curieux phénomène: les valves, au lieu de s'écarter lentement, se séparent par un mouvement brusque, comme si elles étaient mûes par un ressort, et projettent les graines à une distance considérable. Le moindre frottement suffit pour déterminer une rupture de ce genre dans le fruit des plantes appartenant à la famille des Balsaminées, et c'est ce qui a valu à l'une d'elle le nom d'impaliente ou de noli me tangere. 


\section{CLASSIFICATION DES FRUITS.}

70. Les fruits offrent des différences si variées qu'il est très-difficile d'en donner une classification méthodique.

Nous empruntons le tableau suivant à la botanique de Richard, et plusieurs des définitions qui le suivent à celle de M. Ed. Lambert.

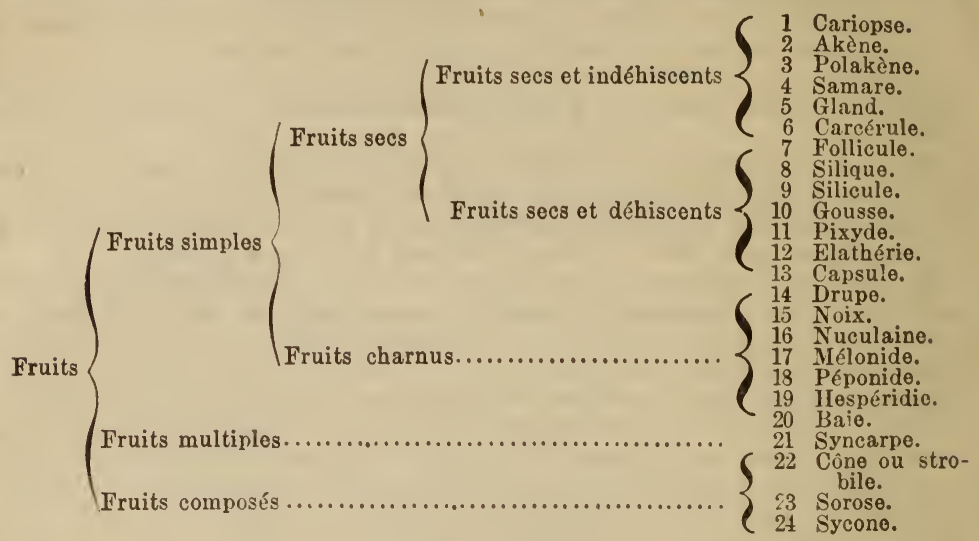

71. Fruits simples.-Les fruits simples sont ceux qui proviennent d'un seul ovaire. Ces fruits peuvent être secs ou charnus.

A. Fruits secs.-Parmi les fruits indéhiscents on distingue : 1o le Cariopse (fig. 143), fruit monosperme dont le péricarpe mince adhère dans toute son étendue aux téguments de la graine (Blé); 2o l'Akìne (fig. 144), fruit monosperme dont le péricarpe mince n'adhère que par un point aux téguments de la graine (Sarrasin); le l'olakene (fig. 145), fruit à plusieurs loges monospermes, séparables les unes des autres et offrant chacune les caractères de l'akène (Capucine); la Samare (fig. 146), fruit uniloculaire muni d'une membrane en forme d'aile (Erable, Orme); le Gland (fig. 147), fruit unilo. culaire monosperme, entouré en tout ou en partie par une cupule (Chêne); la Carcérule, fruit pluriloculaire, polysperme (Tilleul).

Les fruits secs déhiscents sont: 1o la Follicule (fig. 137), fruit uniloculaire univalve et polysperme (Ancolie); la 20 Silique (fig. 14^), fruit biloculaire, bivalve, allongé (Chou); 3o la Silicule (fig. 149), fruit semblable à la silique, mais beaucoup plus court (Thlaspi); 4o la Gousse ou Légume (fig. 138), fruit uniloculaire, bivalve, allongé (Haricot). Parfois le légume est divisé trans. versalement en plusieurs articles, et prend alors le nom de Lomentum (fig. 150). 5o La Pixyde (fig. 142), fruit à déhiscence transversale (Pourpier); 60 l' $E$ latherie (tig. 151), fruit pluriloculaire, à plusieurs côtes, se séparant à la maturité en autant de corps qui s'ouvrent longitudinalement et avec élasticité (Euphorbe réveille-matin); 7o la Capsule (tig. 140). fruit sec déhiscent ne se rapportant à aucune des espèces précédentes (Molène). 
B. Fruits charnus.-1o la Drupe, fruit à mésocarpe succulent et dont l'endocarpe forme un noyau (Cerisier); 2o la Noix, fruit à mésocarpe coriace et dontl'endocarpe forme un noyau (Noyer); 3o la Nuculaine, fruit à méso. carpe charnu, renfermant plusieurs noyaux (Cornouiller); 4o la Mélonide, fruit provenant de plusieurs ovaires simples réunis et soudés dans l'intérieur clu tube calicinal qui devient charnu (Pommier) ; 5o la Péponide, fruit charnu à plusieurs loges monospermes, éparses au milieu de la pulpe (Melon); 6o l'Ilespéridie, fruit charnu dont l'enveloppe est très-épaisse, divisé intérieurement en plusieurs loges par des cloisons membraneuses et dont les loges sont remplies par une matière pulpeuse (Oranger); 7o la Baie, fruit charnu sans noyau, renfermant une ou plusieurs graines dans la pulpe (Vigne, Groseillier).

72. Fruits multiples.-Les fruits multiples sont ceux qui résultent de la soudure de plusieurs ovaires appartenant à une même fleur. Ces fruits, que l'on nomme aussi syncarpes, peuvent être secs ou charnus : c'est à cette dernière catégorie que se rapporte la Framboise (fig. 154).

73. Fruits composés ou agrégés.-Les fruits composés ou fruits agregés sont ceux qui proviennent de la soudure de plusieurs ovaires appartenant à des fleurs différentes mais très-rapprochées. Ils sont de trois sortes: 1o le Cône ou strobile (fig. 152), fruit composé d'akènes ou de samares cachés dans l'aisselle de bractées très-développées et dont l'ensemble a la forme d'un cône (Pin); 2o le Sorose (fig. 153), fruit composé de plusieurs fleurs soudées par l'intermédiaire de leurs enveloppes fiorales devenves charnues (Mûrier, Ananas); 3o le Sycone (fig. 155), fruit à enveloppes charnues, portant à l'intérieur un grand nombre d'akènes ou de drupes provenant de fleurs pistillées (Figuier). 


\section{PHYSIOLOGIE VEGETALE.}

74. Après avoir décrit les organes nourriciers et reproducteurs des plantes, nous devons faire connaître les fonctions propres à chacun d'eux, et montrer commẹt ils agissent pour produire les phénomènes vitaux dont ils sont le siège. Cette partie de la Botanique est appelée physiologie végétale ou étude de la vie dans les plantes.

\section{CHAPITRE I.}

N UTRITION.

75. Aliments.-Pour se nourrir, les végétaux doivent puiser autour d'eux les matières diverses, qui, élaborées dans leurs organes, leur fourniront, d'un côté, les éléments de leur croissance, et, de l'autre, leur permettront de produire à l'intérieur de leurs cellules les substances de nature variée qui donnent à chaque espèce ses propriétés caractéristiques.

Des expériences concluantes ont prouvé que les substances solides ne. peuvent être absorbées dans leur état normal, quelque divisées qu'elles soient, et qu'elles ne peuvent s'introduire dans les tissus vivants et intacts qu'à la faveur de leur solution dans un liquide. Il faut donc que la terre arable, ce mélange de roches désagrégées et de débris organiques au sein duquel croissent les végétaux, subisse, pour devenir nutritive, une préparation analogue à celle de la digestion alimentaire chez les animaux.

L'air et l'eau sont les agents qui interviennent dans cette préparation : loxygène de l'air attaque les détritus de végétaux et d'animaux qui s'accumulent à la surface du sol, les consume lentement et les transforme en acirle carbonique, en ammoniaque et en d'autres substances liquides ou gizeuses; son action sur les roches a aussi pour résultat la formation de composés solubles renfermant du soufre, du phosphore, de la silice, de la potasse, de la chaux, etc. A mesure que ces matières prennent naissance, elles se dissolvent dans l'eau des pluies et pénètrent avec elle dans l'intérieur des racines.

76. Les aliments ne font jamais défaut dans les régions incultes où des végétaux croissent spontanóment. Là, en effet, chaque génération rend à In terre, en mourant, les substances qu'elle lui avait empruntées. Il en est tout autrement de nos prairies et de nos champs auxquels chaque année on enlève des récoltes: ils s'appauvrissent peu à peu et ne tardent pas à devenir stériles, à moins qu'on ne leur rende, sous forme d'engrais, les éléments rlont ils ont été déponillés. 
Le labour, les assolements et les jachères sont des moyens que l'on emploie très-efficacement pour prévenir l'épuisement des terres.

Le labour ameublit le sol, le rend perméable à l'air et à l'eau, en même temps qu'il amène à la surface des couches de terre que leur profondeur avait jusque-là soustraites à l'action des agents chimiques.

L'assolement est l'art d'alterner convenablement les cultures. Il est fondé surce principe que toutes les plantes n'exigeant par les mêmes aliments pour prospérer, un terrain qui se refuse à la production d'une certaine espèce végétale, ne cesse pas pour cela d'être fertile pour les autres. Ainsi il est reconnu que le Trèfle et les Pois peuvent très-bien réussir là où la Betterave ne pousse que difficilement. La raison en est que la potasse, qui est l'aliment indispensable de la dernière plante, est remplacée dans les deux premières par de la chaux, comme on peut s'en convaincre en soumettant leurs cendres à l'analyse.

La jachere est le repos qu'on accorde à une terre trop épuisée pour que, même en variant la culture, elle puisse rémunérer le travail. Un l'abandonne à elle-même pendant une ou plusieurs années, atin de laisser à l'oxygène le temps de préparer de nouveux aliments.

77. Absorption.-L'absorption est l'acte par lequel les végétaux s'emparent des matières propres à les nourrir et les font pénétrer dans leurs tissus. La racine est l'organe principal de cette fonction, mais toutes ses parties n'y concourent pas également. Hales, physicien anglais, ayant disposé des plantes sur un bassin de manière à ne laisser plonger dans l'eau que les extrémités des radicelles ou les spongioles, vit ces plantes prospérer, au lieu qu'elles dépérissaient visiblement lorsqu'il maintenait leurs spongioles dans l'air, quoique tout le reste de la racine fût alors baigné par le liquide.

Cé fait démontre que c'est par les spongioles que les sucs nourriciers de la terre s'introduisent dans les végétaux, et nous explique pourquoi la conservation plus ou moins parfaite de ces organes délicats exerce une si grande influence sur le succès des transplantations.

Chaque fois que les jardiniers ont à enterier des racines dont les radicelles ont trop souffert, ils ont soin de les rafraîchir, c'est-à-dire d'en couper l'extrémité. Cette opération a pour but de mettre à nu les vaisseaux dont l'ourerture béante permettra l'introduction des liquides nourriciers en attendant que de nouvelles spongioles se soient formées. C'est pour la même raison que les fleurs, qu'on fait plonger par leur pied dans un vase rempli d'eau, conservent leur fraîcheur bien plus longtemps, si l'on a eu la précaution de couper la partie inférieure des pédoncules.

Les feuilles et les parties vertes de la tige contribuent dans une certaine mesure au phénomène de l'absorption, en s'emparant de la vapeur d'eau, de l'acide carbonique et des autres gaz contenus dans l'air. C'est même principalement par leurs parties aériennes que se nourrissent une foule d'acotylédones et certaines plantes grasses dont la racine est presque nulle. Nous rapporterons, à ce sujet, un fait très-instructif observé au Collége de Montréal. Un bourgeon d'Aloës ayant été apporté en classe, pour servir à l'étudle des tissus élémentaires, fut ensuite déposé dans un endroit sec, et là, sans recevoir le moindre arrosage, il continua à végéter pendant près de quatre ans, durant lesquels plusieurs feuilles se développèrent successivement.

78. Mésanisme de l'absorption.-L'absorption des liquirles par la racine 
est avant tout le résultat d'une action vitale; on peut cependant l'expliquer en partie par l'intervention des forces physiques connues sous les nonı de capillarité, d'endosmose et de succion.

La capillarite est une attraction spéciale qui se manifeste dans les tuives d'un très-faible diamètre ou tubes capillaires. L'un de ses effets est d'élever' le niveau des liquides qui mouillent les parois des tubes dont nous parlons. C'est en vertu de cette attraction qu'un morceau de sucre qui n'est en contact avec l'eau que par quelques points, s'en imbibe entièrement, que l'huile monte dans la mèche des lampes, etc. Il est naturel de croire qu'un effet semblable doit se produire dans les racines végétales dont l'intérieur présente une multitude de conduits capillaires formés par les vaisseaux, par les fibres ligneuses, par les méats intercellulaires, et qu'il suffit de mettre l'extrémitécle ces racines en contact avec l'eau pour que cette dernière s'y élève.

Dutrochet a donné le nom d'endosmose à un phénomène découvert par lui et qui a lieu entre deux liquides d'inégale densité, lorsqu'ils ne sont séparés que par une membrane organique : on voit ces liquides se porter l'un vers l'autre jusqu'à ce qu'ils aient formé une masse de densité uniforme, mais avec cette circonstance que le courant s'établit principalement du liquide le moins dense vers le liquide le plus dense, par la raisoir, sans doute, que ce dernier éprouve une plus grande résistance à traverser la membrane. On vérifie aisément ce fait en plongeant dans de l'eau pure une vessie remplie en partie d'un liquide mucilagineux etsurmontée d'un long tube de verre (fig. 156). Dans ces conditions, la vessie se gonfle graduellement, et, après un petit nombre d'heures, le liquide s'élève dans le tube à une liauteur de plusieurs pieds au-dessus de son niveau primitif.

Si l'on considère maintenant que les spongioles des racines sont formées de vésicules membraneuses, remplies d'un liquide épais, on verra qu'elles se trouvent, par rapport à l'eau relativement limpide de la terre, dans les mêmes conditions que la vessie de l'expérience précédente, et que cette eau doit, par leur intermédiaire, monter dans les vaisseaux ou tubes qui les sur. montent. L'action endosmique n'est pas limitée aux spongioles ; elle peut, elle doit même s'étendre à toute la masse du tissu cellulaire, car chaque cellule qui a reçu par la racine un supplément de sève contient un suc plus délayé que celui des cellules supérieures et constitue avec elles un véritable appareil d'endoşmose.

La succion est une dernière force dont l'influence se fait particulièrement sentir au printemps. A cette époque du réveil de la nature, un travail immense s'opère, les bourgeons s'allongent, les feuilles et les fleurs se développent. La formation des nouveaux organes et l'évaporation active dont ils deviennent le siège, consument rapidement les sucs accumulés dans la plante durant l'automne et une partie de l'hiver. De là résulte dans les vaisseaux et les cellules, un vide, une sorte d'appel ou de succion qui détermine l'ascension de nouveaux liquides, à peu près comme en aspirant l'air d'un tube dont l'extrémité inférieure plonge dans l'eau, on force celle-ci à s'y élever.

79 Circulation de la Sève.-La sève est le mélange de l'eau absorbée par les racines avec les sucs que ces dernières contenaient déjà.

Nous avons vu tout à.l'heure comment ce liquide est poussé irrésistiblement jusqu'au sommet de la plante. Arrivé dans les feuilles, il subit des transformations radicales qui le rendent assimilable, et ainsi élaboré, il revient, par un mouvement rétrograde, à son point de départ, tout en distri- 
buant aux organes les matériaux nécessaires à leur développement. Ce sont ces mouvements consécutifs d'ascension et de descente qui ont été appelés improprement circulation de la sève.

Dans les arbres de nos forêts et dans toutes les plantes qui possèdent un système ligneux et un système cortical distincts, la sève monte par le premier de ces deux systèmes et redescend par le second. C'est un fait dont on peut se convaincre en examinant un tronc d'arbre fraîchement coupé : la section inférieure, celle qui est en relation avec la racine et vers laquelle, par conséquent, afflue la sève ascendante, se couvre de gouttelettes sur lá partie ligneuse, tandis que la moelle et la zone corticale ne donnent liou à aucun écoulement.

L'inverse a lieu naturellement sur l'autre section, dont le bois demeure sec et dont l'écorce laisse échapper par la partie fibreuse la sève descendante ou élaborée.

Outre le mouvement général dont nous venons de parler, la sève en possède de particuliers que l'on désigne sous les noms de cyclose et de rotation.

La cyclose a lieu dans les vaisseaux laticifères. Ces vaisseaux, on se le rappelle, forment dans les feuilles et l'écorce des tiges un réseau compliqué dont les différentes branches communiquent entre elles. Ils contiennent un suc trèsélaboré, variable suivant les espèces végétales et souvent coloré, qui a été appelé latex. Les physiologistes ne sont point d'accord sur le rôle du latex. Les uns pensent qu'il doit être considéré comme la sève élaborée ou sève descendante ; ce serait lui alors qui fournirait aux tissus tous les éléments de leur croissance. D'autres ne voient, au contraire, dans le latex qu'une sorte de résidu ou ce qui reste de la sève élaborée après que la plante s'en est approprié les principes assimilables. Dans cette opinion, soutenue par Trécul, le grand physiologiste de notre époque, les laticifères seraient proprement les veines des végétaux et le latex une sorte de sang veineux destiné à être jeté de nouveau dans le torrent de la circulation pour aller reprendre, au contact de l'air, ses propriétés vivifiantes. Quoi qu'il en soit de ces théories, il semble établi par de nombreuses expériences que le latex, au lieu de descendre directement, comme la sève contenue dans le.s tibres de l'écorce, parcourt lentement les laticifères et no revient à la racine qu'aprè̀s avoir décrit d'innombrables méandres.

La rotation ou circulation intra-cellulaire a lieu, comme son nom l'indique, dans l'intérieur des cellules. La sève, au lieu de traverser directement ces organes, en suit les parois et les contourne de manière à décrire indéfiniment le mêrne cercle. Cette rotation du fluide cellulaire n'a été obseivée que sur des plantes aquatiques et sur un très-petit nombre de plantes terrestres, mais tout porte à croire qu'il est général.

"C'est au printemps, dit Figuier, que les mouvements de la sève se font avec une grandle activité. Alors, la plante est gor'gée de matières nutritives qui s'étaient conservées en dépôt pendant l'hiver. Elle est pleine de liquides, et ces sucs s'écoulent et se répandent au dehors par la plus légère blossure. Au printemps la Vigne et les autres végétaux pleurent, selon l'expression pittoresque consacrée par l'usage. Mais lorsque les feuilles se sont développées, l'active évaporation qui se fait à leur surface entraîne les liquides à l'extrémité du vé cétal, d'où ils s'exhalent en vapeur's. Alors la Vigne et les autres plantes ne pleurent plus quand on les blesse.

Quand les rameaux se sont développés é consolidés, le mourement de la sève se ralentit. Il se réreille quel $c_{1} u e$ fois rer's la fin de l'été, lorsque, 
le printemps ayant été hâtif, les matériaux que la plante avait préparés pour la végétation de l'année suivante sont prêts trop tôt, et mis prématur'ément en œuvre. Après la chute des feuilles et quand l'approche de l'hire!: abaisse la température extérieure, le mouvenent de la sève s'arrête totalement. L'arbre arrive peu à peu à un état de repos presque absolu, "uni n'est pas la mort, mais l'attente du réveil."

80. Transpiration et respiration. - La circulation amène la sève brute des racines, qui en ont puisé les matériaux dans le sol, jusqu'aux feuilles dans lesquelles le système continu et ramifié de tubes qui suivent tontes les nervures la répandent sur une large surface. Mais ce liquide est alors éminemment aqueux, et, dans cet état, il ne peut servir que très-imparfaitement à lit nutrition des organes. Il faut donc que, d'un côté, il perde une portion notable de l'eau qu'il renferme en excès, de l'autre, qu'il s'enrichisse de matières puisées dans l'atmosphère, qui, modifiées sous l'influence vitale, le rendent plus substantiel et plus nutritif. Cette double moditication est opérée en lui par la transpiration et la respiration.

La transpiration varie naturellement avec les conditions atmosphériques. Un temps sec et une grande chaleur sont les causes dont l'influence se fait particulièrement sentir. La transpiration est si active durant certains jours d'été, que les plantes se fanent et qu'il devient nécessaire de les arroser, surtout si les racines ne sont pas assez développées pour atteindre jusqu'aux couches humides de la terre. Les arrosages ne suffisent même pas toujours pour préserver les végétaux des effets désastreux de la sécheresse, car il peut arriver que l'absorption des racines ne puisse pas suffire à réparer la perte éprouvée par les feuilles. Il ne reste alor's d'autre ressource que de travailler à modérer l'évaporation en mettant les végétrux à l'ombre lorsque cela est possible, ou mieux en arrosant leurs feuilles pour saturer d'humidité l'air ambiant.

Entre les plantes et l'atmosphère qui les entoure, il s'opère constamment des échanges de gaz qui constituent leur respiration.

L'air s'introduit dans la sève par la surface entière des végétaux, mais plus spécialement par les innombrables stomates dont les feuilles sont pourvues. Les feuilles doivent être considérées comme des organes respiratoires: elles remplissent, dins la plante, le même rôle que les poumons chez les animaux, et l'arbre qui en a été dépouillé ne peut plus ni s'accroitre, ni fructifier.

Plusieurs méthodes ont été employées pour étudier l'action de l'air sur la sève. L'une des plus simples consiste à faire végéter des plantes dans une atmosphère limitée que l'on a soin d'analyser avant et après l'expérience pour connaître les changements survenus. En opérant de la sorte, on est arrivé aux conclusions suivantes: 1o. dans l'obscurité, les plantes ahsorbent de l'oxygène et exhalent de l'acide carbonique; 20. à la lumière, les organes colorés se comportent comme dans l'obscurité, mais les organes verts agissent inversement, c'est-à-dire qu'ils absorbent l'acide carbonique et dégagent de l'oxygène; 30 . cette dernière action des parties vertes est (le beaucoup prépondérante, et c'est elle qui représente le résultat définitif d: la respiration végétale.

L'acide carbonique est, comme on le sait, un gaz composé de deux atomes d'oxygène en combinaison avec un atome de carbone. Il prend nuissance dans la respiration des animaux, dans la combustion de nos foyers, dıns la décomposition des mitières organiques, etc. Sa présence 
dans l'atmosphère deviendlait extrêmement nuisible s'il pouvait s'y accumuler en quantités considérables, car il produit l'asphyxie. Mais, par. une disposition toute providentielle, les végétaux s'en emparent, le décomposent, s'en approprient le carbone et remettent l'oxygène en liberté.

La respiration produit donc simultanément deux effets de la plus haute importance : elle nourrit le végétal en lui procurant la presque totalité de son carbone; elle assainit l'air en y jetant constamment de nouvelles quantités d'oxygène qui est l'élément vital par excellence. Des expériences récentes tendent à établir que l'oxygène expiré par les plantes, possède la modification particulière qui lui fait domner le nom d'ozone. s'il en est ainsi, comme il est d'ailleurs admis généralement que l'ozone exerce une influence très-salutaire sur la santé, on ne saurait trop recommander de faire des plantations d'arbres autour des habitations.

81. Assimilation et sécrétion.-Pendant que la sève élaborée, le cambium de quelques auteurs, est ramenée vers la racine, les sucs quielle contient sont absorbés latéralement par les divers organes qui se les assimilent, c'est-à-dire les changent en leur propre nature. En même temps, des substances variées, solides ou liquides, sont sécrétées dans les cavités cellulaires et mises en réserve pour des usages ultérieur's. Il y a donc à considérer, dans le végétal, les matières qui constituent les tissus et d'autres matières qui sont simplement déposées dans les cavités que circonscrivent ces tissus. Nous allons passer rapidement en revue celles qui offrent le plus d'intérêt.

82. Principes organiques.-Un grand nombre de substances organiques, composées exclusivement d'oxygène, de carbone et d'hydrogène, portent le nom de principes ternaires; d'autres, qui contiennnent en outre de l'azote, sont dites quaternaires.

Parmi les principes ternaires les plus importants et les plus répandus, nous signalerons la cellulose, l'amidon, la dextrine, les sucres, les gommes, le ligneux, les résines, les huiles essentielles, les huiles fixes et divers acides.

La cellulose se compose approximativement de 49 parties en poids d'oxygène, pour 6 d'hydrogène et 45 de carbone. C'est elle qui constitue l'enveloppe des cellules, des fibres et des vaisseaux, et par conséquent, la charpente même du végétal. Sa souplesse quand elle est pure, sa ténacité, son inaltérabilité au contact de la plupart des acides et des alcalis étendus, la rendent précieuse pour la confection des cordages, de la toile et du papier.

L'amidon diffère de la cellulose par sa structure granulaire et sa moindre cohésion qui le rendent propre à la digestion et en font l'une dès bases les plus importantes de notre alimentation. On le trouve en dépôt dans les cellules des graines, des racines et des tubercules. La grosseur des grains, leur forme, leur consistance, varient suivant la plante qui les a sécrétés. L'amidon qu'on extrait des céréales est celui qui a le plus de valeur. La fécule de Pomme-de-terre, l'arrow-root, le tapioca, le sagou, etc., ne sont que des variétés d'amidon.

Il se forme dans les végétaux, aux dépens des matières azotées, un ferment très-actif, appelé diastase, qui a pour effet de convertir l'anidon d'abord en dextrine, matière analogue à la gonme, puis en diverses sub- 
stances sucrées connues sous les noms de glucose, de sucre de fruits et de sucre cristallisable. C'est cette dernière espèce de sucre qu'on emploie dans l'économie domestique. Il existe dans la sève de plusieur's végétaux, et notamment dans celle de l'Erable à sucre, de la Canne à sucre, du Maïs et de la Betterave.

Les gommes se distinguent par la propriété qu'elles possècient de se dis. soudre dans l'eau et de lui communiquer une viscosité dite gommeuse. Les ylus connues sont la gomme arabique, la gomme adragante et la cérasine, yui découle du Cerisier et d'autres arbres fruitiers.

Toutes les matières dont nous venons de parler ont la même composition élémentaire, à lexception des sucres qui résultent de la combinaison de la dextrine avec une, deux, ou bien quatre molécules d'eau.

Une augmentation dans la quantité du carbone et de l'hydrogène pro. luit le ligneux, matière dure et cassante qui s'incruste dans l'intérieur des cellules, des fibres et des vaisseaux à mesure que la plante vieillit. Les arbres où prédominent ces incrustations sont les plus recherchés, soit comme bois de chauffage, soit comme bois de construction.

Les résines s'écoulent de l'écor'ce d'un grand nombre d'arbres appartenant pour la plupart à la famille des Conifères ou à celle des Térébinthacées : co sont des substances insolubles dans l'eau et très-inflammables à cause de la grande proportion de carbone et d'hydrogène qu'elles contiennent. Par l'exposition à l'air, elle s'oxydent, deviennent dures et cassantes. On en distingue de trois sortes: 10 les résines liquides ou baumes; 20 les résines solides, telles que la colophane et la laque; 3o les gommes résines, qui tiennent le milieu, comme leur nom l'indique, entre les résines proprement dites et les gommes. Parmi ces dernières on remarque l'assa-fœetida et l'encens. Le Baume du Canada, qui est si employé, provient du Sapin blanc (Abies balsamifera).

Le caoutchouc et la gutta-percha, que l'on extrait du suclaiteux de quelques arbres piopres aux régions tropicales, ont été longtemps classés parmi les résines. Une étude plus approfondie a montré que ce sont des carbures d'hydrogène, c'est-à-dire des composés dans lesquels il n'entre que du carbone et de l'hydrogène.

Certaines plantes de nos climats, la Laitue, l'Euphorbe, le Cotonnier ( $A s$ clepias Cornuti), contiennent des principes analogues au caoutchouc.

Les plantes odorantes doivent leurs parfums à des essences volatiles. C'est principalement dans les fleurs et les fruits que l'on rencontre ces huiles essentielles, souvent aussi dans les feuilles et les tiges, plus rarement dans la racine. Les plantes fournissent encore d'autres huiles qui n'émettent point de vapeurs comme les essences et que pour cette raison on appelle huiles fixes. On les extrait en grande quantité des graines de Lin, de Chanvre, de Hêtre, de Noyer et de plusieurs autres plantes.

Des acides se rencontrent dans toutes les parties des végétaux, surtout dans les fruits, auxquels ils communiquent cette saveur fraîche et piquante que tout le monde connaît. Ils sont généralement combinés à des bases minérales ou végétales avec lesquelles ils forment des sels qui restent en dissolution dans la sève ou se déposent, sous forme de cristaux, dans des cellules spéciales. Comme exemples d'acides végétaux, nous citerons les acides acétique, tartrique, oxalique, pectique, citrique, tannique, dontlusage est très-répandu.

Les principes azotés ou quaternaires ne sont ni moins nombreux, ni moins importants que les principes ternaires. L'un d'eux, nommé protéine, 
donne naissance, en se combinant avec du soufre, du phosphore et quelques sels, à l'albumine, la glutine, la fibrine, la caséine, etc., matières que l'on retrouve dans le sang de l'homme et des animaux et aux dépens desquelles se forment leurs organes.

D'autres principes quaternaires se comportent comme les alcalis, c'està-dire qu'ils peuvent, en se combinant avec les acides, constituer de véritables sels. Cette propriété leur a valu le nom d'alcaloz̈des. Leur saveur est ordinairement âcre et amère ; leur action sur l'économie animale est énergi ique. Employés en petites doses, ils deviennent souvent des médicaments précieux; mais si on les administre en quantités un peu considérables, ils se comportent comme de véritables poisons. C'est à ce groupe de composés quappartiennent la quinine, fébrifuge excellent que l'on extrait de l'écorce du Quinquina; la nicotine, la morphine et la strychnine, qui proviennent, la première du tabac, la seconde de l'opium et la troisième de la noix vomique; la caféine ou theine, que l'on obtient en faisant infuser dans de l'eau chaude les fruits du Caféier et les feuilles du Thé.

La chlorophylle est un autre principe quaternaire qui joue un rôle important dans la végétation. C'est elle qui, vue par transparence à travers la paroi des cellules, donne aux feuilles et aux jeunes rameaux leur couleur verte. La lumière est nécessaire à sa formation, car l'on remarque que les plantes qui croissent dans l'obscurité sont complètement blanches. Aux yeux de plusieurs botanistes, les diverses teintes des végétaux ne sont que des modifications de la chlorophylle.

83. Excrétions.-Dans l'examen que nous venons de faire des principes organiques, nous avons vu que plusieurs d'entre eux, comme les résines, les gommes, les essences, sont exsudés ou exhalés par les végétaux. On nomme excrétions les matières ainsi rejetées par l'organisme. Ces matières sont généralement nuisibles aux plantes qui les produisent et rendent le sol impropre à leur culture, lorsqu'elles s'y accumulent.

On sait qu'une plante cultivée plusieurs fois de suite dans le même champ donne des produits de moins en moins abondants; qu'un arbre ne prospère point là où a vécu un autre arbre semblable; enfin, que certaines plantes paraissent se plaire ensemble, tandis que d'autres ne se voient jamais dans les mêmes lieux. Plusieurs physiologistes ont attribué ces faits aux matières excrétées par les racines, qui seraient un poison pour quelques espèces et un aliment pour d'autres. Cette explication est aujourd'hui généralement rejetée, parce qu'elle n'est basée que sur quelques faits isolés et susceptibles d'une autre interprétation. Si les plantes ne croissent pas également bien partout, c'est qu'elles ne trouvent pas dans tous les endroits les principes particuliers nécessaires à leur développement, comme nous l'avons dit en parlant des assolements (no. 76).

84. Nutrition comparée des animaux et des plantes.-Il y a des analogies, mais aussi beaucoup de différences entre la nutrition des animaux et celle des plantes:

1o Les animaux ne peuvent se nourrir que de matières ayant eu vie et provenant par conséquent d'autres animaux ou des végétaux; les plantes se nourrissent de matières inorganiques, telles que l'acide carbonique, l'sau, la chaux, etc.

20 Les animaux digèrent leurs aliments, c'est-à-dire qu'ils leur font subir 
dans l'estomac et les intestins une préparation en vertu de laquelle les principes nutritifs se séparent sous forme d'un liquide blanc comme le lait, le chyle, pendant que les matériaux inutiles sont rejetés de l'organisme; les plantes trouvent leurs aliments tout préparés dans la terre et ne possèdent point d'appareil digestif.

3o L'absorption se fait chez les animaux au moyen de villosités qui tapissent l'intestin; la même fonction s'opère chez les plantes au moyen des radicelles qui les mettent en communication intime avec le sol.

4o Clrez la plupart des animaux, le sang est contenu dans un système de veines et d'artères qui se ramifient indéfiniment dans les membres, et ce sang est mis en mouvement par un muscle d'une grande puissance appelé le cour; chez le plus grand nombre des plantes, on trouve aussi des fibres et des vaisseaux qui sont comme leurs veines et leurs artères, mais le cœur fait défaut; leur sang, appelé sève, est mis en circulation par l'endomose, la succion, la capillarité et d'autres forces inconnues.

5o Les animaux se débarrassent, par les pores de la peau et par les poumons, de l'excès d'eau que renferme leur sang; les plantes exhalent de même, par toute leur surface mais surtout par les feuilles qui leur servent de poumons, une abondante transpiration.

6 o Il est nécessaire pour les animaux de respirer, c'est-à-dire de vivifier leur sang au contact de l'air; dans cet acte ils absorbent de l'oxygène et rejettent de l'acide carbonique. La respiration n'est pas moins nécessaire aux plantes, qui meurent asplyyxiées quand cette fonction est entravée; mais elles respirent à l'inver'se des animaux, c'est-à-dire qu'elles absor ent l'acide carbonique et rejettent l'oxygène.

7o Enfin, les animaux, en s'assimilant les matières qui forment le sang, réparent les pertes continuelles queéprouvent leurs organes et, dans une certaine période de leur' existence, prennent de l'accroissement; ils sont munis de glandes, telles que les glandes lacrymales, les glandes salivaires, le foie, etc., où sont élaborés des principes qui devront plus tard servir à des fonctions vitales; d'autres glandes, comme les reins, servent à extraire du sang les matériaux nuisibles. Les plantes s'accroissent de la même manière aux dépens de la sève; dans certaines cellules, elles sécrètent de l'amidon et d'autres substances qu'elles mettent en réservo pour des besoins ultérieurs, et enfin elles se débarrassent, par voie d'excrétion, de tous les résidus inutiles ou nuisibles.

\section{CHAPITRE II.}

REPRODUOTION.

85. La conservation indéfinie rles espèces chez les êtres vivants repose uniquement sur la faculté qui leur a été donnée de se reproduire, c'est-àdiro de donner naissance à d'autres êtres qui leur ressemblent et qui, à leur tour, revivront dans leur descendance. En effetet, tout individu doué de la vie naît, se développe pour atteindre l'apogée de son énergie vitale, s'affaiblit ensuite et meurt. Les végétaux doivent donc se reproduire sous peine de disparaître à une époque plus ou moins éloignée, mais certaine. 
Cette reproduction peut se faire de deux manières : par bourgeons et par semences. Ce n'est qu'exceptionnellement que la nature emploie le premier mode, et il n'est aucune espèce végétale qui ne soit pourvue de semences propres à la multiplier.

\section{REPRODUCTION PAR BOURGEONS.}

86. Nous savons que des bourgeons naissent régulièrement à l'extrémité des rameaux et à l'aisselle des feuilles. Tout point de la surface végétale a aussi le pouvoir latent d'en produire, lorsqu'il se trouve placé dans des conditions favorables.

Que sont ces bourgeons, ou les rameaux qui en proviennent, sinon des végétaux qui croissent sur la mère-plante et en tirent leur nourriture ? Il suffirait donc, pour en faire autant d'êtres distincts, vivant d'une vie propre, de les détacher et de leur fournir une autre source d'alimentation. Cette opération s'accomplit naturellement dans un grand nombre de circonstances et par des voies différentes dont le Fraisier, le Lis bulbifère, la Pomme-de-terre et la Cuscute nous offrent des exemples familiers.

Le Fraisier (fig. 21) émet latéralement des jets ou coulants qui tombent sur la terre par leur propre poids et y prennent racine, pendant qu'une rosette de feuilles se produit au-dessus du point où les racines ont poussé. Plus tard, les coulants se flétrissent, se désarticulent, et les touffes enracinées deviennent autant de pieds distincts.

Les bulbiles que le Lis bulbifère porte sur ses rameaux sont, comme nous l'avons vu à l'article des bourgeons, de petites masses charnues formant une sorte de transition entre le bourgeon ordinaire et la graine. Il suffit que ces bulbiles tombent dans une terre fertile pour qu'ils produisent une plante semblable à celle qui leur a donné naissance. Les caïeux des rhizomes bulbeux jouissent de la même propriété.

La Pomme-de-terre est ainsi appelée à cause des tubercules, plus ou moins semblables à une pomme, qui naissent sur divers points de son rhizome. Ces tubercules se détachent de la mère-plante à la maturité, et lorsque le printemps vient ranimer la végétation, on voit leurs yeux, véritables bourgeons, s'allonger en une tige qui vit d'abord aux dépens de la fécule mise en réserve dans les cellules, puis émettre des racines qui s'enfoncent dans le sol. Chaque tubercule donne ainsi naissance à une ou plusieurs plantes nouvelles.

La Cuscute est un végétal parasite, c'est-à-dire qui puise sa nourriture sur d'autres végétaux. Sa tige est filiforme et entièrement dépourvue de feuilles. On voit cette tige, après qu'elle s'est élevée à une certaine hauteur au-dessus de terre, enrouler ses rameaux, armés de nombreux suçoirs, autour des plantes voisines dont elle s'approprie les sucs. Chaque rameau ainsi enroulé peut être détaché de la mère-plante ou s'en détache même seul, sans qu'il ait à en souffirir. C'est désormais une plante complète, poúvant se suffire à elle-même, fleurir, fructifier et se reproduire.

87. Les modes de reproduction artificielle connus sous les noms de marcottage, de bouturage et de greffe, ne sont qu'une imitation des procédés employés par la nature dans les exemples que nous venons de citer.

Pour faire une marcotte, on plie une branche, tenant à la mère-plante, de manière que son extrémité plonge dans la terre ou dans un vase rempli de terre. La partie enterrée pousse bientôt des racines qui suftisent pour la 
nourrir et permettent de la détacher de sa tige. On multiplie ainsi trèsfréquemment les Eillets et la Vigne.

La bouture est un rameau complètement séparé de la mère-plante dont on enfonce l'extrémité dans le sol. Dans ces conditions, il se développe des racines sur la partie inférieure et des bourgeons foliacés sur la partie supérieure. Le Saule, le Peuplier, le Groseiller et, en général, tous les arbres ou arbrisseaux à croissance rapide se reproduisent facilement par bouture.

$\mathrm{Au}$ lieu de mettre le rameau, dont on veut faire un végétal distinct, en rapport immédiat avec la terre, on peut l'appliquer sur un autre végétal avec lequel il puisse se souder et qui soit de nature à lui fournir les matières nécessaires à son alimentation. Ce rameau prend alors le nom de greffe, et l'arbre qui le reçoit, celui de sujet ou de sauvageon.

Quelle que soit la méthode employée pour greffer, il est indispensable d'u. nir intimement les tissus similaires du sujet et de la greffe, c'est-à-dire de les disposer liber contre liber, aubier contre aubier, en ayant soin d'assurer le contact au moyen de ligatures (fig. 157). Leur soudure ne s'opérera qu'à cette condition. Il faut, en outre, qu'il existe une certaine analogie dans la structure anatomique de ces tissus, dans la nature de leur sève et dans leurs conditions physiologiques. C'est ce qui explique pourquoi la greffe réussit si rarement entre plantes qui ne sont pas de mểme espèce, entre plantes dont l'une est herbacée et l'autre ligneuse ou entre resquelles il $e^{x i s t e}$ une trop grande disproportion de taille.

La greffee est une des opérations les plus importantes de i'norticulture. Par elle on parvient à conserver une foule de variétés qui ne se reproduiraient que très-difficilement par graines. C'est par elle aussi que les jardiniers changent avec avantage les produits d'un végátal en ceux d'un autre végétal de même espèce, lui font porter des fleurs et des fruits différents de ceux qui sont propres à la tige principale, enfin qu'ils rajeunissent un arbre ou un arbrisseau déjà usé.

\section{REPRODUCTION PAR GRAINES.}

83. Fécondation.-La fécondation est la fonction par laquelle le pollen, mis en contact avec l'ovaire, détermine dans l'ovule la formation de l'embryon. "L'anthère des étamines, dit Duchartre, restée close jusque vers le moment où le pollen atteint son état parfait, s'ouvre alors de diverses manières, et permet ainsi aux grains généralement libres du pollen de se laisser emporter par l'agitation de l'air, par les insectes, etc., jusque sur le stigmate du pistil, que l'état humide de sa surface rend partaitement apte à le retenir et à exercer sur lui une action toute spéciale. Sous l'influence de cette action qui n'est pas l'une des moindres merveilles de la vie végé. tale, chaque grain de pollen présente un phénomène que, sans trop de hardiesse, on a pu appeler une sorte de germination: il s'allonge en un tube très-délié, fermé à son extrémité, dans lequel se porte le liquide fécondant ou fovilla, qui le remplissait; ce tube (fig. 153) s'insinue entre les cellules du stigmate laissé à découvert par une lacune de l'épiderme général de la plante; il s'allonge graduellement, grâce à une nutrition locale dont il puise les éléments autour de lui, et il arrive ainsi jusque dans la partie inférieure du pistil, c'est-à-dire dans l'ovaire, dont la cavité renferme les ovules 
auxquels son action mystérieuse va imprimer une vie nouvelle qui en fera des graines."

Des expériences très-nombreuses prouvent que, dans les plantes cotylédonées, aucun ovule ne peut passer à l'état de graine féconde, sans avoir subi l'influence vivifiante du pollen; en d'autres termes, il ne peut y avoir reproduction par graines sans fécondation préalable. On s'explique ainsi pourquoi les arbres fruitiers, le Blé, la Vigne, etc., restent stériles lorsque des pluies trop abondantes, survenues au moment de la déhiscence des anthères, entrainent le pollen à terre avant la fécondation des ovaires.

89. HIybridation.-Une plante peut être fécondée par le pollen d'une autre plante dont elle diffère comme espèce ou du moins comme variété, et de cette fécondation croisée résulte un être nouveau, un hybride, intermédiaire entre ses deux parents et participant aux caractères de l'un et de l'autre. C'est en utilisant ce curieux phénomène physiologique, en répandant le pollen d'une fleur sur une autre, que les horticulteurs sont parvenus à créer cette multitude de formes nouvelles qui se recommandent, les unes par leur beauté, les autres par les qualités distinguées de leurs produits.

90. Dissémination des graines.-Pour assurer la perpétuité des espèces et leur distribution régulière sur la surface du globe, il fallait que les graines, après leur maturité, fussent transportées à des distances plus ou moins considérables. La Providence a pourvu à leur dissémination par des moyens aussi admirables que variés.

Certaines plantes, comme les Balsamines et les Géraniums, ont leurs fruits munis de valves élastiques qui se détachent brusquement, se détendent comme un ressort et lancent au loin les graines qu'elles renfermaient.

Les courants d'air sont de puissants agents de dissémination: ils emportent les semences légères et vont les déposer sur les montagnes, les édifices, et jusque dans le fond des cavernes. Plusieurs espèces de fruits, ceux de l'Erable, de l'Orme, du Frêne, du Pin, par exemple, sont munis d'ailes membraneuses qui donnent beaucoup de prise au vent; un certain nombre se terminent par des aigrettes et d'autres sont surmontés par une sorte de chevelure ou de plumet, comme dans le Saule et le Peuplier.

On voit des fruits, trop lourds pour être enlevés par les efforts du vent, accomplir de longs voyages sur les eaux des fleuves et des rivières qui les entraînent. Les courants marins répandent aussi au loin certaines plantes qui pour la plupart sont pourvues de semences à enveloppe très-résistante. Il est bien établi que plusieurs espèces végétales qui croissent aujourd'hui sur les plages d'Afrique, ont été amenées là du Brésil et de la Guyane, par le grand courant qui naît sur la côte orientale de l'Amérique du Sud.

Les animaux concourent amplement à la dispersion des semences. Les Ecureuils et d'autres rongeurs approvisionnent de fruits leur demeure souterraine, et une partie de leurs rapines, souvent oubliée sous le sol, y germe et s'y développe au retour du printemps. D'autres mammifères travaillent à la disséminatien par des procédés encore plus simples: les semences s'accrochent à leur toison et sont transportées çà et là par eux, dans leurs pérégrinations. Les fruits de la Bardane, du Gratteron, de l'Aigremoine, du Cerfeuil des bois, et une foule d'autres, sont terminés à cet effet par 
des poils en forme d'hameçon qui leur permettent de s'accrocher aux poils des animaux ou aux vêtements qui viennent les frôler.

Si les animaux consomment pour leur nourriture une fort notable quan. tité de semences, par une heureuse compensation, leurs déprédations deviennent une source inépuisable de régénération, car très-souvent la pulpe seule des fruits est attaquée, et les graînes, rebelles à la digestion, se retrouvent intactes dans leurs excréments. Le Gui, si célèbre dans l'ancienne Gaule et qui est une plante parasite du Chêne et d'un petit nombre d'autres arbres, ne se reproduit que par l'intermédiaire des Grives, qui sont extrêmement avides de ses fruits.

L'homme doit être considéré lui-même comme un des grands agents de la dissémination végétale. Indépendamment des efforts qu'il a faits pour naturaliser les espèces utiles dans les contrées où elles ne croissent pas d'elles-mêmes, ses vaisseaux et ses caravanes, en franchissant l'Océan et les déserts, transportent à son insu des semences et des plantes qui envahissent des pays nouveaux.

Le Canada possède aujourd'hui un grand nombre de végétaux originaires de l'Ancien-Monde, et sa flore s'enrichit chaque année d'espèces nouvelles. Réciproquement, certaines plantes originaires du Canada peuplent maintenant des régions entières de l'Europe. La Vergerolle du Canada (Erigeron Canadense), qui infeste tout le nord de la France, y a été apportée, dit-on, au dix-septième siècle, dans une caisse d'emballage.

91. Germination.-La germination est le développement de l'embryon contenu dans les graines; elle ne peut s'accomplir que par le concours de circonstances dépendant de la graine elle-même et des influences extérieures.

C'est au moment où le fruit se détache spontanément de la plante, que les graines possèdent toute leur puissance de germination : semées plus tôt ou beaucoup plus tard, elles demeureraient stériles. L'espace de temps pendant lequel elles conservent la propriété de germer varie selon les espèces. Il est d'un grand nombre d'années pour le Blé et pour la plupart des Légumineuses, et de quelques jours seulement pour l'Orme et le Café.

La chaleur, l'humidité et l'air sont les agents extérieurs qui déterminent le développement des germes.

Il est reconnu que toute semence reste inactive au-dessous de 0 o et audessus de 50o centigrades. La température la plus favorable est celle qui tient le milieu entre ces extrêmes. L'humidité est nécessaire pour ramollir les tissus et pour dissoudre les substances alimentaires de la graine, qui ne peuvent être absorbées, comme nous le savons, qu'à l'état liquide. L'oxygène de l'air attaque les enveloppes des fruits indéhiscents, les décompose et met ainsi les graines en liberté; il agit sur l'amidon de la graine elle-mème pour le transformer en matières sucrées, assimilables.

La graine, une fois déposée à une faible profondeur dans la terre, et soumise à la triple influence dont nous venons de parler, subit une décomposition rapide: ses téguments se déchirent pour livrer passage à l'embryon; son albumen se transforme en une émulsion sucrée, analogue au lait, pour le nourrir ; et, circonstance qui dénote l'œuvre d'une Providence infiniment sage, la réserve de nourriture accumulée autour de la jeune plante dure exactement le temps qu'il faut à celle-ci pour produire des racines et les premières feuilles, en un mot pour pouvoir se suffire à elle-même. 
30 REPRODUCTION PAR LES SPORES.

92. Les plantes acotylédones, comme nous l'avons fait observer au commencement du traité, ne produisent point de fleurs proprement dites, ni rien qui ressemble à des graines. Leurs semences sont des corps arrondis, analogues aux bulbiles, mais infiniment plus petits : on leur a donné le nom de spores (fig. 170).

On s'est assuré que les spores des Fougères, une fois tombés dans une terre convenable, se développent et donnent naissance à un petit végétal, de durée tout-à-fait transitoire, qu'on a appelé le prothallium. Sur ce prothallium 'apparaissent deux sortes d'organes: les antheridies et les archégones. Les premiers sont analogues aux anthères et les seconds aux ovaires des plantes cotylédonées.

Des anthéridies on voit s'échapper des petits filaments animés de mouvements rapides qui pourraient les faire prendre pour des animalcules microscopiques et que, pour cette raison, on a appelés anthérozoüdes; ces filaments finissent par se fixer sur d'autres corpuscules renfermés dans les archégones et la fécondation est alors opérée. Après cette série d'actes le prothallium se flétrit et disparaît, tandis que les archégones fécondés prennent de l'accroissement et produisent une nouvelle Fougère.

Des phénomènes analogues ont été observés sur les Prêles et quelques autres acotylédones; mais on ignore complètement comment s'opère la fécondation de la plupart des plantes de cette classe, ou si même elle existe.

\section{CHAPITRE III.}

TENDANCES ET MOUVEMENTS.

93. La tendance que montrent divers organes à se porter dans une direction déterminée, les mouvements que d'autres exécutent en obéissant à l'excitation d'agents extérieurs, sont des phénomènes du plus haut intérêt, dont l'étude appartient à la physiologie.

94. Direction de l'axe végétal.-La généralité des tiges tend à monter verticalement vers le ciel, tandis que la racine se dirige vers le centre de la terre. Toutes les tentatives qu'on a faites pour modifier ces tendances ont échoué; des plantes qu'on avait mises dans une position renversée se sont repliées sur elles-mêmes et ont repris leur direction première.

Certains agents peuvent cependant faire dévier notablement ces organes de la ligne verticale.

- La tige est particulièrement sensible à l'action de la lumière. On est surpris dans une foule de cas, spécialement pour les plantes cultivées dans une chambre, de la promptitude avec laquelle les rameaux en voie de développement s'inclinent vers l'ouverture par où le jour arrive. M. Grimard cite, dans son livre sur la botanique, l'histoire d'une Clandestine écailleuse qui, ayant germé au fond d'une mine, s'est élevée à la prodigieuse hauteur de cent vingt pieds pour se porter vers la lumière, elle qui, dans les conditions normales, n'a jamais que cinq ou six pouces d'élévation! 
Si la lumière exerce une sorte d'attraction sur les organes destinés à vivre dans l'atmosphère, elle reste sans action sur la racine qui, dans l'im. mense majorité des cas, a été créée pour rester dans le sol, soustraite à son influence, ou bien elle produit sur cet organe un effet de répulsion sensible. On a cependant constaté, dans ces dernières années, qu'un petit nombre de racines se portent vers la lumière à la manière des tiges.

L'humidité, la richesse du sol, son ameublissement plus ou moins parfait influent notablement sur la direction des racines et sur leur développement. "Qui n'a vu, dit Figuier, des racines d'arbres ou d'arbrisseaux, gênées, empêchées dans leur marche, développer une force mécanique considérable, renverser des murs ou fendre des rochers; dans d'autres circonstances se réunir en touffes, ou bien étaler leurs ramuscules sur une longueur prodigieuse, pour suivre le trajet d'un ruisseau aux eaux bienfaisantes? Qui n'a vu avec admiration les racines s'accommoder aux dispositions spéciales du sol : dans un sol convenable, diviser à l'infini leur chevelu; ailleurs, abandonner un sol stérile pour aller chercher plus loin une terre propice, et varier leurs formes, selon que la terre est plus ou moins dure, selon qu'elle est humide ou sèche, forte ou légère, sablonneuse ou pierreuse? On ne peut s'empêcher de reconnaître qu'il y a dans cette élection faite par les racines la manifestation d'un véritable instinct vital."

95. Mouvements des feuilles-Sommeil des plantes.-Les feuilles d'un grand nombre de plantes sont susceptibles d'exécuter des changements de position tantôt lents et insensibles, tantôt assez rapides pour que l'œil puisse les suivre. Ces derniers sont déterminés le plus souvent par une excitation momentanée. C'est ainsi que la Sensitive (fig. 159), et quelques autres espèces irritables comme elle, relèvent brusquement leurs folioles sous l'action d'un choc, d'une brûlure, d'une goutte d'un liquide caustique; que la Dionée attrape-mouche (fig. 65) rapproche rapidement l'une de l'autre les deux moitiés du limbe de sa feuille, lorsqu'un insecte, en se posant à sa surface, la chatouille avec ses pattes. Plus rarement la cause de ces mouvements nous échappe, comme, par exemple, pour le Sainfoin oscillant du Bengale: les feuilles de cette plante sont composées de trois folioles, l'une terminale très-grande et les deux autres latérales beaucoup plus petites: ces dernières exécutent continuellement, la nuit comme le jour, des mouvements saccadés analogues à ceux de l'aiguille d'une montre à secondes.

Quant aux mouvements assez lents pour n'être observés qu'à l'aide d'une comparaison attentive et continue, les plus remarquables sont certainement ceux qui donnent à la plupart des feuilles, pendant la nuit, une position différente de celle qu'on leur voit pendant le jour. Linné les a désignés poétiquement sous le nom de sommeil des plantes, qui indiquerait avec le sommeil des animaux une analogie non justifiée par les faits.

La plupart des plantes sommeillantes ont un sommeil diurne ou une sorte de sieste, amenée par l'action directe du soleil, pendant les heures les plus chaudes de la journée. Alors leurs folioles se relèvent pour se rapprocher par paires, au point que parfois elles arrivent à se mettre en contact par la face supérieure. Ce mouvement est quelquefois inverse de celui qui con. stitue le sommeil nocturne, mais le plus souvent il reproduit ce dernier, à l'intensité près (Sensitive, fig. 159).

C'est toujours sur des plantes dicotylédones qu'on a signalé les mouve. ments qualifiés de sommeil ; les plantes monocotylédones ne paraissent pas 
généralement pouvoir offrir rien de semblable, leurs feuilles étant presque toujours simples et attachées à la tige par une large base qui rend difticile tout changement de position.

96. Mouvements des fleurs-Horloge de Flore.-Les enveloppes florales offrent des mouvements analogues à ceux des feuilles, et produits, la plupart du temps, par des variations de lumière, de chaleur ou d'humidité. C"est l'état d'ouverture ou d'épanouissement qui constitue leur réveil; c'est, au contraire, la fermeture ou l'occlusion qui caractérise leur sommeil. Linné a eu l'ingénieuse idée de réunir des plantes qui s'ouvrent aux différentes heures du jour, pour en composer une horloge de Flore. Cette horloge, il faut bien le dire, n'a jamais été d'une grande utilité pratique, car l'heure du réveil des fleurs varie suivant les pays et l'état de l'atmosphère.

Les organes de la fécondation exécutent, chez quelques plantes, des mouvements particuliers au moment où s'opère la déhiscence des anthères. C'est à des phénomènes de cette nature que la Vallisnérie spirale doit toute sa célébrité. La Vallisnérie est une humble plante herbacée dont les feuilles ressemblent à celles des Graminées. Elle abonde dans les eaux tranquilles et peu profondes de nos lacs. Ses fleurs sont monoïques: les fleurs staminées naissent près de la racine en masses compactes portées sur un pédoncule très-court; les fleurs pistillées sont, au contraire, solitaires à l'extrémité d'une hampe filiforme, longue et contournée en spirale. Lorsqu'arrive le temps de la fécondation, les premières rompent leur attache et viennent flotter à la surface des eaux; les secondes déroulent en même temps leur hampe, se portent au milieu des étamines pour recevoir l'influence du pollen, après quoi les spires se resserrent de nouveau et entrainent la fleur qui va mûrir ses fruits au fond de l'eau.

Mentionnons, comme dernier exemple de mouvements des organes floraux, le déplacement de l'Héliotrope et du grand Soleil de nos jardins, dont les fleurs se tournent constamment vers l'astre du jour comme pour en aspirer les rayons.

97. Cause des tendances et des mouvements des plantes.-Les étonnants phénomènes que nous venons d'exposer n'ont pas encore reçu d'explication satisfaisante. "Portés aujourd'hui à ne voir dans les manifestations de la vie que de pures et simples applications des lois de la physique et de la chimie, dit Duchartre, les physiologistes ont, pour la plupart, cherché à les faire dériver d'actions physiques ou mécaniques; mais, il faut bien le reconnaitre, ils ne sont parvenus ainsi qu'à déplacer la difficulté, à remplacer les explications par des mots ; au total, à encombrer la science d'hypo. thèses souvent contradictoires et qui ne résistent point à l'épreuve d'une discussion série'xse." 


\section{TAXONOMIE.}

98. La Taxonomie est la partie de la Botanique qui traite de la classifica. tion méthodique des plantes.

Un livre où se trouveraient décrits sans ordre les végétaux connus, ne saurait être d'aucune utilité. Ce ne serait, en effet, la plupart du temps, qu'au prix d'un travail excessivement long et pénible que l'étudiant finirait par découvrir, au sein de cet immense chaos, la description particulière qui fait l'objet de ses recherches ; on ne pourrait d'ailleurs s'élever, par la lecture d'un tel ouvrage, à aucune vue d'ensemble sur le règne végétal.

Il a donc fallu, de toute nécessité, songer à disposer les plantes dans un ordre rationnel, et à les diviser en un petit nombre de groupes faciles à reconnaître; c'est là ce qu'on appelle faire une classification.

99. Chaque plante considérée isolément, se nomme un individu. Dang un champ de Maïs, par exemple, il y a autant d'individus-plantes qu'il s'élève de tiges de la terre.

En réunissant tous les individus issus d'une même souche, on aura un premier groupe appelé espece. Les membres d'une même espèce se distinguent par leur extrême ressemblance et par la faculté qu'ils possèdent de se reproduire indéfiniment avec les mêmes caractères essentiels.

Les especes sont aussi anciennes que le monde. Nous savons, par l'Ecriture, qu'au troisième jour de la création, Dieu commanda à la terre de se couvrir d'herbes et d'arbres qui eussent en eux-mêmes des semences propres ; ces plantes primitives furent autant d'espèces distinctes dont les types sont parvenus jusqu'à nous sans altération.

Mais, si les caractères essentiels de l'espèce se conservent intacts à travers les âges, il n'en est pas de même des qualités purement accidentelles, que la nature du terrain, le climat et plus encore la culture peuvent faire varier dans des limites assez étendues. C'est un fait bien connu qu'avec les graines d'une même plante, l'horticulteur peut obtenir des produits qui diffèreront par la taille, par la couleur, par l'odeur ou la saveur : il aura créé ce qu'on nomme des variétes. C'est ainsi qu'ont pris naissance les différentes sortes de Raisins, de Pommes, de Cerises, etc., qui figurent sur nos tables ; c'est ainsi encore qu'on a pu donner tant de nuances si diverses à la Tulipe, à la Pensée, à la Reine-Marguerite et à une foule d'autres espèces ornementales.

Il peut arriver qu'une espèce diffère considérablement de toutes les autres; mais, en général, il en existe un nombre plus ou moins grand qui présentent le même aspect général, la même disposition des organes, la même structure de la fleur et du fruit. C'est à ces groupes naturels qu'on a donné le nom de genres.

Le langage vulgaire, dit Figuier, ou plutôt l'observatiou générale, avait créé, avant les études des savants, de véritables noms de genre. Les mots Chêne, Peuplier, Orge, sont des noms collectifs vulgaires, qui ont servi, avant la création des sciences naturelles, à désigner un certain groupe de plantes; ce sont de véritables noms de genres qui ont été créés par le public, et que les botanistes ont acceptés, parce qu'ils étaient fondés sur une observation exacte. 
Ce fut Tournefort, professeur au Jardin des Plantes de Paris, sous Louis XIV, qui, le premier, définit et limita nettement le genre dans les végétaux, et lui donna sa formule, déduite des caractères communs aux espèces qu'il renferme. Les six cent quatre-vingt-dix-huit genres créés par lui sont, pour la plupart, restés dans la science, ce qui montre toute la valeur des caractères qui avaient servi à les établir.

Linné, illustre botaniste de Suède, étendit et periectionna l'œuvre de Tournefort. II réduisit le nom de toute plante à deux mots : le premier substantif, désignant un genre ; le second adjectif, désignant une espèce de ce genre : c'est ainsi qu'on dit ie Chêne rouge, le Chêne vert, le Chêne liège, etc., pour désigner les différentes espèces de plantes appartenant au genre Chêne. Avant Linné, on indiquait les espèces par une phrase plus ou moins longue qui renfermait leurs caractères; mais de graves inconvénients êtaient attachés à cette manière de dénommer les plantes : ces phrases étaient souvent si longues, que la mémoire la plus exercée ne pouvąit les retenir ; elles devenaient incomplètes à mesure que le nombre des végétaux s'accroissait, parce qu'il fallait un plus grand nombre de caractères pour faire reconnaître chaque plante au milieu d'une plus grande quantité d'espèces voisines; enfin, les phrases caractéristiques variaient suivant les auteurs, qui, attachant une plus ou moins grande valeur à certains caractères, les employaient plutôt que ceux dont s'étaient servis leurs prédécesseurs. La nomenclature linnéenne a donc eu les plus heureux résultats sur les progrès de la science.

De même qu'en groupant ensemble les espèces qui ont entre elles une analogie marquée, on en a fait des genres; de même, en réunissant les genres qui se ressemblent beaucoup ou qui sont liés du moins par des caractères communs, on compose des tribus nouvelles appelées ordres ou familles. Les ordres groupés d'après des caractères plus généraux, forment les classes, qui se distribuent à leur tour, suivant le même principe, en séries ou embranchements.

Ainsi, pour classer les végétaux, on divise le règne végétal en embranchements; les embranchements en classes; les classes en

ordres ou familles; les familles en

genres; les genres en

especes, qui ne sont elles-mêmes que des réunions d'individus.

100. Quoique les classifications, en botanique, soient soumises à une marche commune et qu'elles s'accordent en général sur l'établissement des genres et des espèces, elles peuvent différer beaucoup selon les principes suivis dans la formation des groupes supérieurs.

On nomme artificielles ou systematiques celles où les plantes sont groupées d'après un petit nombre de caractères choisis arbitrairement, et sans tenir compte de la ressemblance générale qui peut exister entre les genres qu'on sépare ou des différences qui se remarquent entre ceux qu'on réunit. Ia classification est dite, au contraire, naturelle ou méthodique, lorsqu'elle tient compte des caractères fournis par l'ensemble de l'organisation, de manière à n'admettre dans une même division que les genres qui se rapprochent sensiblement par leur structure et leurs propriétés.

Linné est l'auteur d'une classification artificielle qui a été longtemps suivie dans les écoles; la méthode naturelle, seule admise aujourd'hui, est surtout l'œuvre d'Antoine-Laurent de Jussieu. 
SYSTÈME DE LINNÉ.

Linné a pris pour base de son système les organes essentiels de la fleur c'est à.dire les étamines et le pistil.

Il divise tous les végétaux en deux grandes sections : ceux dont les étamines et les pistils sont visibles, et ceux dans lesquels ces organes sont invisibles ou bien n'existent pas. Ces derniers se nomment cryptogames; ils ne forment qu'une seule classe, la cryptogamie. Les premiers, appelés phanérogames, sont distribués en vingt-trois classes, d'après le nombre et les rapports de position ou de grandeur des étamines. Les treize premières classes comprennent toutes les plantes à fleurs parfaites, dont les étamines sont égales et libres d'adhérence soit entre elles, soit avec le pistil. Ce sont :

La Monandrie, comprenant les plantes dont la fleur ne possède qu'une seule étamine.

La Diandrie, où les étamines sont au nombre de deux.

La Triandrie, où les étamines sont au nombre de trois.

La Tétrandrie, où les étamines sont au nombre de quatre.

La Pentandrie, où les étamines sont au nombre de cinq.

L' Hexandrie, où les étamines sont au nombre de six.

L'Heptandrie, où les étamines sont au nombre de sept.

L'Octandrie, où les étamines sont au nombre de huit.

L'Ennéandrie, où les étamines sont au nombre de neuf

La Décandrie, où les étamines sont au nombre de dix.

La Dodécandrie, où le nombre des étamines varie entre onze et dix-neuf.

L'Icosandrie, où les étamines sont au nombre de vingt ou davantage, et naissent du calice (Etamines périgynes).

La Polyandrie, où les étamines sont au nombre de vingt ou davantage, et naissent du réceptacle ( Etamines hypogynes).

La quatorzième et quinzième classe comprennent les plantes à fleurs parfaites dont les étamines, au nombre de quatre ou six, sont libres d'adhérence entre elles et d'inégale longueur. Ce sont:

La Didynamie, où les étamines sont au nombre de quatre, dont deux grandes et deux petites.

La Tétradynamie, où les étamines sont au nombre de six, dont quatre grandes et deux petites.

Dans les cinq classes suivantes, Linné renferme les plantes à fleurs parfaites dont les étamines adhérent, soit entre elles, soit avec le pistil. Ces classes sont:

La Monadelphie, où les étamines sont soudées, par les filets, en un seul faisceau.

La Diadelphie, où les étamines sont soudées, par les filets, en deux faisceaux.

La Polyadelphie, où les étamines sont soudées, par les tilets, en plus de deux faisceaux.

La Syngénésie, où les étamines sont soudées par les anthères.

La Gynandrie, où les étamines sont soudées en un seul corps avec le pistil.

Les dernières classes sont:

La Monøcie, comprenant les plante à Heurs monoïques.

Ia Dicecie, comprenant les plantes à fleurs dioïques.

La Polygamie, comprenant les plantes à fleurs polygames.

Ce système se trouve résumé dans le tableau suivant: 
TAXONOMIL.

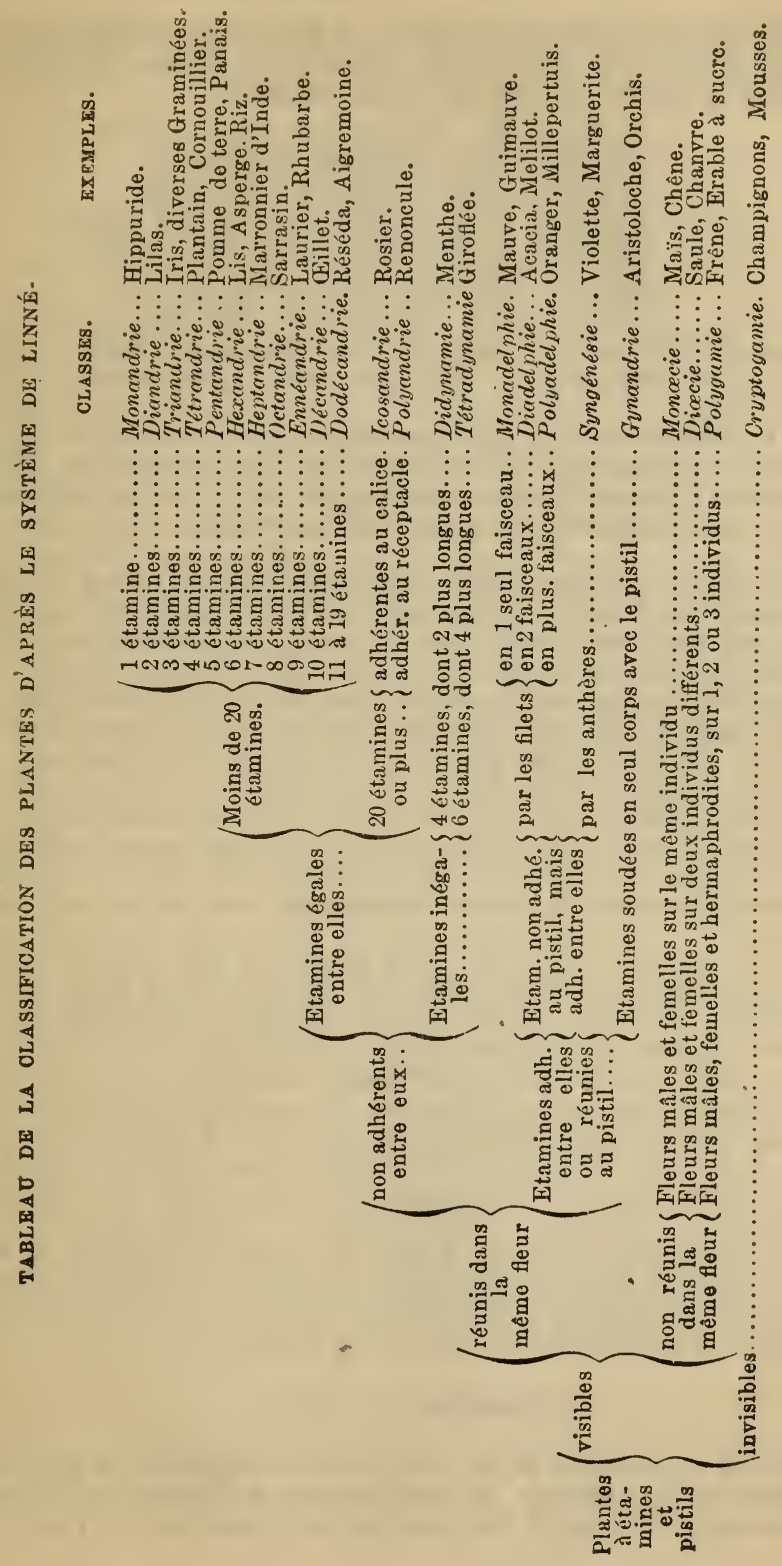


Chaque classe ainsi formée se divise en un certain nombre d'ordres. Dans les treize premiers, les ordres sont basés sur le nombre des styles ou des stygmates, et portent les dénominations suivantes:
Premier ordre.-Monogynie, un seul style.
Deuxieme ordre-Dygrinie, deux styles.
Troisieme ordre.-TRIGXNIE, trois styles.
Quatrieme ordre.-TÉTRAGXNIE, quatre styles.
Cinquieme ordre.-PENTAG YNIE, cinq styles.
Sixieme ordre.-HEXaGYNIE, six styles.
Septieme ordre.-Heptag ynie, sept styles.

Ainsi on dira Icosandrie monogynie, icosandrie pentagynie,... . icosandrie polygynie, pour distinguer les différents ordres appartenant à la douzième classe.

Dans la didynamie et la tétradynamie, ce n'est plus sur le nombre des styles, mais sur la nature du fruit que Linné fonde ses ordres. Enfin, dans les classes suivantes il tire les caractères de ces divisions secondaires, soit du nombre absolu des étamines, soit de leurs rapports entre elles ou avec le pistil.

Le système de Linné est d'une admirable simplicité ; dans la plupart des cas, il conduit au nom d'une plante inconnue presque aussi facilement que s'il s'agissait de la recherche d'un mot dans un dictionnaire : c'est là son grand avantage et ce qui a fait sa célébrité. Mais il a aussi de graves inconvénients, celui, en particulier, de rompre les affinités naturelles des végétaux, de réunir dans le même groupe des espèces qui n'ont aucune analogie essentielle. Le Jonc prend place à côté de l'Epine-Vinette parce que ces plantes ont chacune six étamines et un seul style. La Vigne, se range à côté de la Pervenche, parce que ces deux plantes ont cinq étamines et un style; la Carotte s'associe au Groseiller, etc. Or, il n'y a, entre les plantes ainsi rapprochées, que des traits de ressemblance isolés dans l'organisation et qui peuvent également se trouver réunis dans une foule de plantes très. différentes.

Linné, dit Figuier, était doué d'un jugement trop sain, d'un tact trop exquis, pour ne pas sentir lui-même les défauts de ce mode artificiel de classification. Il devina, par la force de son génie, l'existence de groupes végétaux supérieurs aux genres, et liés entre eux par un grand ensemble de rapports. Il appela ces groupes ordres naturels; c'est ce qu'on appela après lui familles naturelles. Bien plus, il essaya de distribuer les plantes l'après une classification naturelle, c'est-à-dire en véritables familles.

Après la mort et pendant la vie de Linné, bien des botanistes se sont efforcés de découvrir sur quel principe il avait fondé ses ordres naturels, mais personne n'y a réussi. Linné lui-même ne paraît pas avoir eu à cet igard des vues bien arrêtées. Il créa ses ordres par une sorte d'instinct supérieur propre à Y̌homme de génie, par cette demi-divination que finit par acquérir tout naturaliste, tout savant qui possède une connaissance vaste et approfondie des êtres qu'il passe sa vi à observer.

\section{MÉTHODE NATURELLE.}

Bernard de Jussieu a jeté les premiers fondements de la méthode naturelle, mais c'est à son neveu, Antoine-Laurent de Jussieu, qu'appartient la gloire d'en avoir développé les principes et d'en avoir fait l'application à 
l'ensemble du règne végétal. Le livre intitulé Genera plantarum, qu'il publia vers 1789 et dans lequel il expose le résultat de ses recherches, peut être considéré comme le plus beau monument que l'esprit humain ait élevé à la science des végétaux.

C'est par l'étude d'un petit nombre de groupes considérés par tous les botanistes comme formant de véritables familles naturelles, que de Jussieu découvrit les principes qui devaient le guider dans le classement des genres auxquels la nature n'a pas nettement imprimé ce cachet de famille. Il choisit, nous dit son fils, Adrien de Jussieu, sept familles universellement admises : celles qu'on connaît sous les noms de Graminées, Liliacées, Labiées, Composées, Ombellifểres, Crucifères et Légumineuses. Il reconnut que l'embryon est identique dans toutes les plantes d'une de ces familles ; qu'il est monocotylédoné dans les Graminées et les Liliacées, dicotylédoné dans les cinq autres; que la structure de la graine est identique aussi : l'embryon monocotylédoné placé au centre d'un albumen charnu chez les Liliacées, sur le côté d'un albumen farineux chez les Graminées ; l'embryon dicotylédoné au sommet d'un albumen dur et corné chez les Ombellifères, dépourvu d'albumen chez les trois autres; que les étamines qui peuvent varier par leur nombre dans une même famille, les Graminées par exemple, ne varient pas en général par leur mode d'insertion, hypogyne dans les Graminées, dans les Crucifères; sur la corolle dans les Labiées et les Composées; sur un disque épigyne dans les Ombellifères. Il obtenait ainsi la valeur de certains caractères qui ne devaient pas varier dans une même famille naturelle. Mais au-dessous de ceux-là s'en trouvaient d'autres plus variables qu'il chercha à apprécier de même, soit par l'étude d'autres familles indiquées par la nature même, soit dans celles qu'il formait en appliquant ces premières règles et plusieurs autres fondées sur l'observation. Nous ne pourrions le suivre ici dans les détails de ce long travail duquel résulte l'établissement de cent familles comprenant tous les végétaux alors connus; mais on voit partout l'application d'un même principe : la subordination des caracteres, qui dans la méthode de de Jussieu sont pesés et non comptés, suivant l'expression de l'auteur lui-même.

Lorsque les familles furent constituées, de Jussieu les groupa en quinze classes qu'il réunit, à leur tour, dans trois grands embranchements : les acotylédones, les monocotylédones et les dicotylédones.

Les acotylédones (fig. 160-170) ne forment qu'une seule classe.

Les monocotylédones (fig. 171-175) renferment trois classes différenciées par le mode d'insertion des étamines qui est hypogyne dans la première, périgyne dans la seconde et épigyne dans la troisième.

Les dicotylédones (fig. 176-178) sont divisées en monoclines, comprenant les plantes à fleurs parfaites et à fleurs monoïques, et en diclines ou à fleurs diö̈ques. Les monoclines sont polypétales, monopétales ou apétales, et chacun de ces groupes comprend différentes classes qui se distinguent par le mode d'insertion des étamines, comme chez les monocotylédones, ou par le rapport des étamines entre elles.

Le tableau suivant résume la distribution des végétaux en quinze classes.

On trouvera la description des familles dans la FLORE DU CANADA qui fait suite à ce traité élémentaire. 


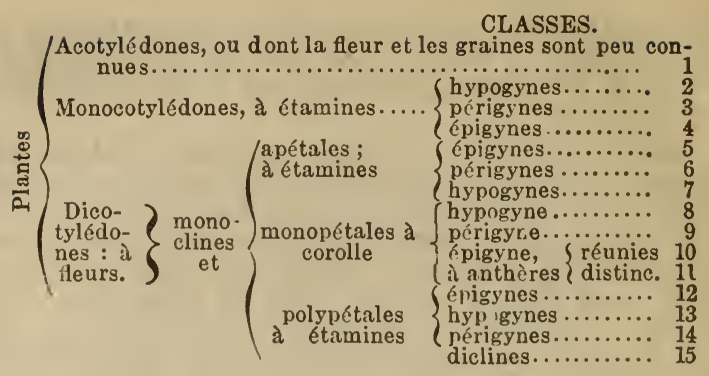

Depuis la publication du Genera plantarum, des modifications importantes ont été introduites dans la classification naturelle. Les travaux de Richard sur le fruit, ceux de de Candolle sur les soudures et les avortements des organes floraux, de Dunal sur leur multiplication; les observations si précises de R. Brown sur la préfloraison et l'organisation de l'ovaire; la comparaison, avec les végétaux anciennement connus, d'une multitude d'espèces nouvelles rapportées du fond des solitudes par de hardis explorateurs, ont mis en lumière des affinités qu'on n'avait point encore soupçonnées, ont fourni d'autres éléments pour perfectionner la délimitation des familles dont le nombre est maintenant porté à trois cents; mais il est remarquable que tous les changements que l'on a faits à l'œuvre de Laurent de Jussieu ne portent que sur des points secondaires et laissent parfaitement inticts les grands principes qui lui avaient servi de base. 


\section{TABLE DES MATIÈRES}

\section{DU \\ TRAITÉ ÉLÉMENTAIRE.}

A mes élèves...u. PaGk

ORGANOGRAPHIE VEGETALE....................................... 7

Organes élémentaires..................................................... 8

Cellules ........................................................................... 8

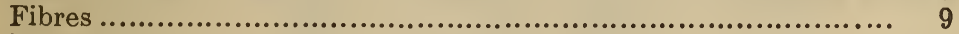

Vaisseaux ......................................................................... 9

Plantes cellulaires et vasculaires..................................... 10

ORGANES COMPOSÉS................................................... 10

Plantes dicotylédones, monocotylédones et acotylédones ......... 11

Plantes phanérogames et cryptogames............................... 11

ORGANES DE NUTRITION :

Racine.................................................................... 12

Tige............................................................................... 13

Feuilles..................................................................... 19

ORGANES DE REPRODUCTION:

10 FLEUR.................................................................. 26

Calice ....................................................................... 26

Corolle .................................................................... 27

Etamines .................................................................. 28

Pistil ................................................................. 29

Verticilles floraux considérés dans leurs rapports..................... 31

Inflorescence ............................................................ 33

20 FrUtT .................................................................. 34

Nature et formes du péricarpe............................................ 35

Graine..................................................................... 36

Classification des fruits................................................. 38

PHYSIOLOGLE VÉGÉTALE.......................................... 40

NUtrition ................................................................... 40

Aliments des végétaux................................................... 40

Absorption........................................................................ 41

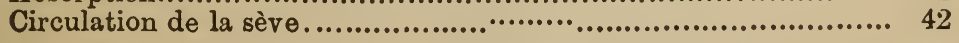


TABLE DES MATIÈRES DU TRAITE் ÉLE்MENTAIRE.

Transpiration et respiration.

.

Arinciation. Secretions.................................................... 45

Principes végétaux.................................................. 45

Excrétions ........................................................ 47

Nutrition comparée des animaux et des plantes...................... 47

REPRODUCTION......................................................... 48

Reproduction par bourgeons........................................ 49

Marcotte, Bouture, Greffe................................................ 49

Reproduction par graines............................................... 50

Fécondation........................................................... 51

Dissémination des graines................................................. 51

Germination......................................................... 52

Reproduction par les spores chez les Cryptogames...................... 53

Tendances et mouvements dans les plantes............................ 53

TAXONOMIE.......................................................... 56

Système de Linné....................................................... 58

Méthode naturelle..................................................... 60

\section{TABLE DES GRAVURES.}

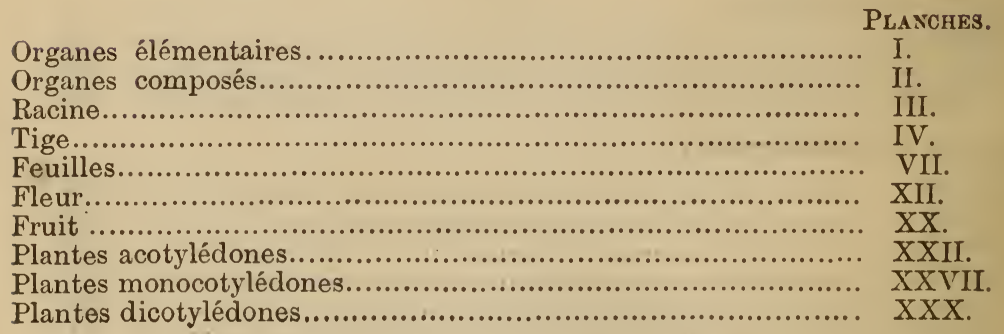


PLANCHE I.

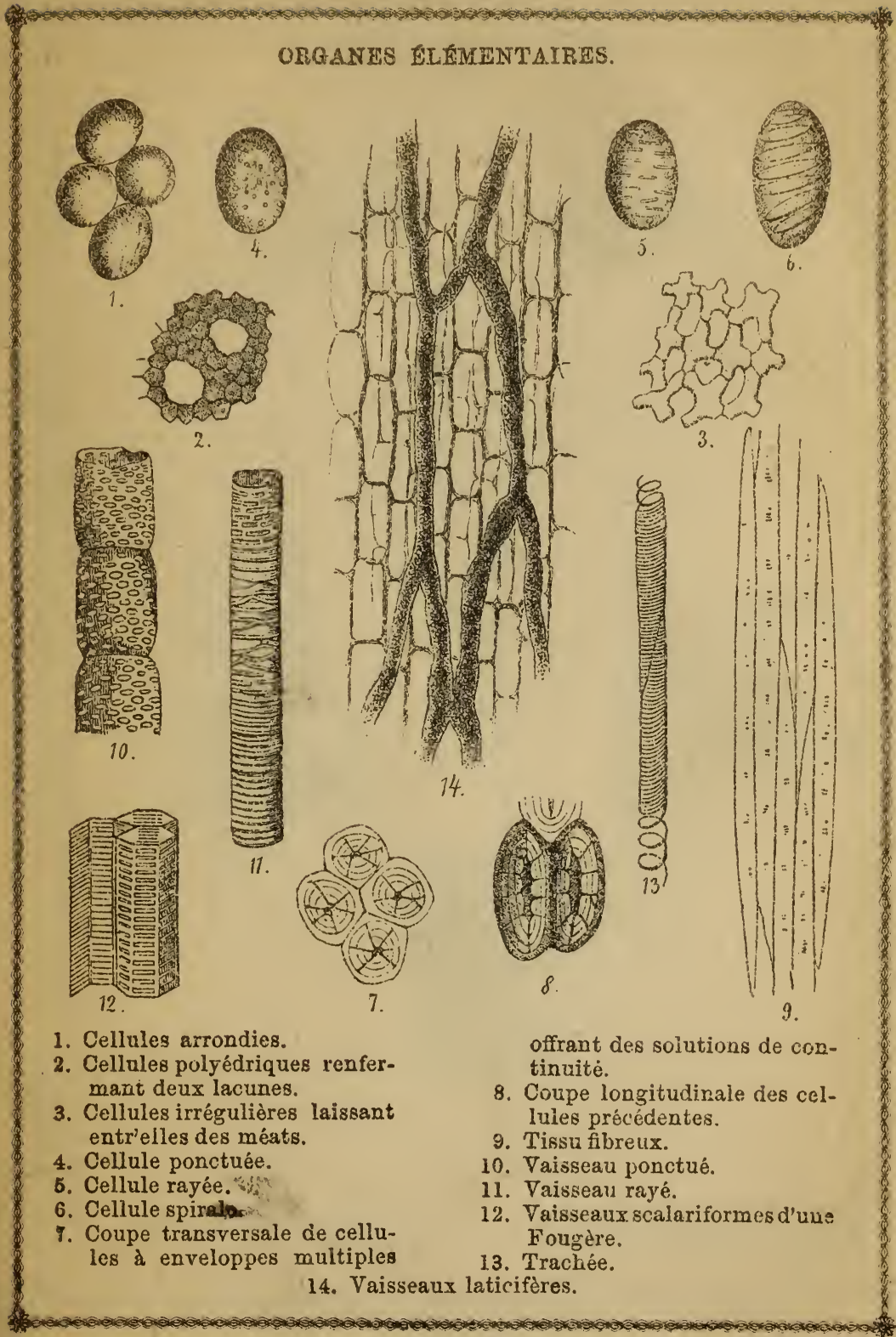


PLANCHE II.

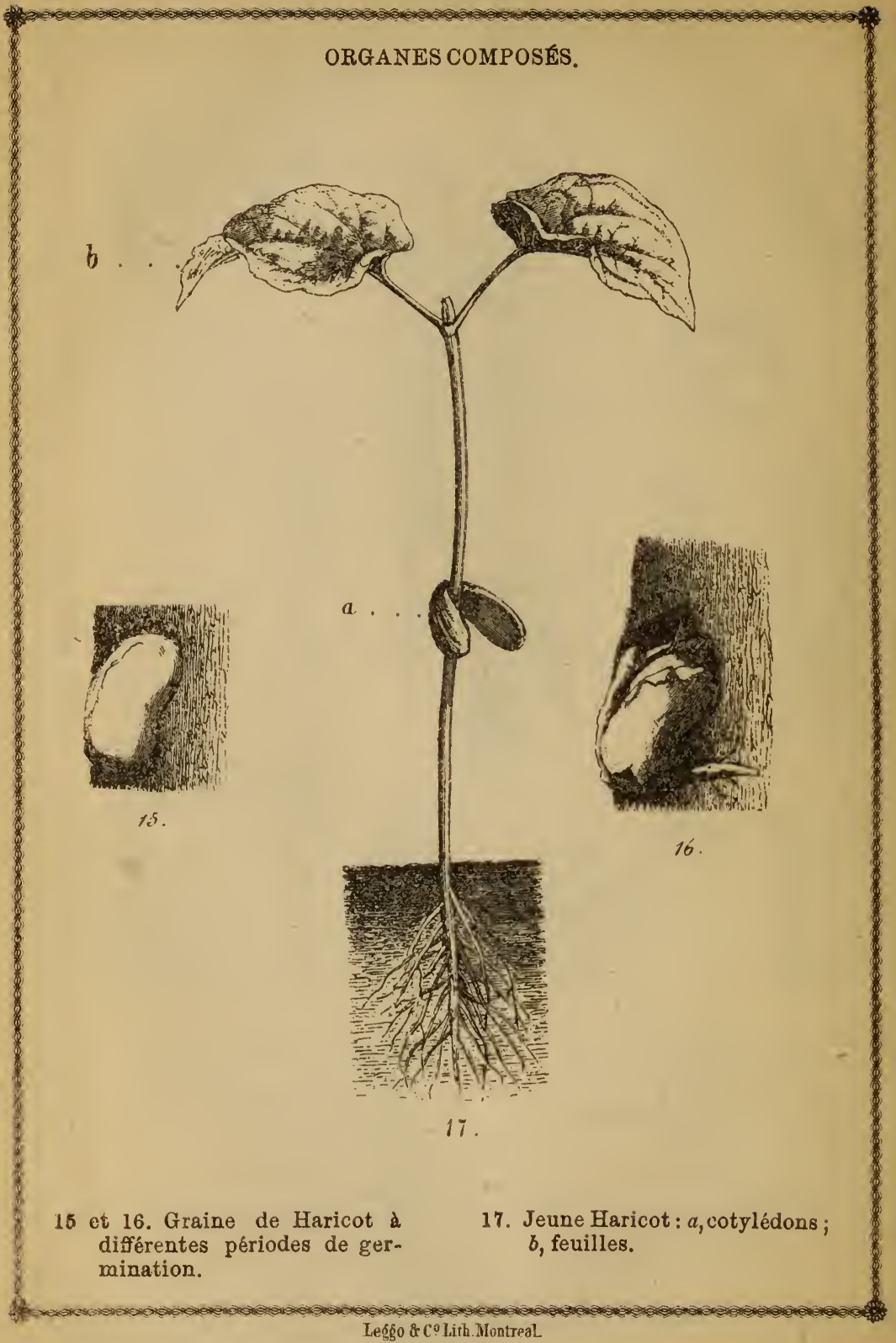


PLANCHE III.

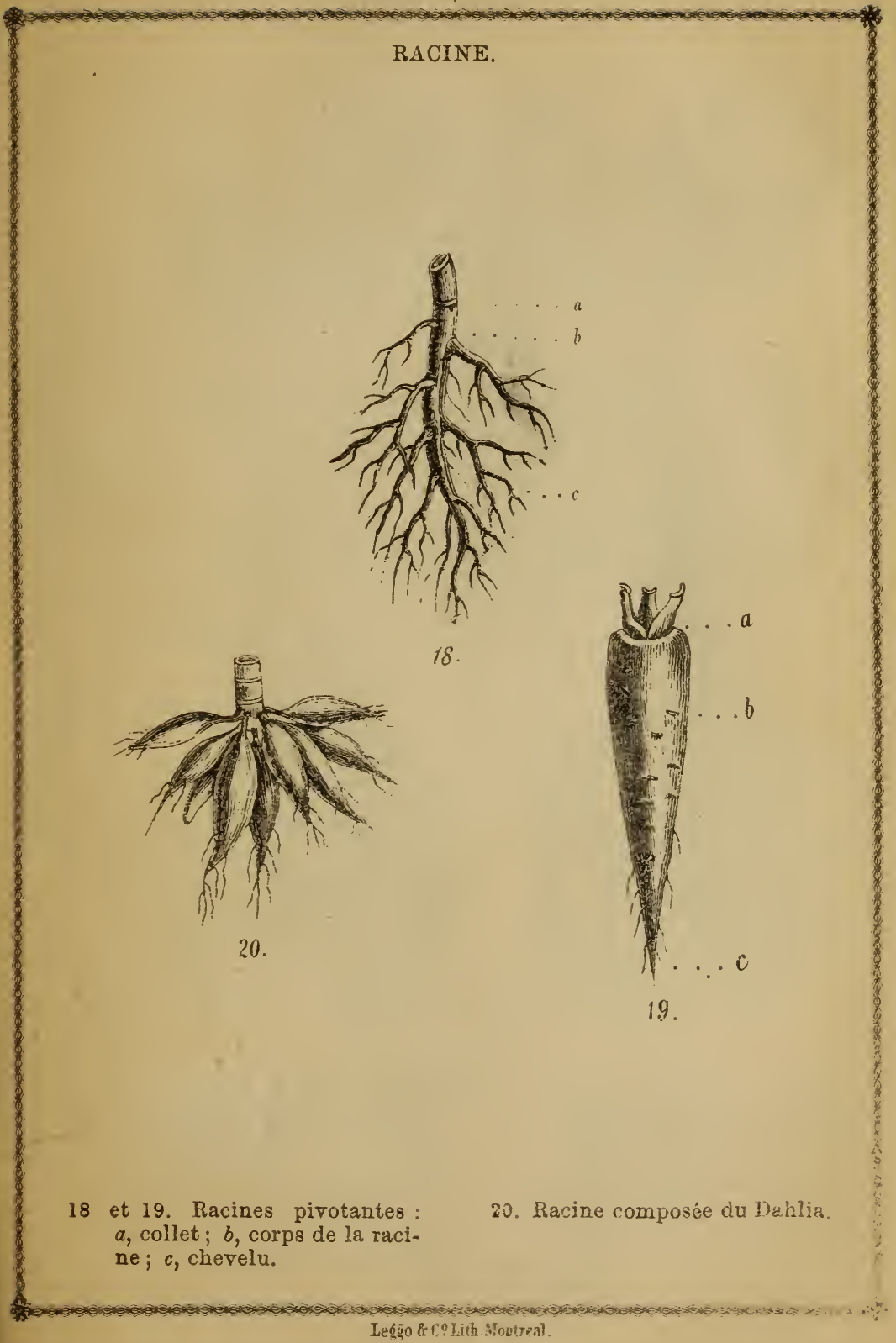


PLANCHE IV.

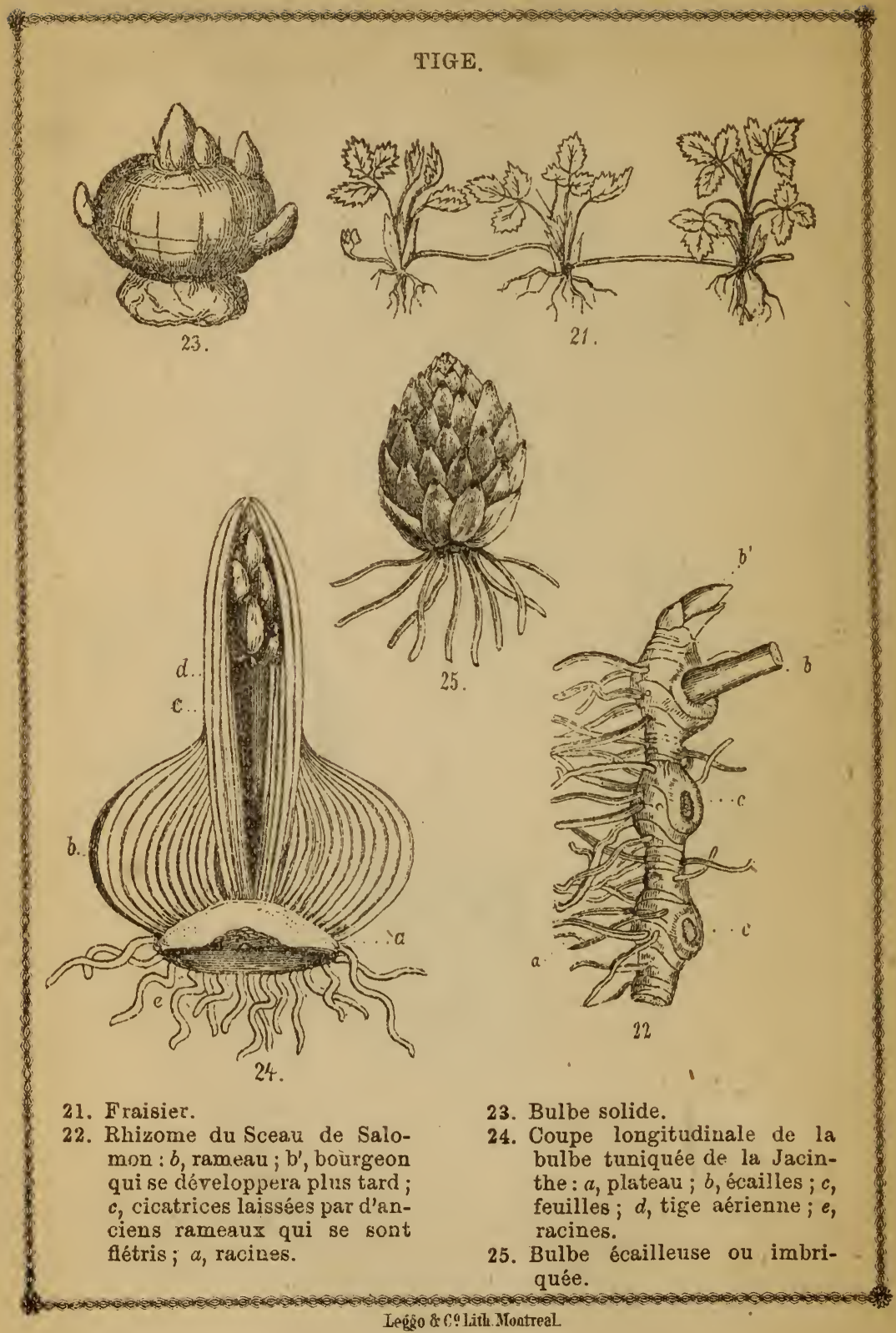


PIANCHE V.

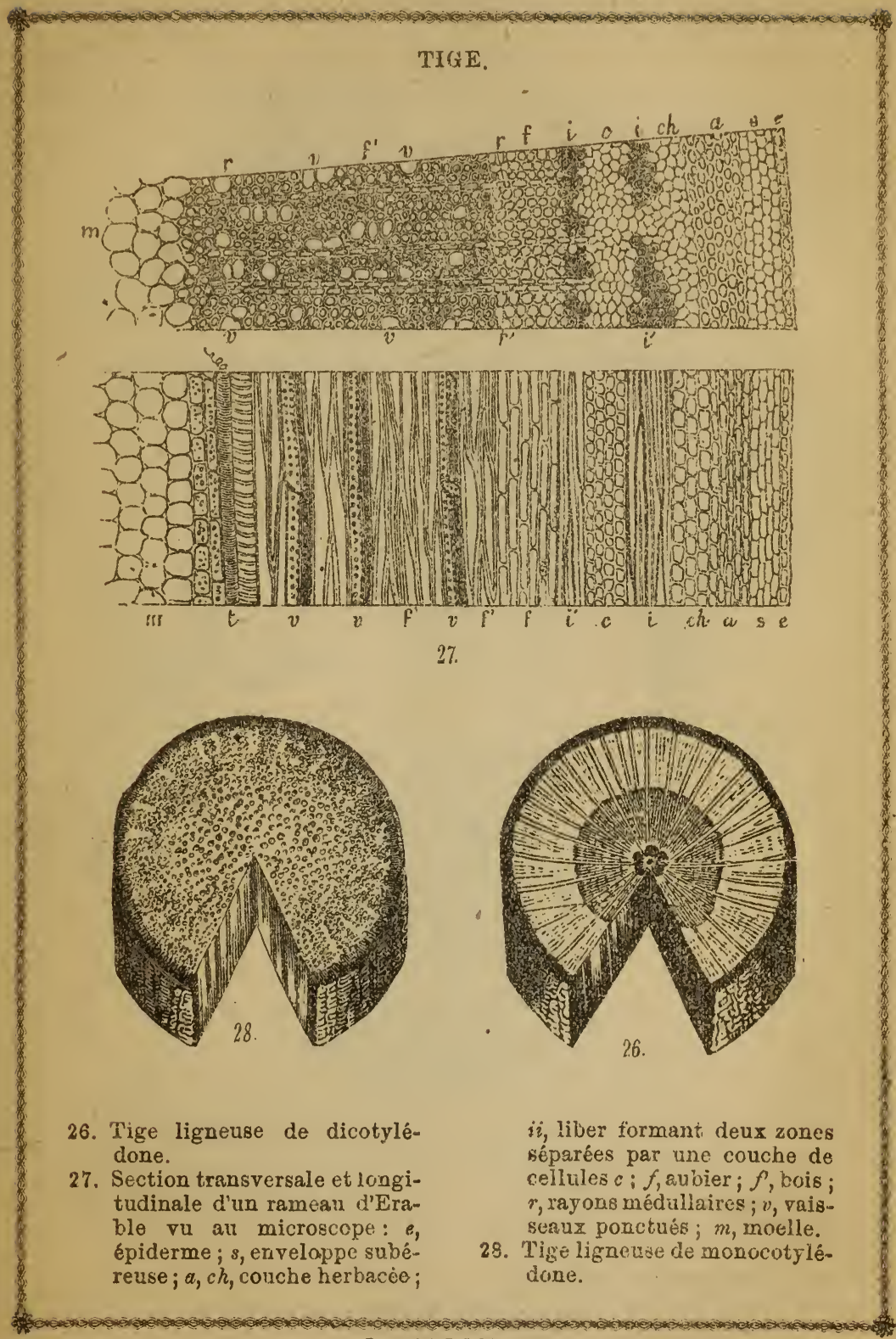


PLANCHE VI.

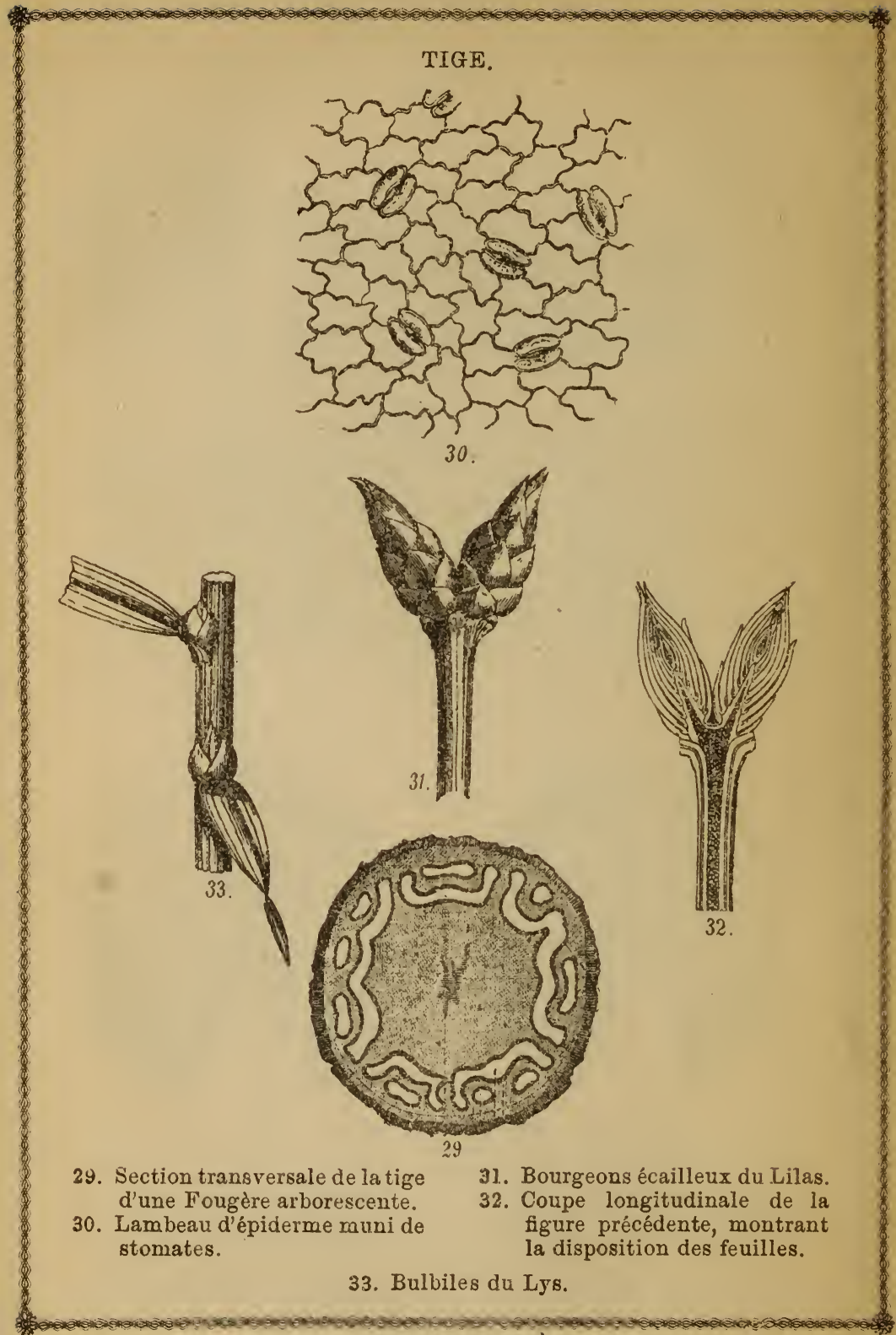


PLANCHE VII.

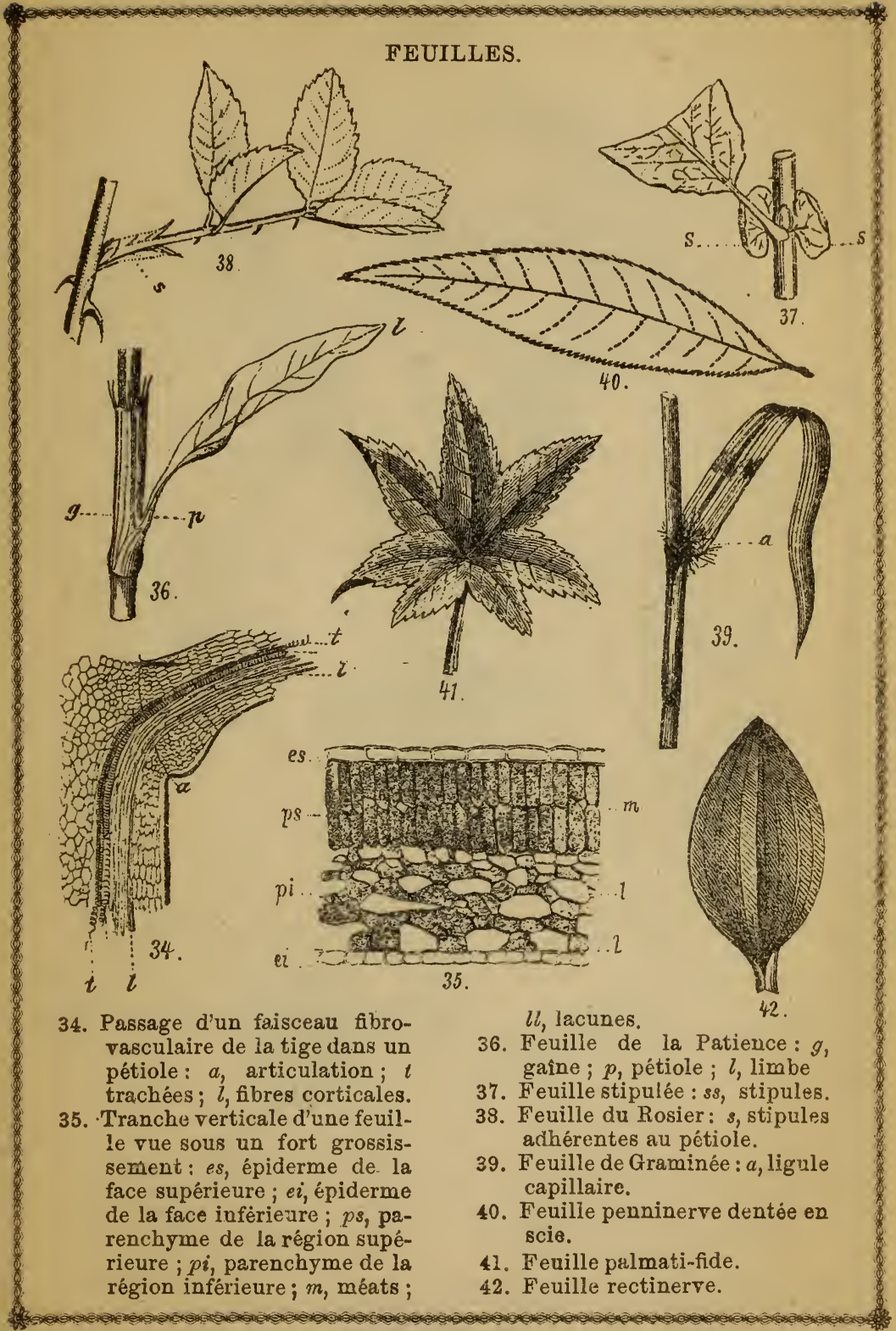

Leĥgo \& C? Lith Montreal 


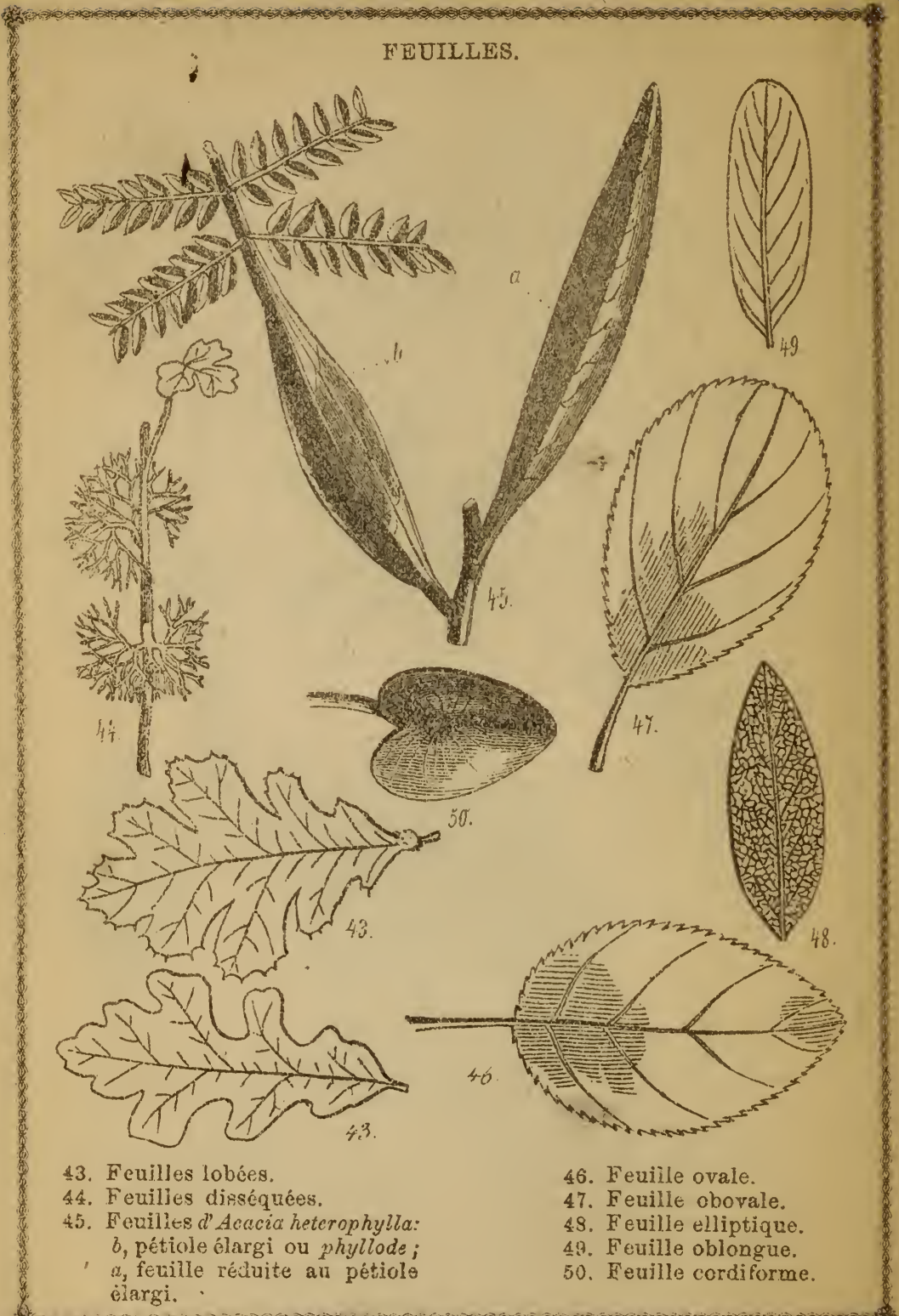




\section{PLANCHE IX.}

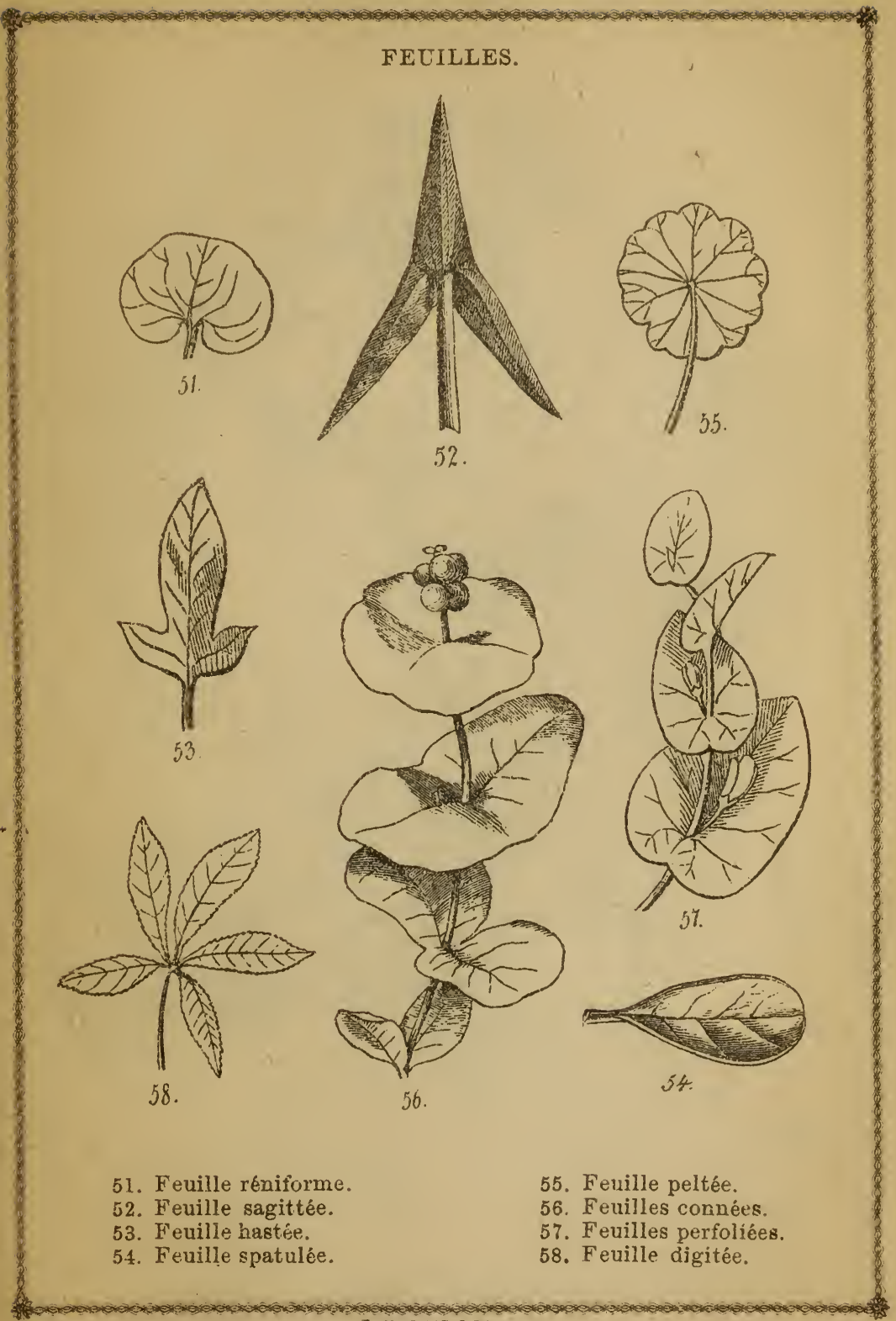


PLANCHE $\mathrm{X}$.

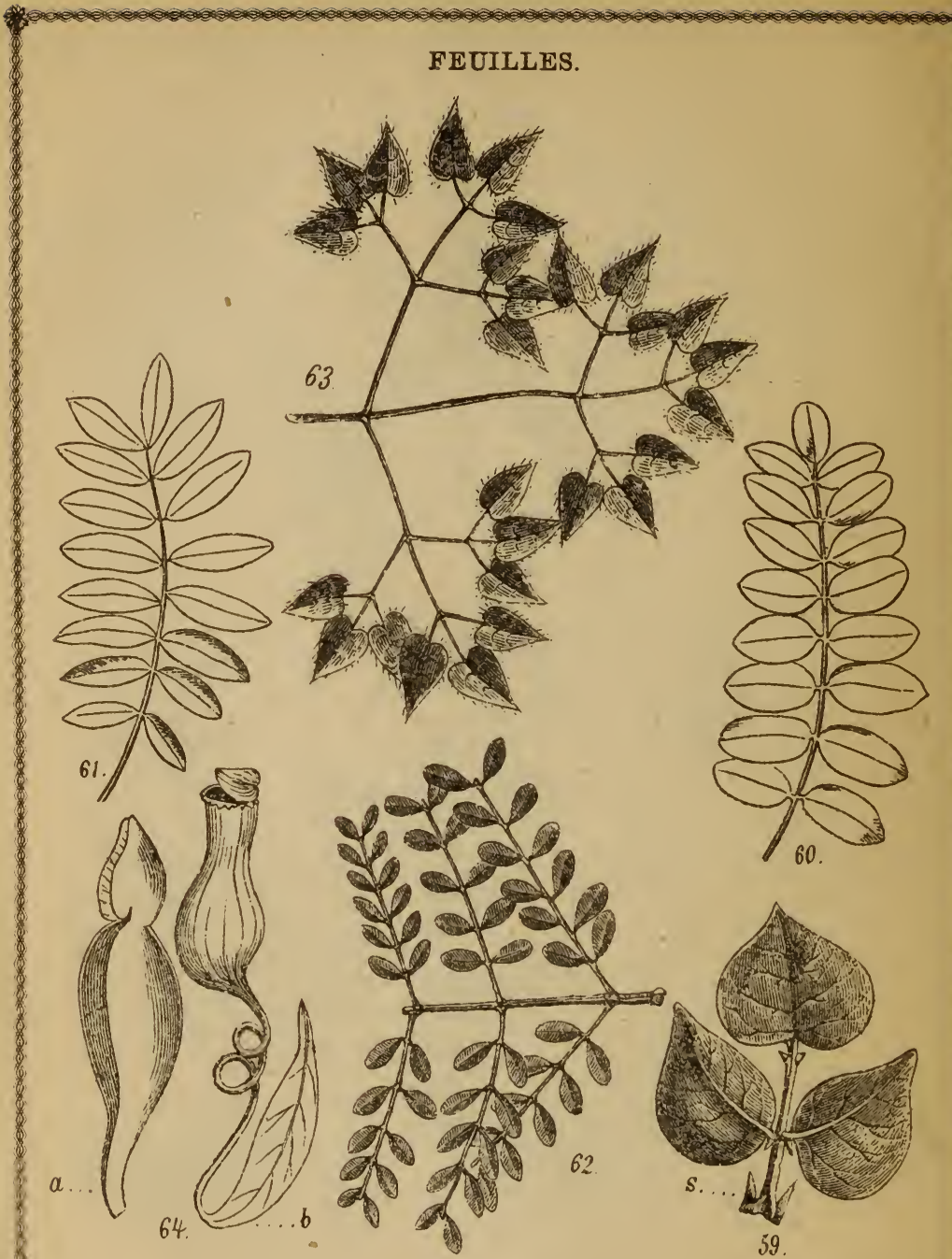

59. Feuille pennée, munie do stipules $s$.

60. Feuille impari-pennée.

61. Feuille pari-pennée.

62. Feuille décomposée, bi-pennée.
63. Feuille surdécomposée, triternée.

64. Feuilles anomales: $a$, feuilles de Sarracenia ; $b$, feuilles de Nepenthes distillatoria. 
PLANCHE XI.

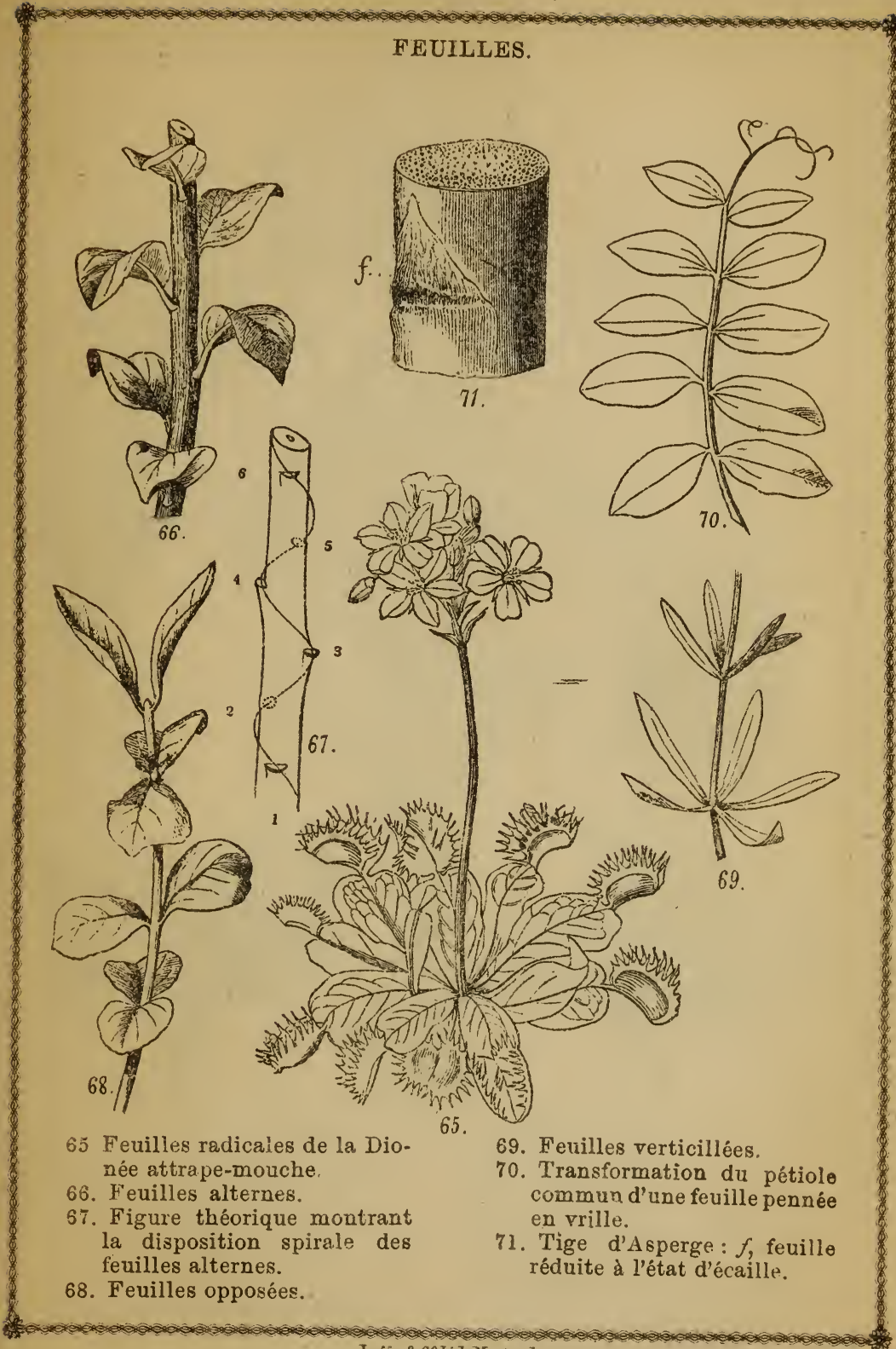


PLANCHE XII.

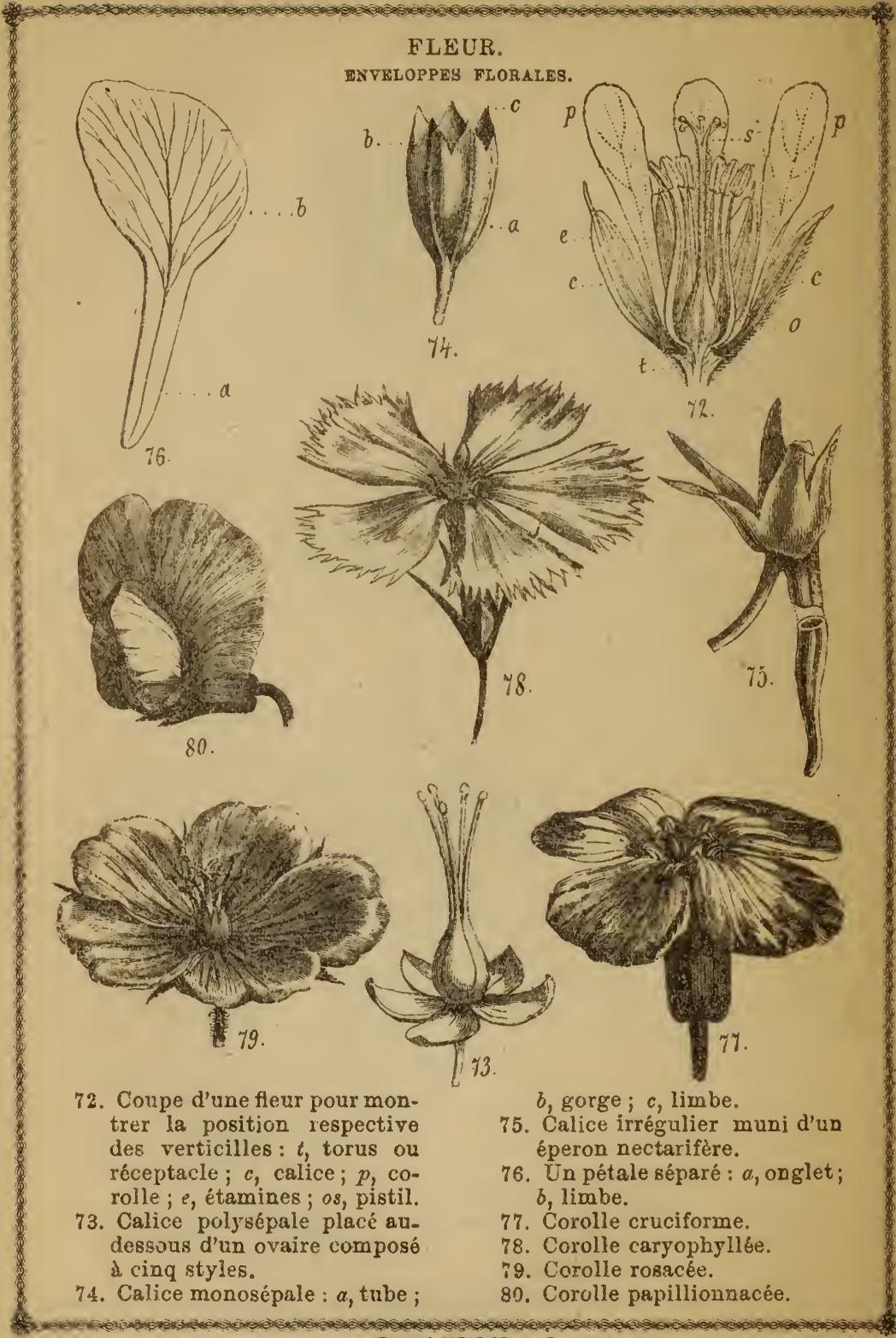


PLANCHE XIII.

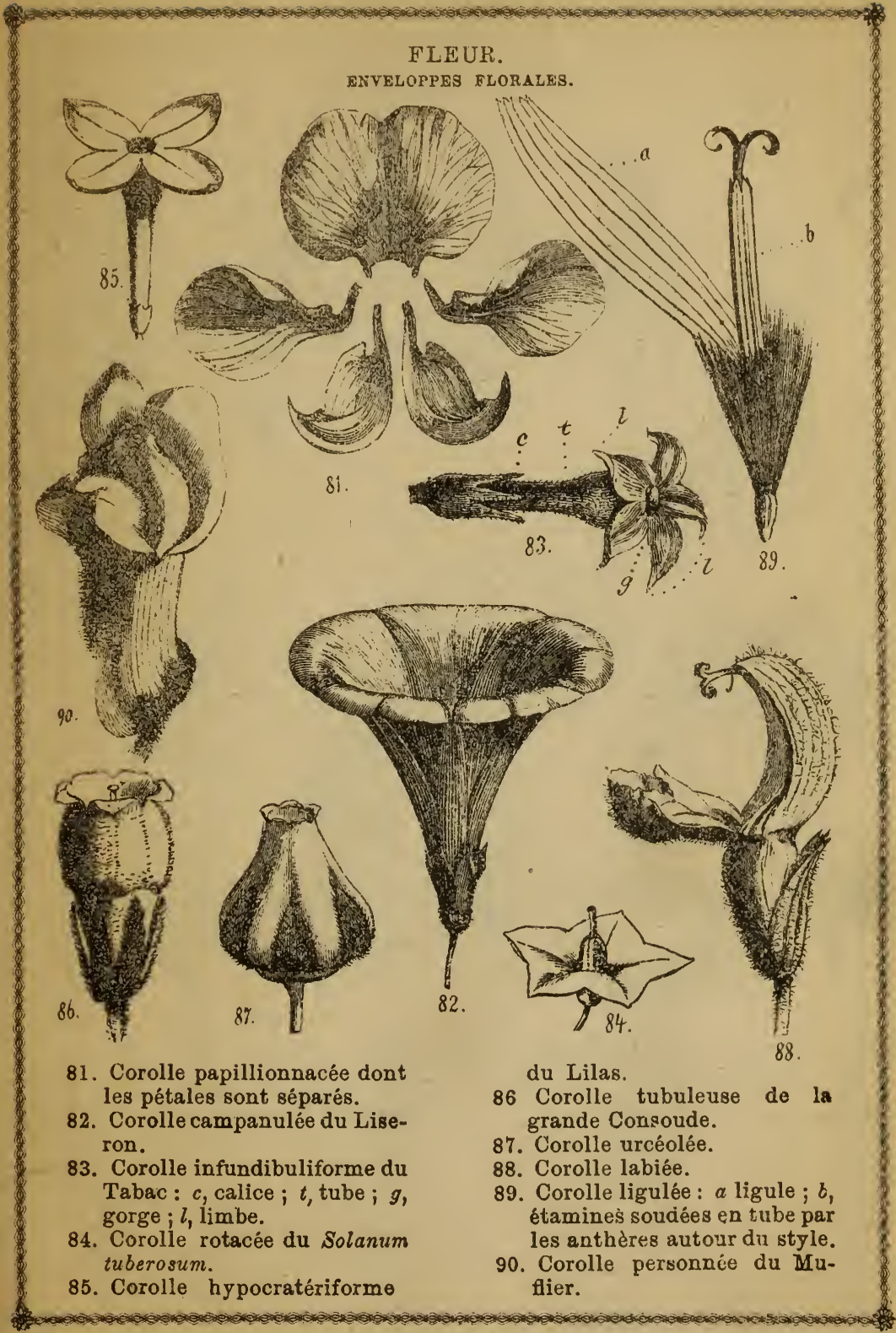

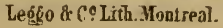




\section{PLANCHE XIV.}

\section{FLEUR.}

ORGANES DE LA FŔCONDATION.

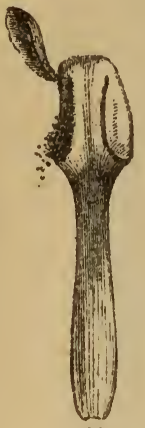

93.
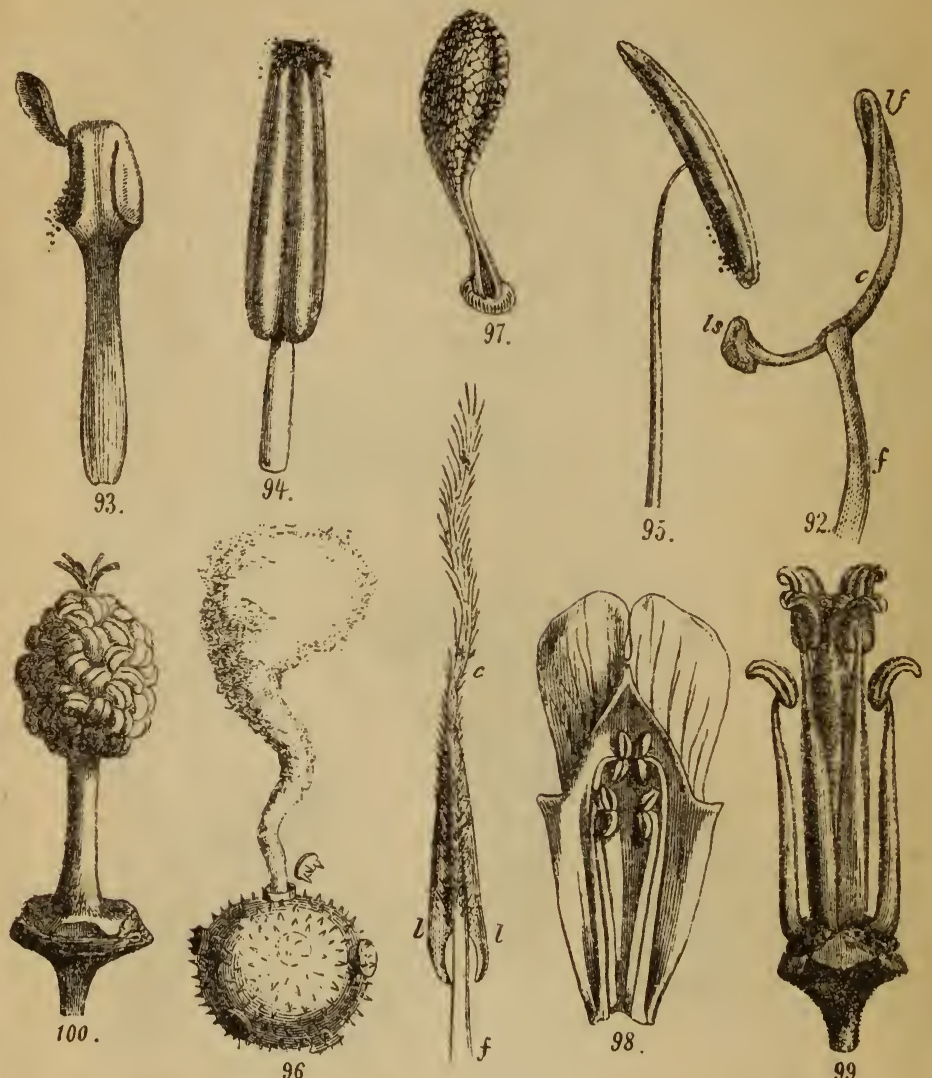

91. Etamine : $f$, filet; $i$, loges de l'anthère ; $c$, connectif plumeux.

92. Etamine a deux loges, l'une stérile $l s$, l'autre fertile $l f$, réunies par un long connectif $c$.

93. Etamine dont les loges s'ouvrent par des valves.

94. Etamine basifixe dont les loges s'ourrent par des pores.

95. Etamine oscillante dont les loges s'ouvrent suivant une ligne longitudinale.

96. Un grain de pollen émettant la fovilla, vu sous un fort grossissement.

97. Pollinie d'un Orchis.

98. Etamines didynames.

99. Etamines tétradynames.

100. Etamines monadelphes de la Mauve. 
PLANCHE XV.

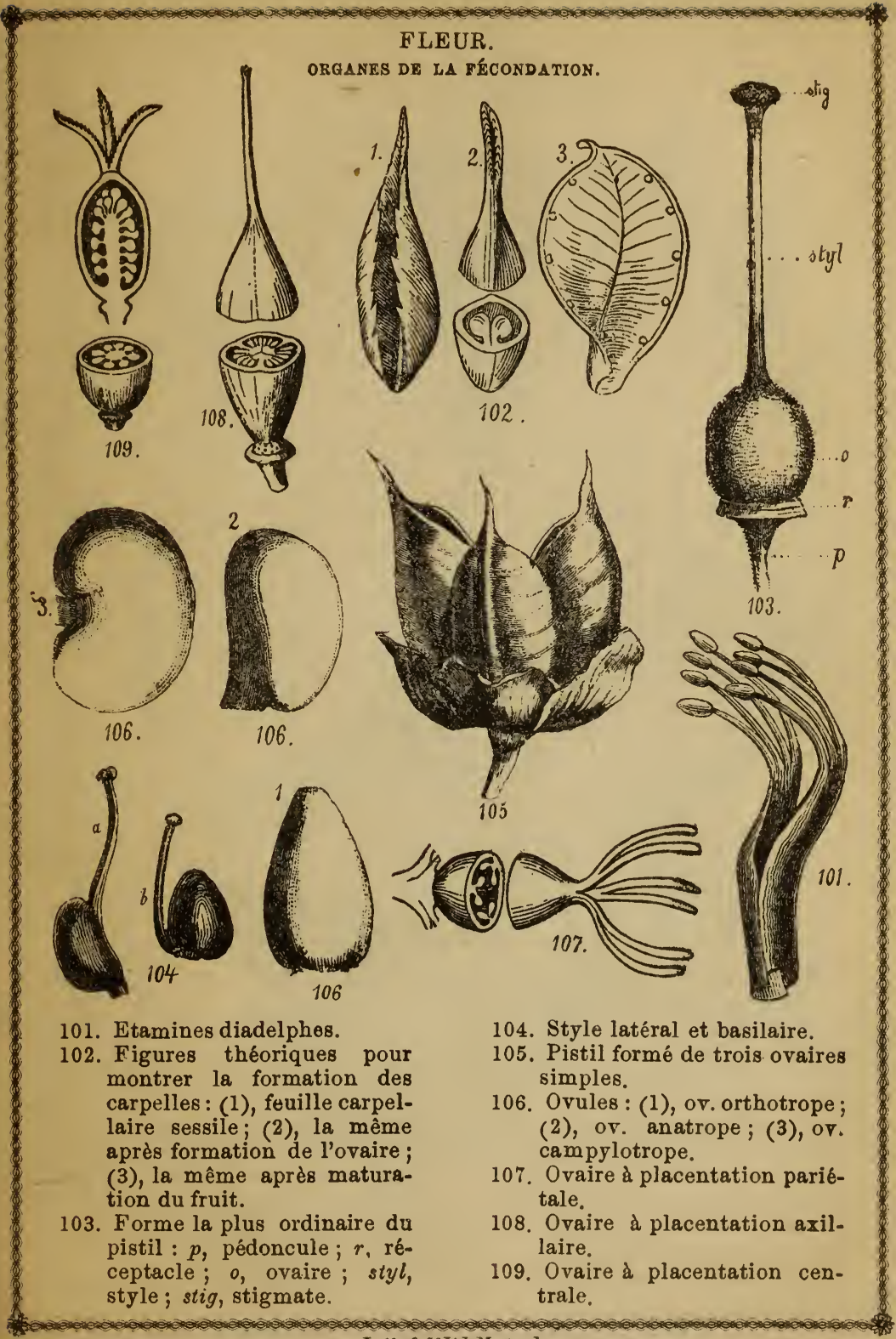




\section{PLANCHE XVI.}

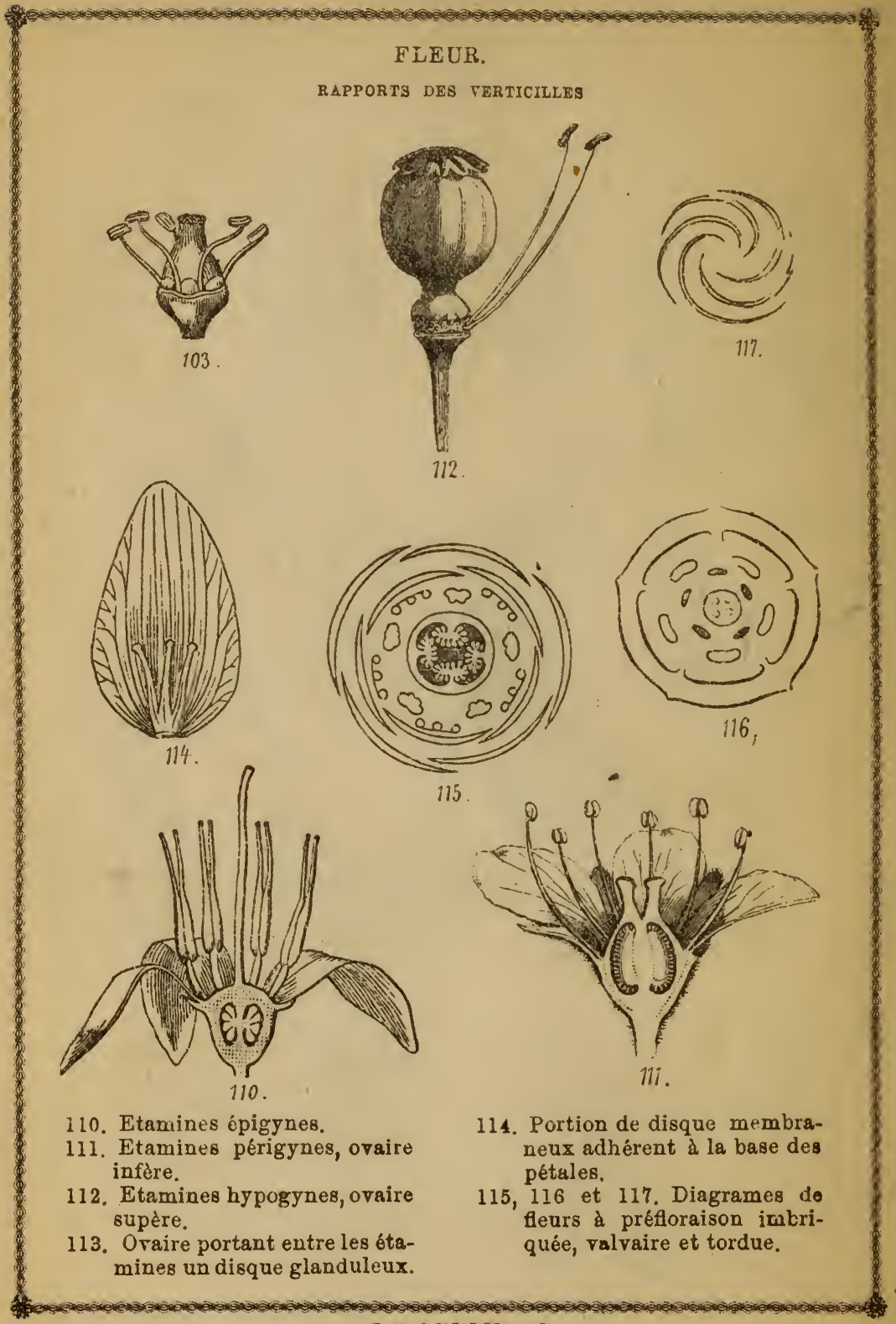




\section{PLANCHE XVII.}

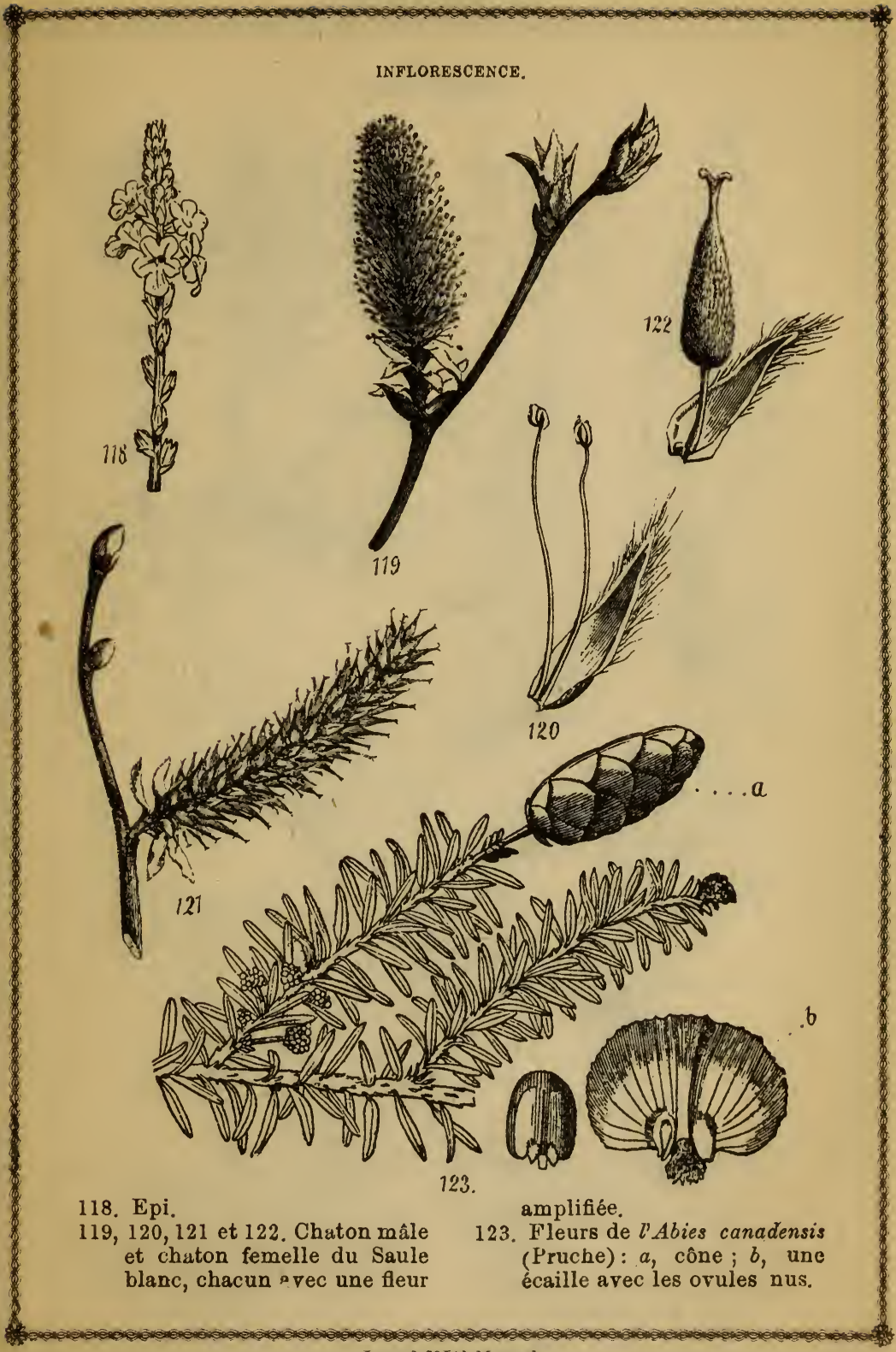




\section{PLANCHE XVIII.}

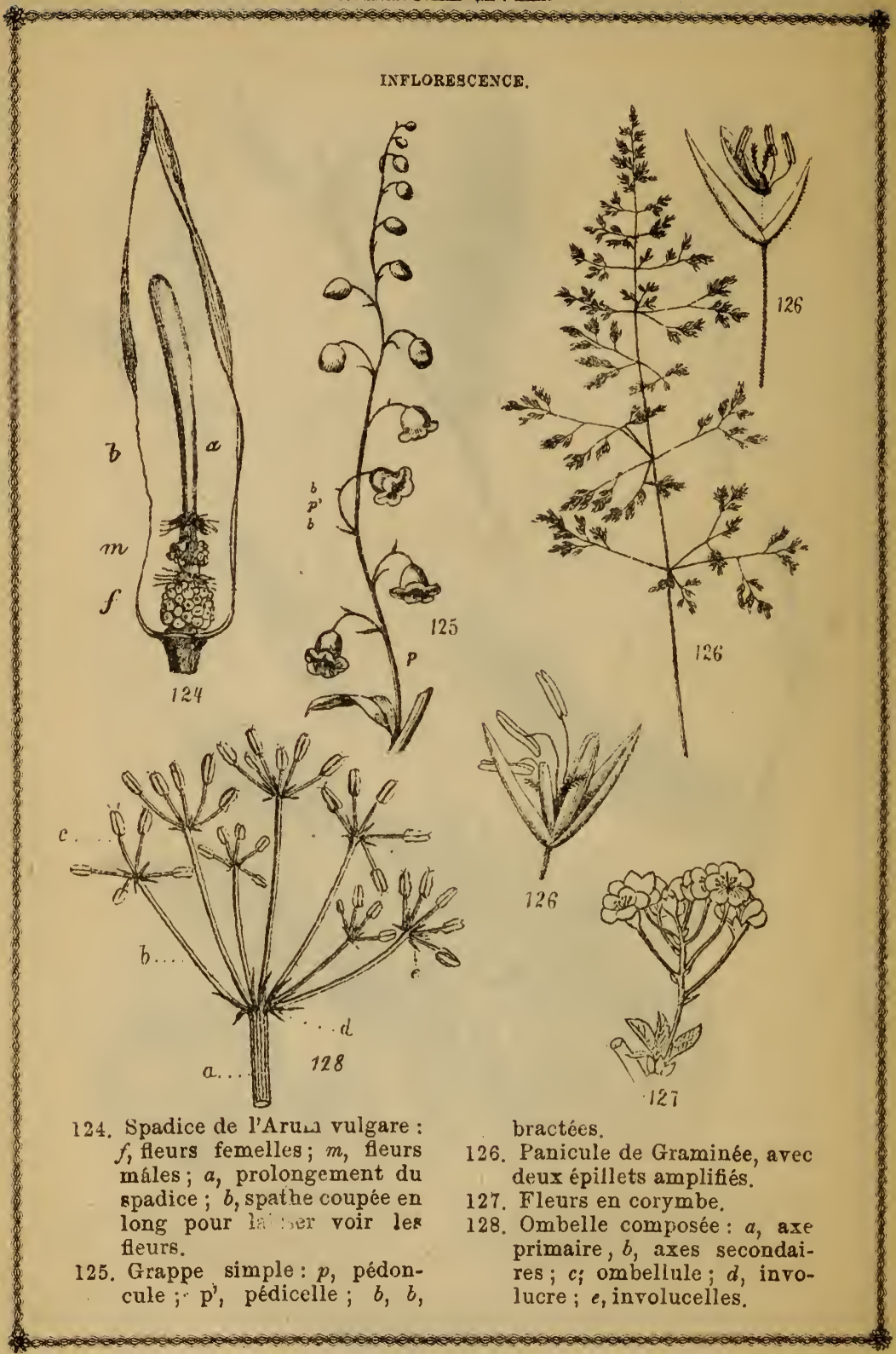


PLANCHE XIX.

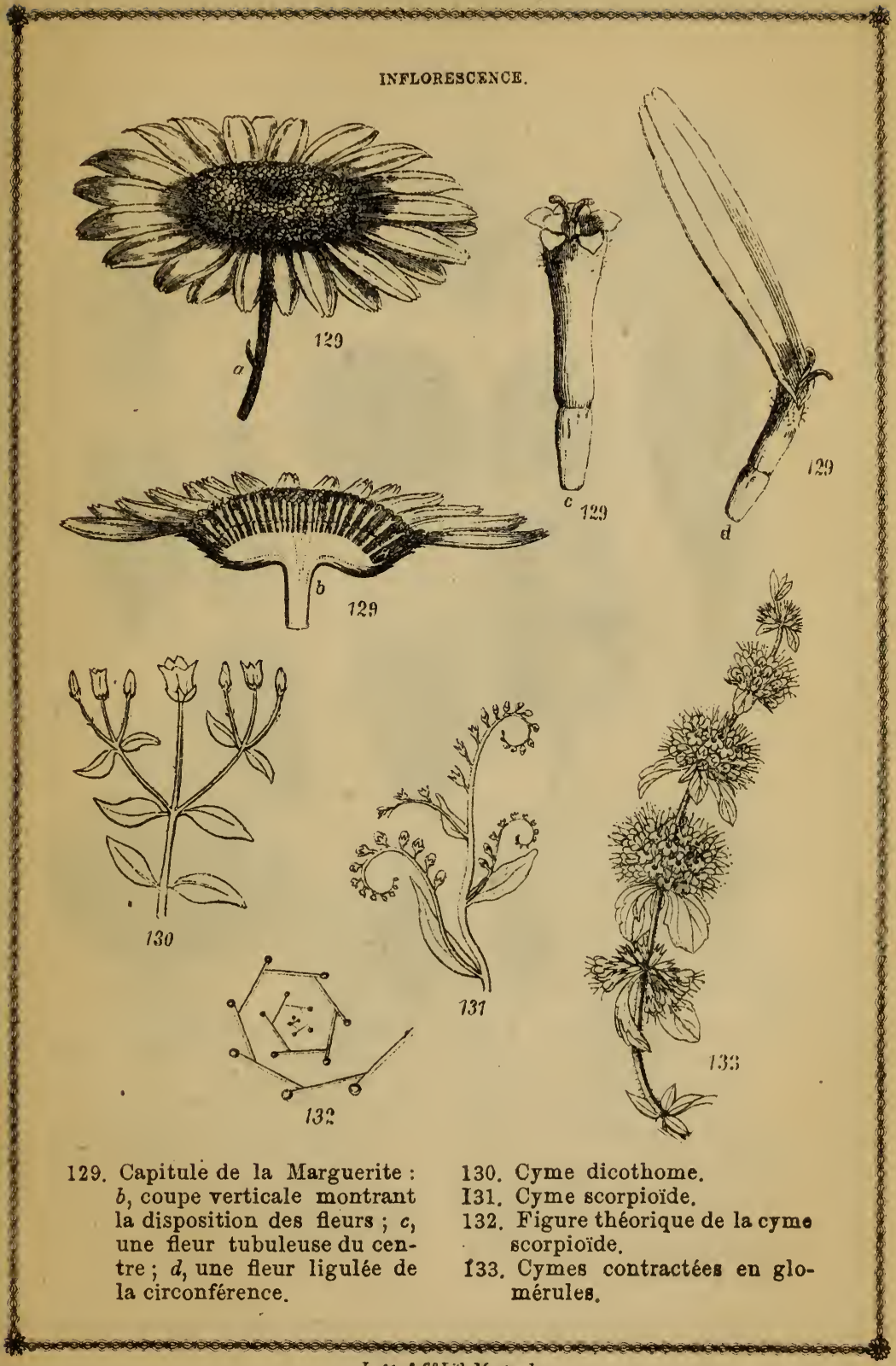




\section{PLANCHE XX.}

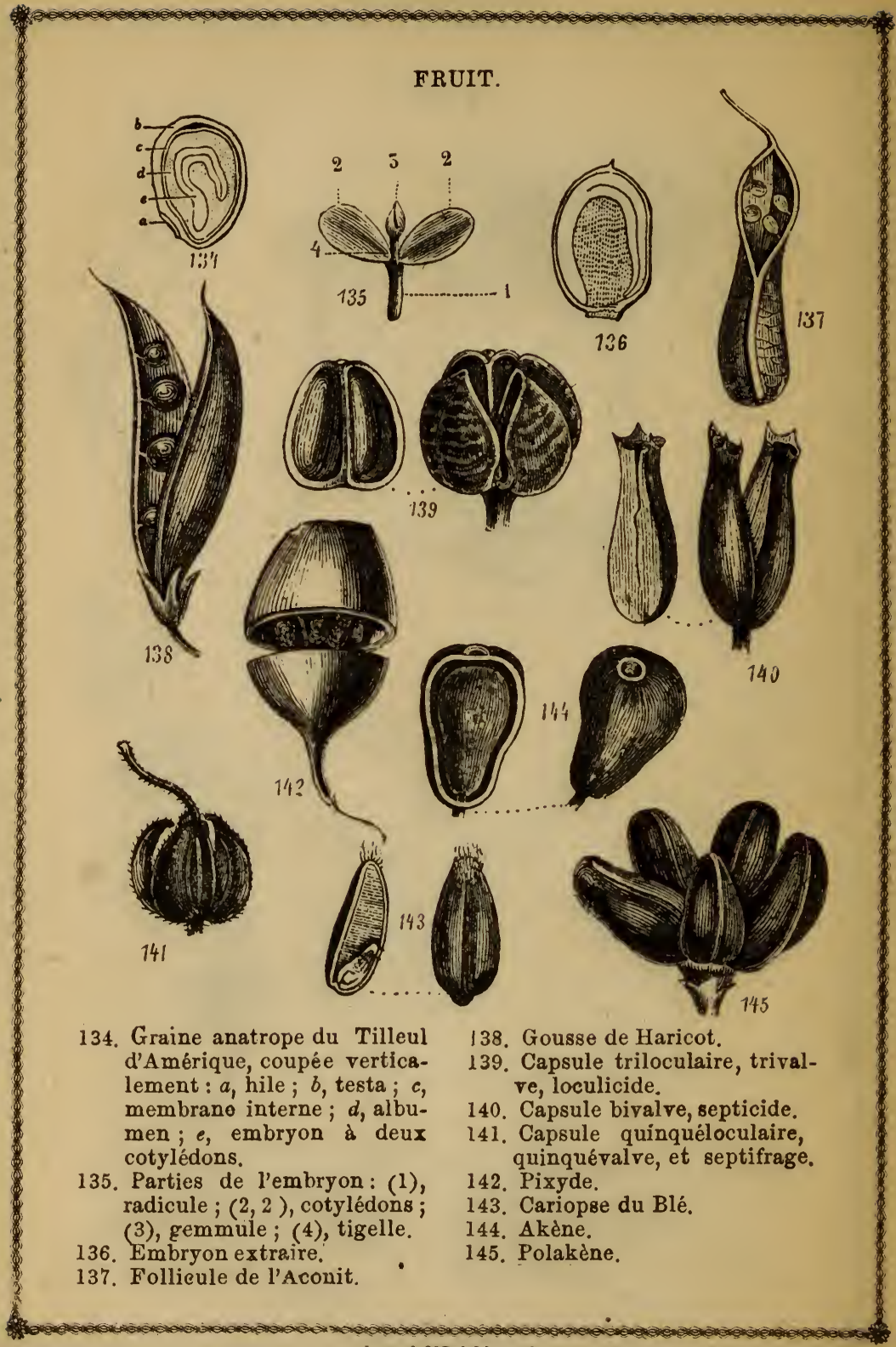


PLANCHE XXI.

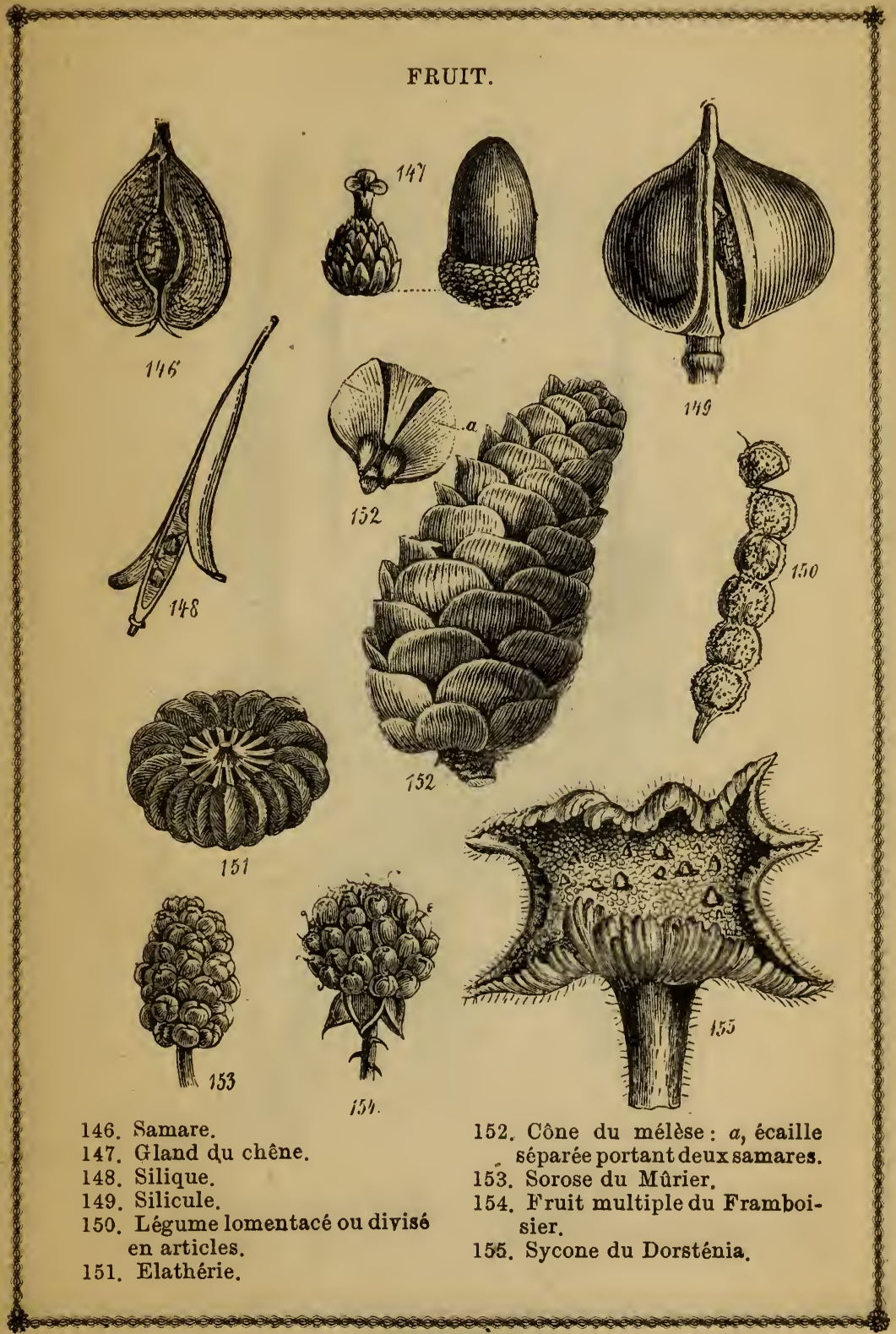

Leşgo \& C? Lith Montreal. 


\section{PLANCHE XXI.}

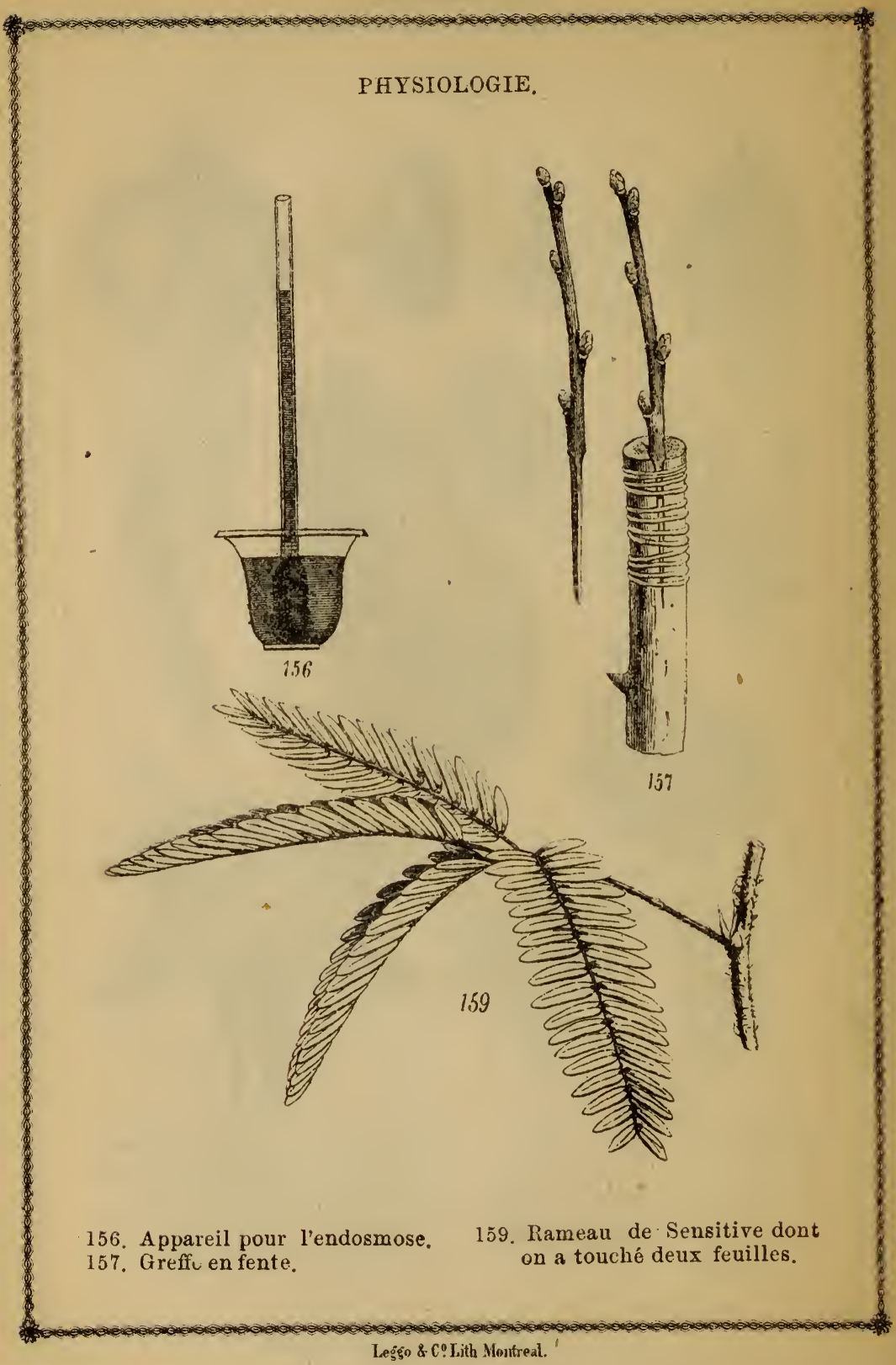




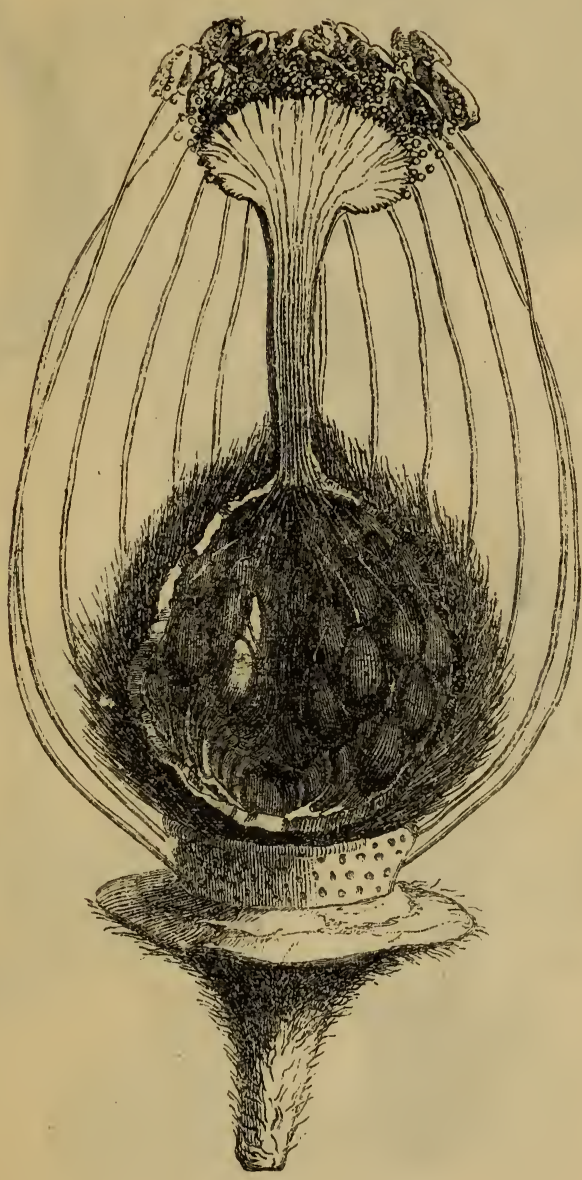

158

158. Coupe grossie d'un ovaire pour montrer la fécondation. des ovules par le pollen qui s'échappe des étamines. 
PLANCHE XXIV.

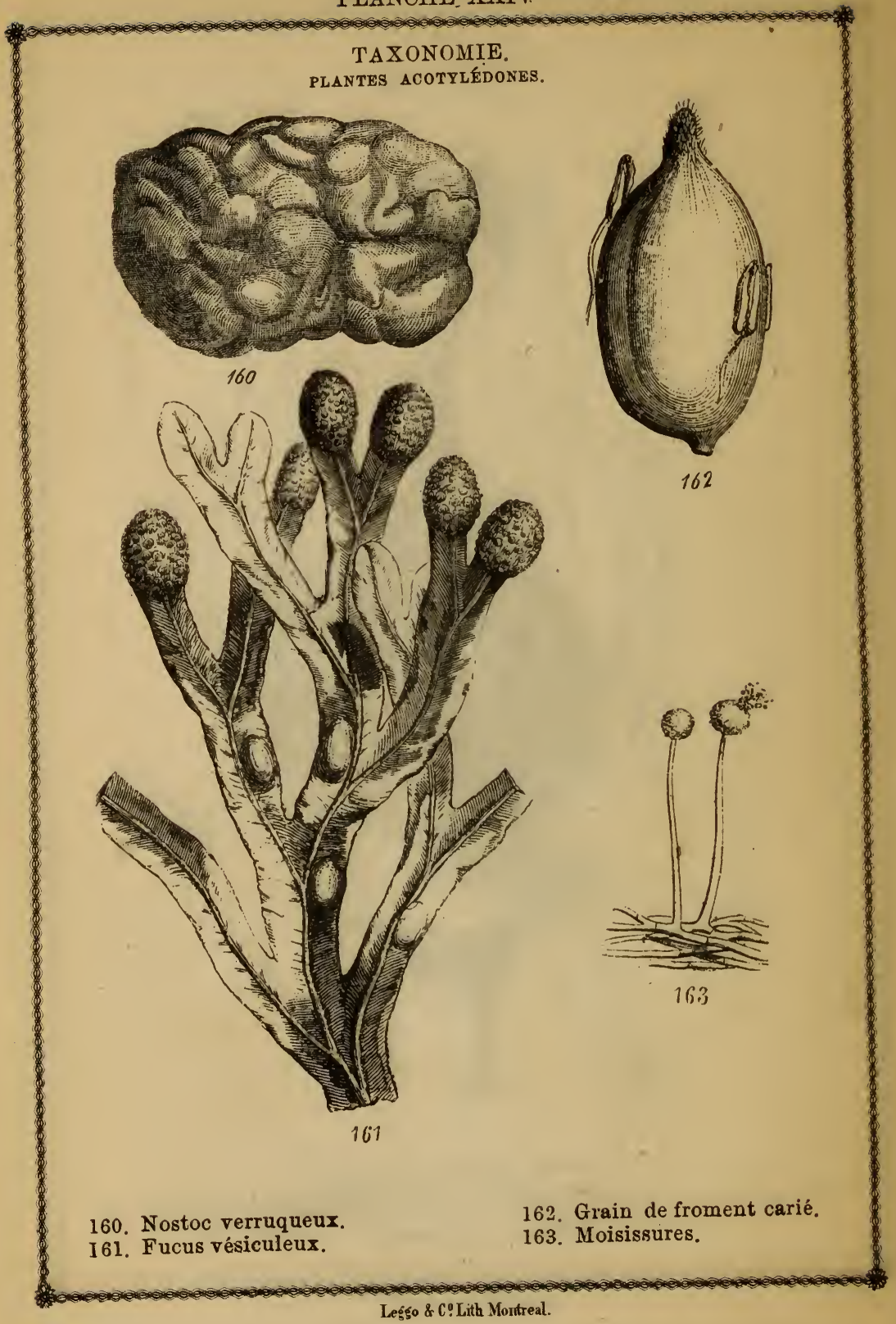


PLANCHE XXV.

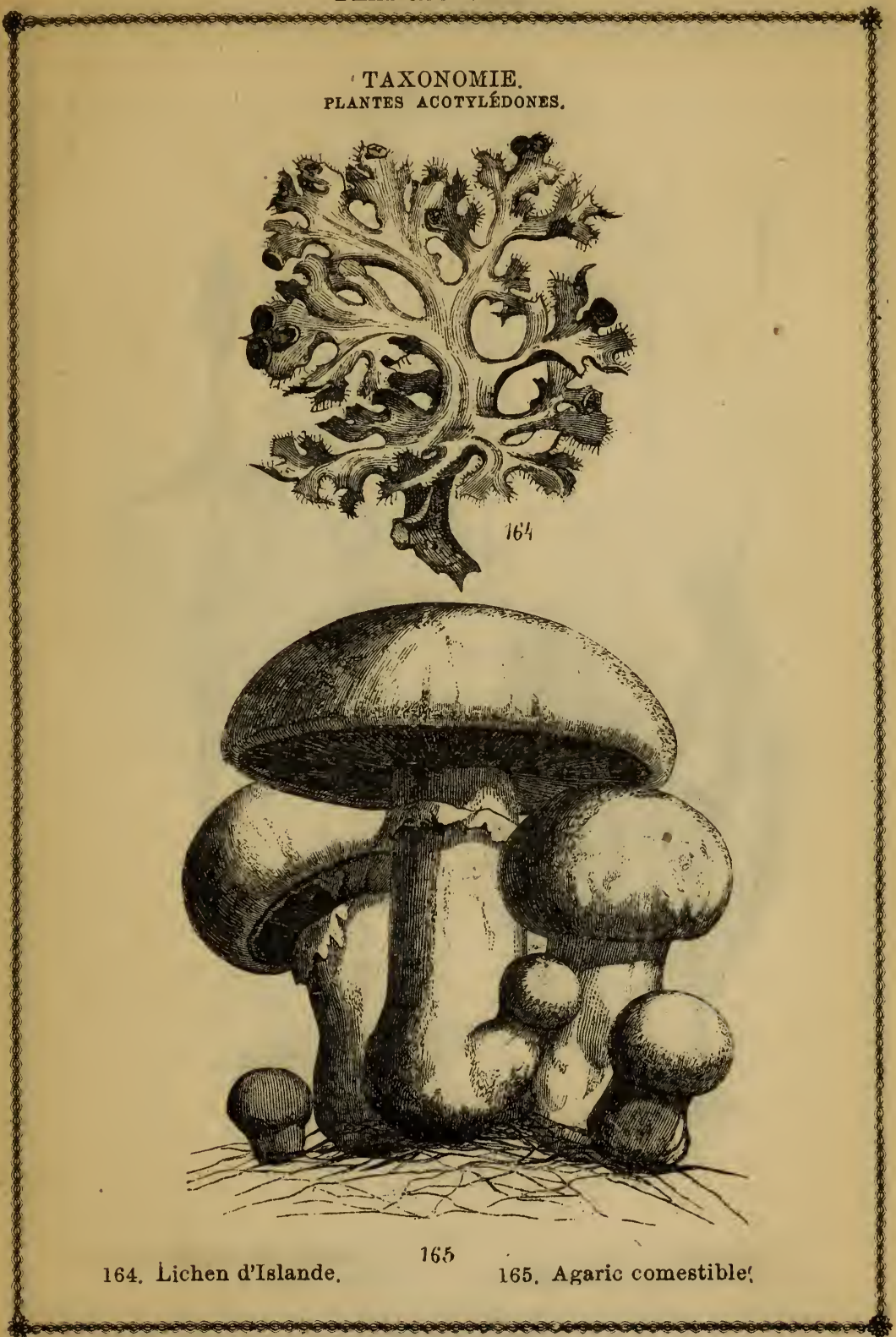

Leşรo \& C? Lith Montreal. 
PLANCHE XXVI.

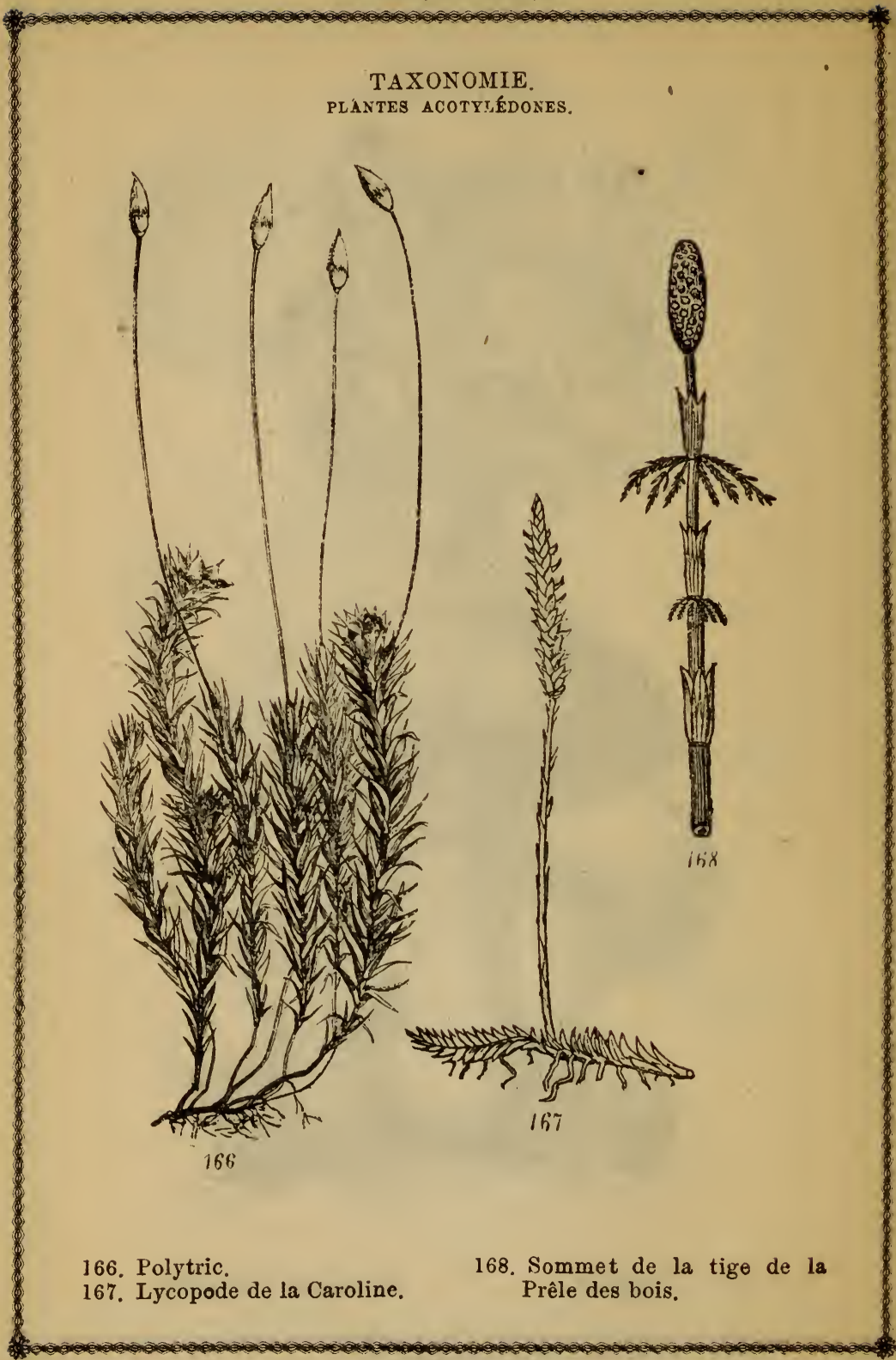


PLANCHE XXVЦ.

TAXONOMIE.

PLANTES ACOTYLÉDONES.

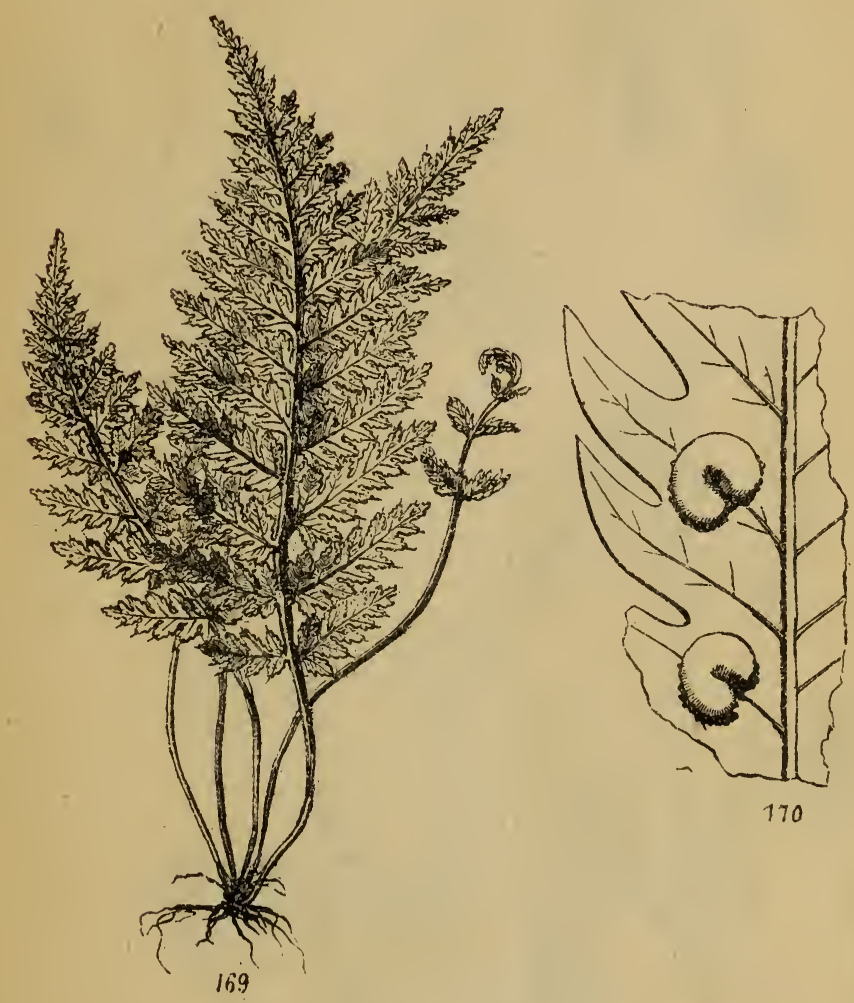

169. Trichomanes.

170. Fronde de Fougère grossie groupes de sporanges. 
PLANCHE XXVIII.

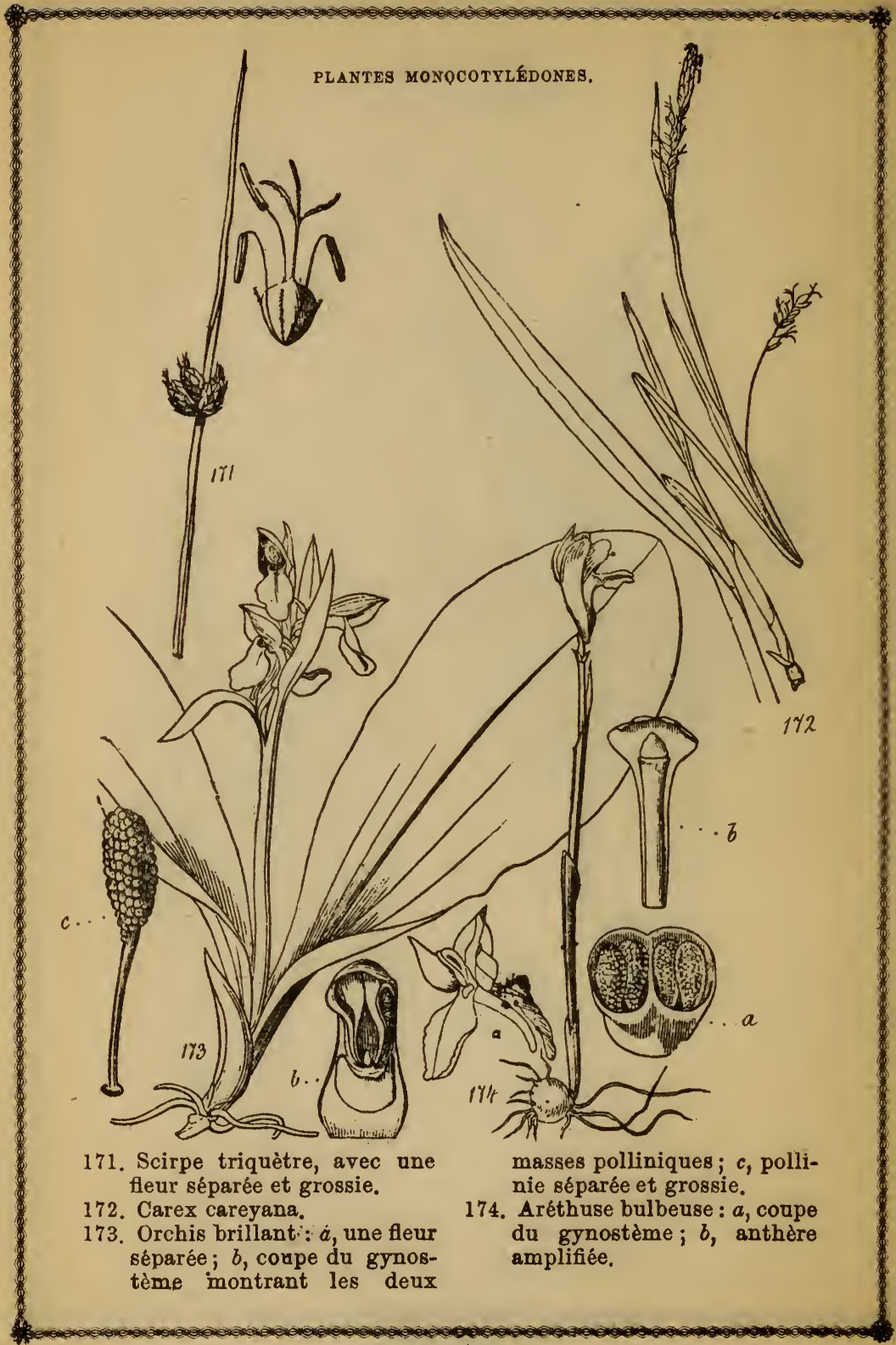


PLATCHE IXIX.

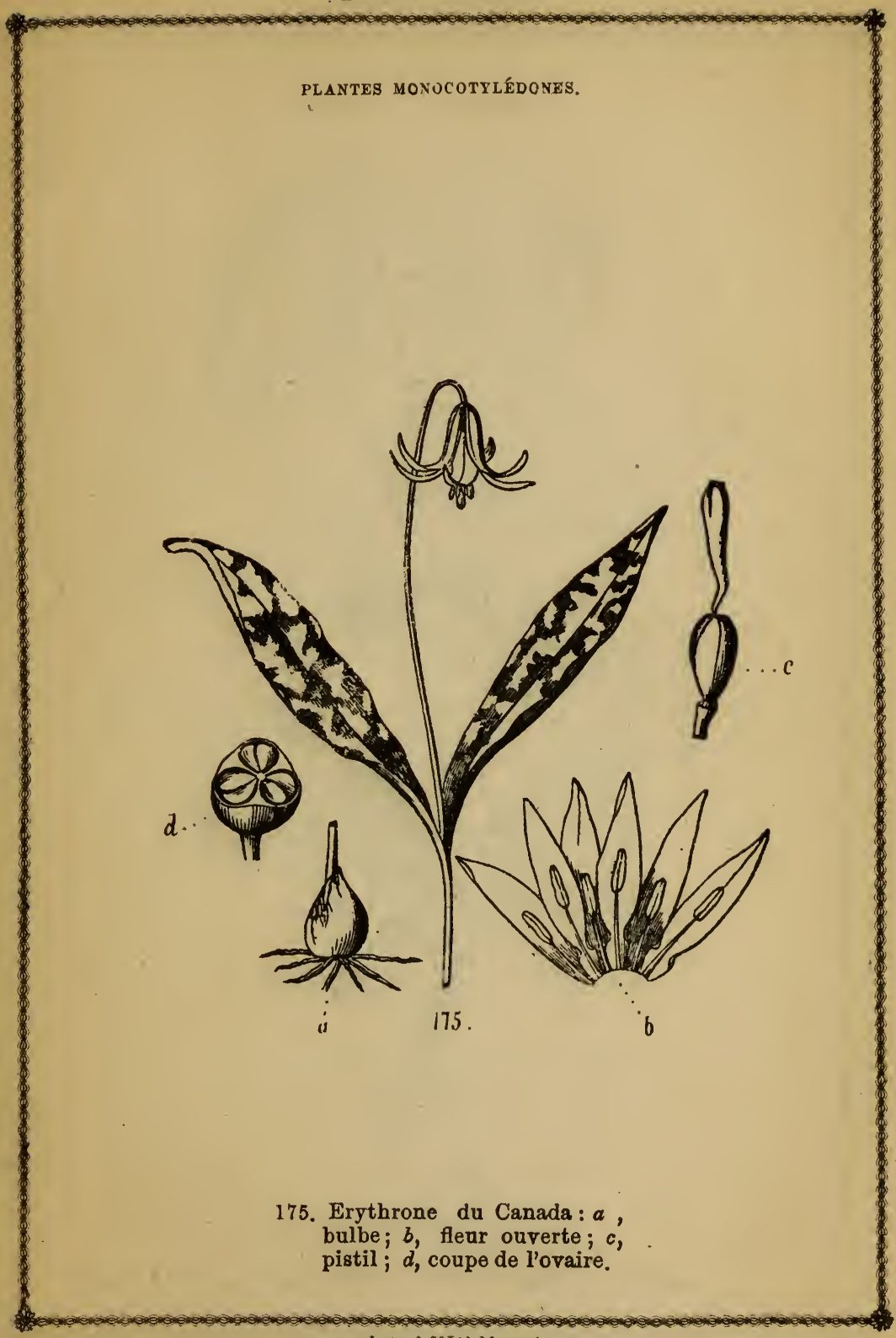

Leşo \& C? Lith Montreal. 
- PLANCHE XXX.

PLANTES DICOTYLÉDONES:
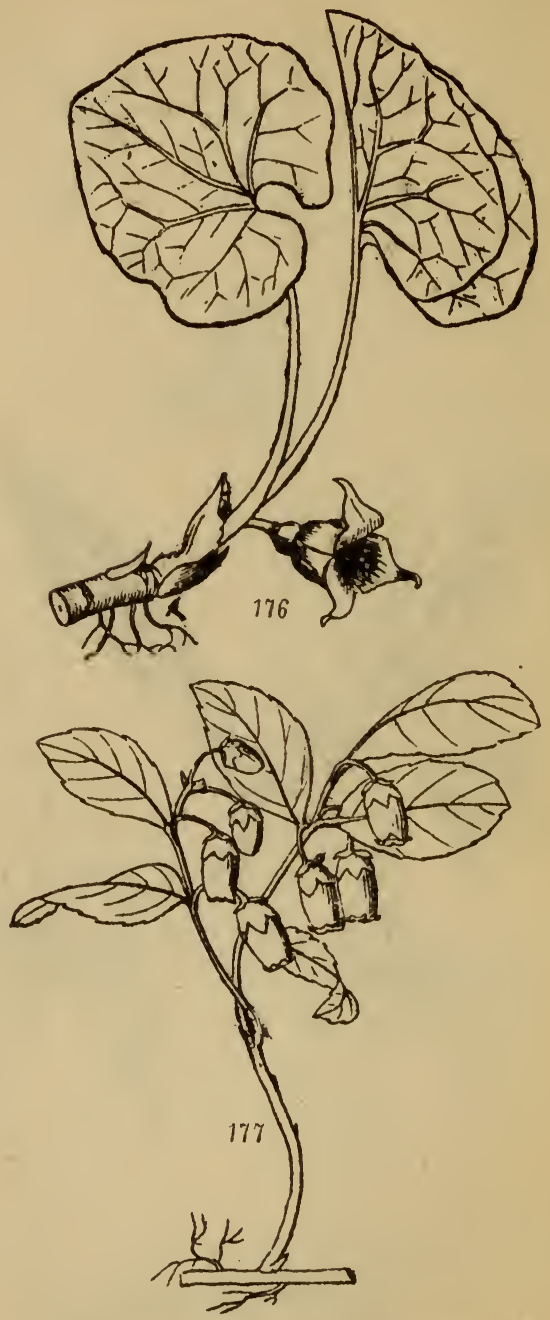

176. Azaret du Canada.

177. Gaultérie ou the des bois. 
PLANCHE XXXI.

PLANTES DICOTYLÉDONES:

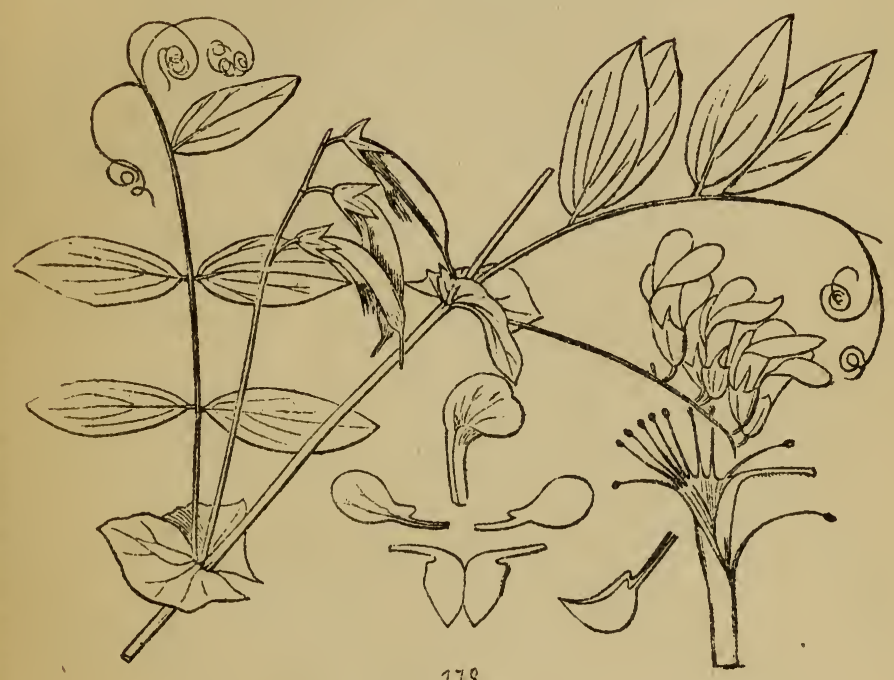

178

178. Gesse des marais. 


